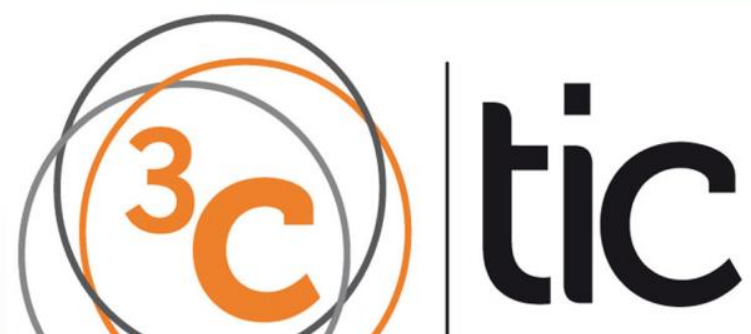

Cuadernos de desarrollo aplicados a las TIC

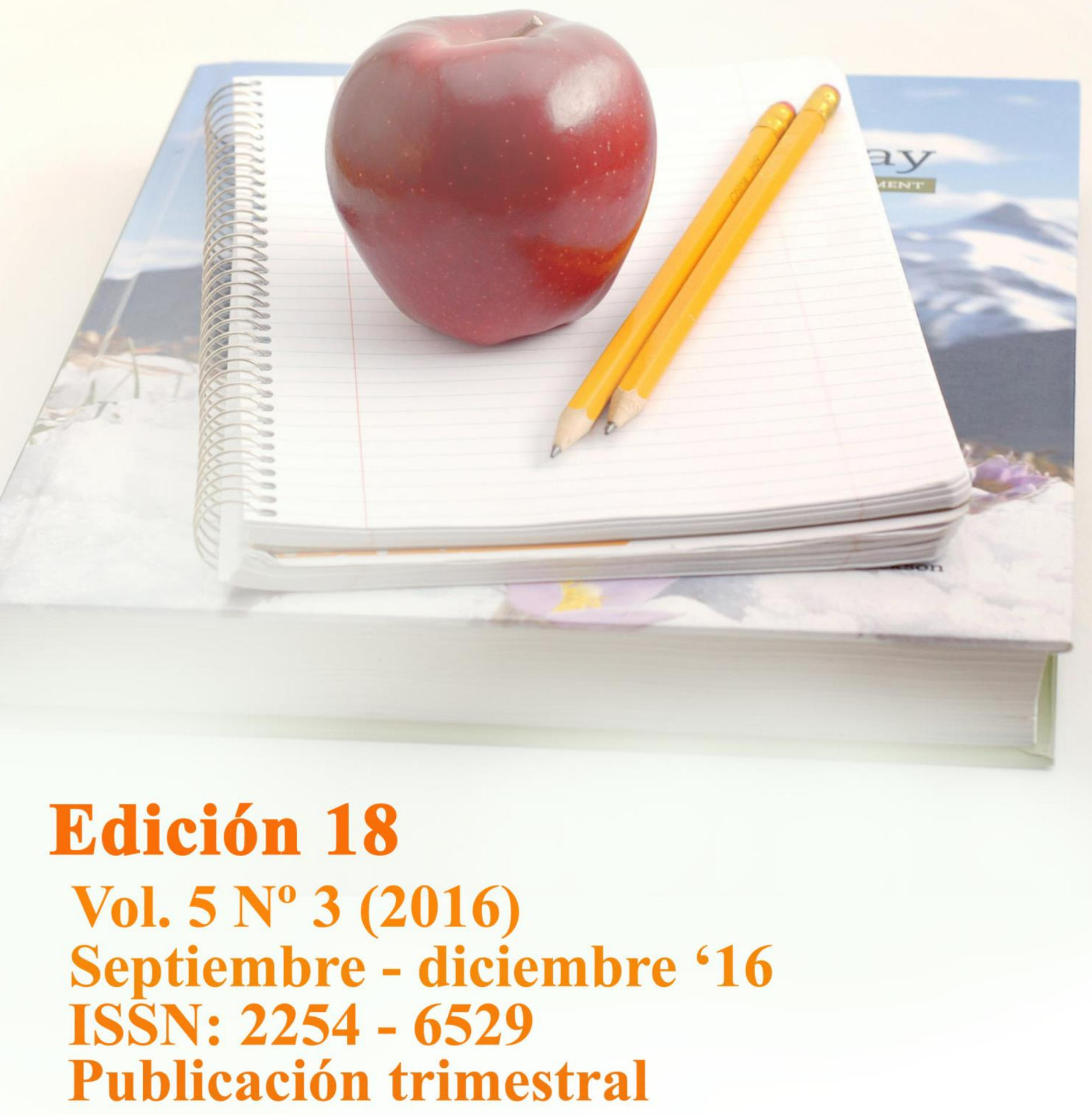

Depósito legal: A299-2012 Área de Innovación y Desarrollo, S.L 


\section{3ciencias}

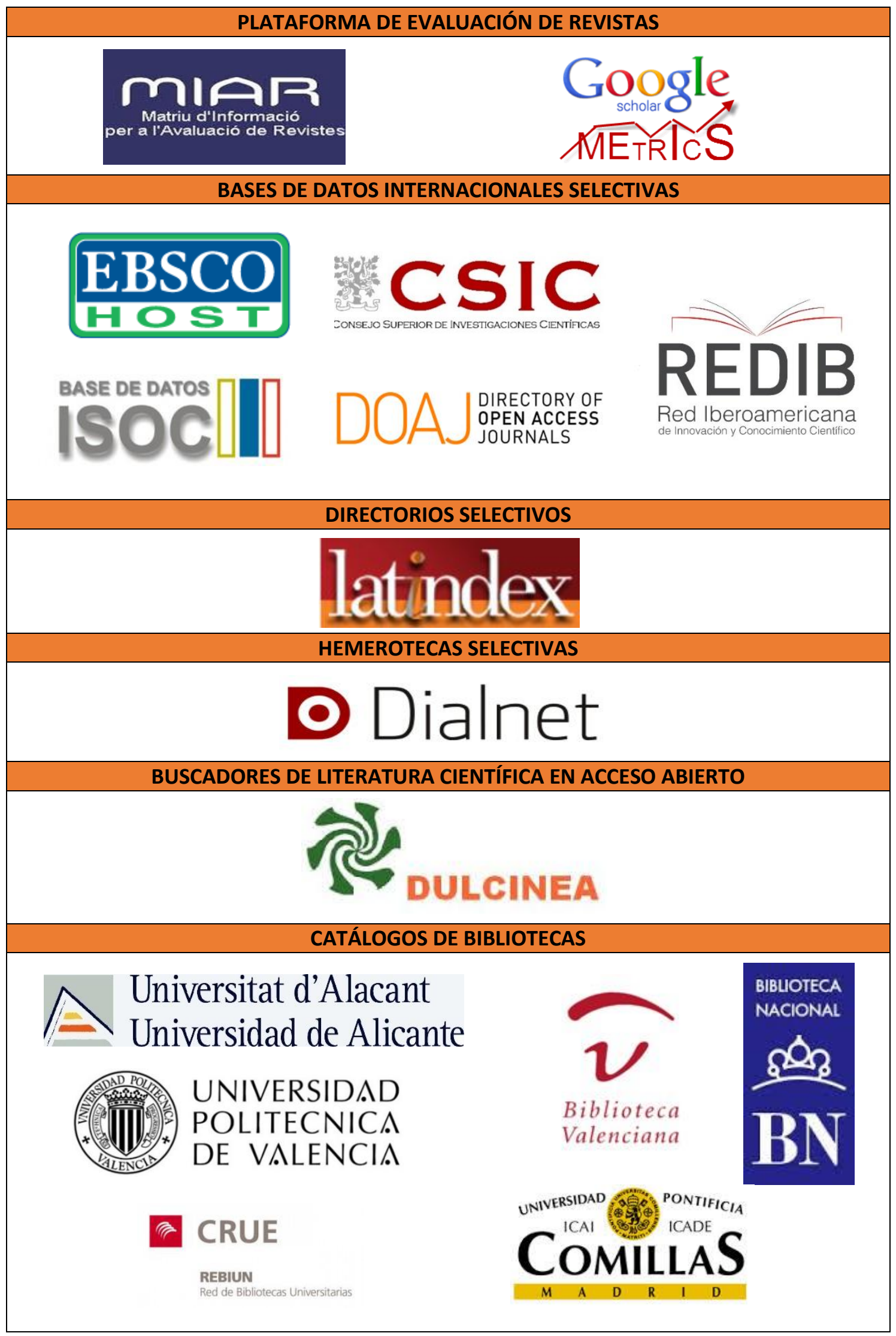




\section{OBJETIVO EDITORIAL}

La Editorial científica 3Ciencias pretende transmitir a la sociedad ideas y proyectos innovadores, plasmados, o bien en artículos originales sometidos a revisión por expertos, o bien en los libros publicados con la más alta calidad científica y técnica.

\section{NUESTRO PÚBLICO}

- Personal investigador.

- Doctorandos.

- Profesores de universidad.

- Oficinas de transferencia de resultados de investigación (OTRI).

- Empresas que desarrollan labor investigadora y quieran publicar alguno de sus estudios.

\section{COBERTURA TEMÁTICA}

La Revista 3 C TIC es una revista de carácter científico-social donde se difunden trabajos originales de investigación que abarcan diferentes temáticas relacionadas con las Tecnologías de la Información y la Comunicación, la docencia, Internet y las telecomunicaciones.

\section{INFORMACIÓN PARA AUTORES}

Toda la información sobre el envío de originales se puede encontrar en el siguiente enlace: http://www.3ciencias.com/normas-de-publicacion/instrucciones-para-el-envio-de-articulos/.

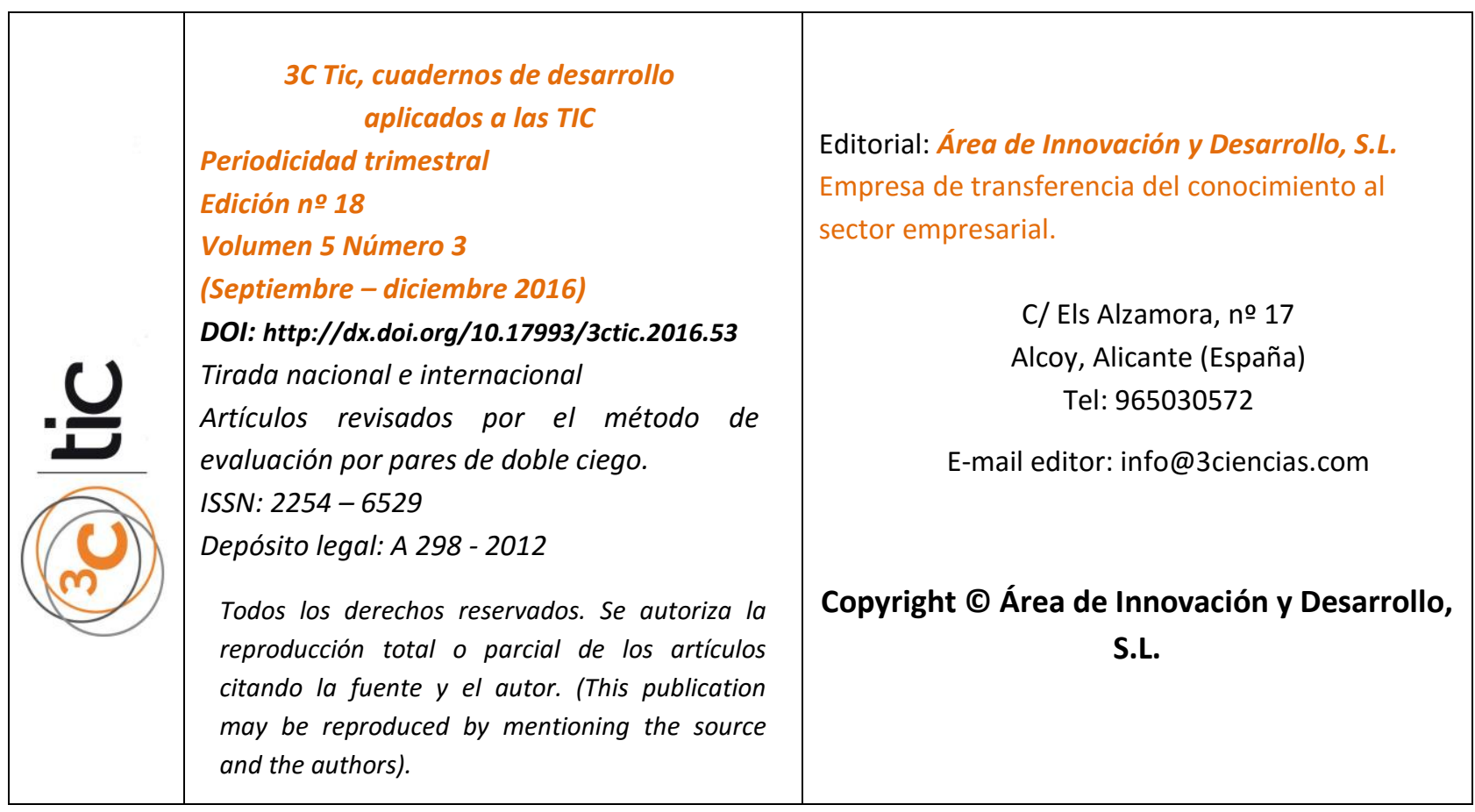




\section{PUBLISHING GOAL}

3Ciencias wants to transmit to society innovative projects and ideas. This goal is reached thought the publication of original articles which are subdue to peer review or thorough the publication of scientific books.

\section{OUR PUBLIC}

- Research staff.

- PhD students.

- Professors.

- Research Results Transfer Office.

- Companies that develop research and want to publish some of their works.

\section{TEMATIC COVERAGE}

3C TIC journal is a scientific-social journal, where original works are disseminated. These works cover different themes related to Information and Communication Technologies, Learning, Internet and Telecommunications.

\section{INFORMATION TO AUTHORS}

All information about sending originals can be found at the following link: http://www.3ciencias.com/normas-de-publicacion/instrucciones-para-el-envio-de-articulos/ 


\section{SUMARIO}

EL USO DE LA APLICACIÓN WEB EFFITCIENCY MEJORA LA ADHERENCIA AL TRATAMIENTO EN PACIENTES CON ALTERACIONES NEUROLÓGICAS. ESTUDIO PILOTO EFFITCIENCY WEB APPLICATION USE IMPROVES PHYSIOTHERAPY TREATMENT ADHERENCE IN PATIENTS WITH NEUROLOGICAL DISORDERS. PILOT STUDY

Ángel Esparcia Jiménez; Francesc Inza Pla; Sara Cortés-Amador y Núria Sempere-Rubio

ASPECTOS BÁSICOS PARA UNA ENSEÑANZA E-LEARNING DE CALIDAD EN LA EDUCACIÓN SUPERIOR 8

BASIC ASPECTS FOR A LEARNING OF QUALITY IN THE HIGHER EDUCATION

Juan Miguel Torres Martín

ALGORITMO DE BOOTH EN FORMA DE DÍGITOS SIGNADOS

BOOTH ALGORITHM IN SIGNED-DIGIT REPRESENTATION

Jesús Ayuso Pérez

MODELO DE RED DE COMUNICACIÓN A TRAVÉS DE LA APLICACIÓN DE NUEVAS TECNOLOGÍAS PARA EL FORTALECIMIENTO DE ACCESO A INTERNET 44 MODEL OF COMMUNICATION SYSTEM THROUGH NEW TECHNOLOGIES APPLICATION FOR STRENGTHENING OF INTERNET ACCESS

Christian Ruperto Caicedo Plùa; Roberto Wellington Acuña Caicedo; Antonieta Del Carmen Rodríguez González y Kleber Plutarco Castro Valeriano

SISTEMA PARA LA GESTIÓN DE INFORMACIÓN DE LOS SERVICIOS Y MEDIOS DE CÓMPUTO EN EL GRUPO EMPRESARIAL CONSTRUCCIONES GRANMA 65 MANAGEMENT INFORMATION SYSTEM OF THE SERVICES AND COMPUTER RESOURCES IN THE GRUPO EMPRESARIAL CONSTRUCCIONES GRANMA

Yudi Castro Blanco; Susana Teresa Carbonell Hernánde y Eric Ismael Leonard Brizuela 



\section{EL USO DE LA APLICACIÓN WEB EFFITCIENCY MEJORA LA ADHERENCIA AL TRATAMIENTO EN PACIENTES CON ALTERACIONES NEUROLÓGICAS. ESTUDIO PILOTO}

\section{EFFITCIENCY WEB APPLICATION USE IMPROVES PHYSIOTHERAPY TREATMENT ADHERENCE IN PATIENTS WITH NEUROLOGICAL DISORDERS. PILOT STUDY}

Esparcia Jiménez, Ángel ${ }^{1}$ Inza Plà, Francesc ${ }^{2}$ Cortés-Amador, Sara ${ }^{3}$ Sempere-Rubio, Núria ${ }^{4}$

1. Licenciado en Ciencias de la actividad física y el deporte y Graduado en Fisioterapia por la Universidad de Valencia, Fisioterapeuta en el Instituto Valenciano de Recuperación Deportiva. E- Mail: angel.esparcia@gmail.com

2. Ingeniero Técnico Industrial esp. Electrónica Industrial por la Universidad Politécnica de Valencia, desarrollador web freelance y desarrollador front-end en Tuvalum Sports. Valencia. España. E-mail: francesc.inza@gmail.com

3. Dra. en Fisioterapia, Profesora Asociada, departamento de Fisioterapia, Universidad de Valencia y Co- Fundadora de Fundación ACAVALL. E-Mail: sara.cortes@uv.es

4. Profesora Asociada, departamento de Fisioterapia, Universidad de Valencia y fisioterapeuta en la Clínica Fisioterapia Marítim, Lirios Dueñas. E-Mail: nuria.sempere@uv.es

Esparcia Jiménez, Á., Inza Pla, F., Cortés-Amador, S. y Sempere-Rubio, N. (2016). El uso de la aplicación web effitciency mejora la adherencia al tratamiento en pacientes con alteraciones neurológicas. Estudio piloto. 3C TIC: Cuadernos de desarrollo aplicados a las TIC, 5(3), 1-7. DOI: <http://dx.doi.org/10.17993/3ctic.2016.53.1-7/>. 


\section{RESUMEN}

En la actualidad, el porcentaje de incumplimiento de las pautas de ejercicio físico en pacientes con problemas neurológicos supera el 50\%, teniendo esto un impacto negativo en la calidad de vida de los usuarios/as. La bibliografía disponible pone de manifiesto que las app pueden ser herramientas que fomenten la implicación de la persona en su proceso de rehabilitación (Østerås et al. 2014; Peña, Juan y Moreno, 2010). Siguiendo esta línea de investigación, se ha diseñado una aplicación web destinada a la gestión de rutinas de ejercicio físico de un centro de fisioterapia y además, se ha comparado el soporte para la gestión de las mismas: formato papel o formato electrónico favorece la adherencia al tratamiento.

\section{ABSTRACT}

Nowadays non-adherence in physiotherapy treatment in patients with neurological disorders stands at $50 \%$. Data suggests that web based applications could be useful to promote the patients involvement in their rehabilitation process ( $\varnothing$ sterås et al. 2014; Peña, Juan y Moreno, 2010). Following this research Effitciency has been designed, a web application that manages patients workout routines in a physiotherapy center. Additionally has been determinated which routine treatment presentation format, paper or App, improves treatment adherence.

\section{PALABRAS CLAVE}

Adherencia, Fisioterapia, rutina, App, papel.

\section{KEYWORDS}

Adherence, Physiotherapy, exercise-programme, App, paper. 


\section{INTRODUCCIÓN}

La Organización Mundial de la Salud (OMS) define la salud en línea electrónica (e-health), como el uso de las tecnologías de información y comunicación (TICS) en la salud, ocupándose de mejorar el flujo de información a través de medios electrónicos, para apoyar la prestación de servicios de salud y la gestión de sistemas sanitarios (World Health Organization, 2011). Ante ello, surge la necesidad de desarrollar confianza en las nuevas tecnologías, tanto entre los profesionales de salud como entre los pacientes y ciudadanos, dado que de esto dependerá el éxito en la implementación de las TICs (Galán-Rodas y Zamora, 2014). En el ámbito de las TICs, una aplicación móvil o app es un software o programa informático que está diseñado para funcionar en teléfonos inteligentes (smartphones), tablets y otros dispositivos móviles. La bibliografía científica muestra que las TICs son un medio también para la mejora de algunos aspectos en salud, como permitir la mejor gestión de las organizaciones, posibilitar un mejor aprovechamiento de los recursos, y brindar un servicio de mayor calidad a los usuarios (Montero, García y Ríos 2004; Norman et al., 2004; Oviedo y Fernández 2010).

"En fisioterapia es común prescribir actividades y ejercicios por periodos prolongados de tiempo, en ocasiones se dan las instrucciones de forma rápida y sin revisiones de mantenimiento que confirmen el ajuste al tratamiento del propio paciente", llegándose a no comprobar ni la comprensión ni la adecuada ejecución del ejercicio propuesto. Existen datos de estudios epidemiológicos de éste y otros países que indican que los pacientes incumplen las prescripciones alrededor del $50 \%$ de las veces en tratamientos de fisioterapia.

La bibliografía justifica la prescripción de ejercicio físico como una prioridad en la prevención de las manifestaciones de enfermedades crónicas degenerativas no transmisible. Una rutina de ejercicio físico adecuada mejora el pronóstico y la calidad de vida en fatiga por inactividad física, obesidad, diabetes, hipertensión, debilidad o alteraciones músculo esqueléticas y cardiovasculares (Zurita et al., 2009; Jiménez et al., 2014). No obstante, el trabajo de los profesionales de la salud pierde significado en el momento en el que no se aplica con la eficacia deseada en un paciente, es decir, una rutina de ejercicios realizada por fisioterapeutas, adaptada a las características del paciente y en busca de unos objetivos concretos se encuentra sesgada en la medida en que el paciente destinatario de la misma no la realiza de forma adecuada, ya sea por falta de comprensión o de motivación. Como sostienen Montero et al., (2004) "La mayoría de los pacientes que llegan a una consulta de Fisioterapia no son técnicos en la materia. Los profesionales de la salud tienden a explicar y dar instrucciones demasiado técnicas, esto hace que el paciente no entienda ni lo que pasa ni lo que debe hacer para mejorar su situación".

La OMS sostiene que la implicación activa de un paciente va a depender de cinco aspectos fundamentales: aspectos socioeconómicos, aspectos del sistema de asistencia sanitaria, aspectos relacionados con la enfermedad, y aspectos relacionados con el paciente. Si bien es cierto que desde la fisioterapia no se puede influir en todos estos factores, es importante incidir en aquellos en los que sí existe esta posibilidad. Los usuarios necesitan, además de una asistencia individualizada, componentes motivacionales que mantengan el hábito de seguimiento de una rutina de ejercicios, sin olvidar que nuestros pacientes pueden presentar 
hándicaps como bajos niveles de actividad física o dificultad de compresión de las explicaciones dadas por el fisioterapeuta, lo que condiciona negativamente la adherencia a este tipo de tratamiento. Niveles altos de cumplimiento y adherencia a los tratamientos fisioterapéuticos aumentan la efectividad de los mismos y se sabe que la comprensión, la motivación y la implicación activa de los pacientes son determinantes en la misma (Montero et al., 2004; Reed et al., 2015; World Health Organization, 2011).

El diseño de una aplicación web teniendo en cuenta todos estos factores puede ser una herramienta que facilite a la comprensión, mejore la implicación y motivación de los pacientes en su proceso de rehabilitación y, además, sea un instrumento que facilite la comunicación usuario-profesional. La comunicación y la relación terapéutica paciente terapeuta condicionan la adherencia al tratamiento. Es necesario un proceso interactivo de comunicación para la correcta relación terapéutica ( $\varnothing$ sterås et al. 2014; Peña, Juan y Moreno, 2010).

El objetivo general del presente trabajo es diseñar una aplicación web destinada a la gestión de rutinas de ejercicio físico de un centro de fisioterapia para poder comparar que soporte de gestión de rutinas: el formato papel o formato electrónico favorece la adherencia al tratamiento.

\section{METODOLOGÍA}

Se realizó un estudio de casos en el que participaron 8 usuarios del centro Tetrasport Wellness. Se seleccionaron a aquellos usuarios que cumplían con los siguientes criterios de inclusión:

- Tener prescrita una rutina de ejercicio físico en el centro Tetrasport Wellness.

- Estar en un proceso de rehabilitación funcional a largo plazo.

- Disponibilidad y voluntad personal.

- Poseer un Smartphone con versión de Android posterior a 4.0 y de IOS posterior a la 7.0.

- Ser capaz de contestar las 30 preguntas del cuestionario.

- Capacidad de concentración, atención, entendimiento y comunicación verbal y escrita.

- Finalmente, aceptar su participación en el estudio.

En total se incluyeron 8 usuarios, con una media de edad 33,8 años, siendo el $62.5 \%$ menores de 25 años y el $37.5 \%$ mayores de 50 años. La media de edad de los usuarios de la muestra es de 33.8 años, siendo el $62.5 \%$ menores de 25 años y EL $37.5 \%$ mayores de 50 años.

Para la medición de las variables de estudio: cantidad y comprensión de información, motivación y satisfacción, se elaboró un cuestionario ad hoc de 30 ítems, con 5 opciones de respuesta siendo 1 totalmente en desacuerdo y 5 totalmente de acuerdo. 
Los usuarios, durante tres semanas, realizaron sus rutinas de ejercicio teniendo como soporte de apoyo una hoja de papel. En ella podían visualizar un dibujo que representaba el ejercicio que debía llevar a cabo. Finalizado este periodo, el usuario cumplimentaba el cuestionario ad hoc. A continuación, a los mismos usuarios que habían usado el formato papel, se les enseñó el manejo de la aplicación. Una vez aprendido, el participante, realizaba su entrenamiento teniendo como apoyo la app Effitciency. Esta app permitía al usuario ver en la pantalla de su móvil un video en bucle de la ejecución del ejercicio, el material necesario para hacerlo, parámetros de cuantificación de la carga, así como un contador de tiempo de descanso sincronizado con el contado de series. Después de 3 semanas de utilización de la app, como apoyo para la realización de la rutina de ejercicio, el participante cumplimentaba el cuestionario.

Se utilizó el paquete estadístico SPSS versión 21.0 para el análisis los datos. De cada variable se realizó, en primer lugar, un análisis descriptivo de las medidas de tendencia central y en segundo lugar, un análisis inferencial empleando Pruebas $\mathrm{T}$ para muestras relacionadas, siendo el valor de significación $p<0.05$.

Todos los participantes del estudio cumplimentaron el consentimiento informado, en el que se les informó del desarrollo del estudio así como de los riesgos del mismo.

\section{RESULTADOS Y DISCUSIÓN}

En la Tabla 1, se reflejan los estadísticos descriptivos y la significación de las variables objeto de estudio, y en ella se puede observar que el soporte electrónico Effitciency obtiene en todas las variables de estudio una media superior a las del papel como recurso de apoyo. Además, cuando se comparan las medias obtenidas por el formato papel y las alcanzadas con el formato electrónico, se observa que la diferencia es estadísticamente significativa, ocurriendo esta situación en cada una de las variables analizadas.

Tabla 1. Análisis de las variables de estudio.

\begin{tabular}{|c|c|c|c|c|c|c|c|c|c|}
\hline Estadísticos & \multicolumn{3}{|c|}{ Motivación } & \multicolumn{2}{c|}{ Satisfacción } & \multicolumn{2}{c|}{$\begin{array}{c}\text { Comprensión } \\
\text { Información }\end{array}$} & \multicolumn{2}{c|}{$\begin{array}{c}\text { Cantidad } \\
\text { Información }\end{array}$} \\
\hline & Papel & App & Papel & App & Papel & App & Papel & App \\
\hline Media & 3,48 & 4,41 & 3,07 & 4,75 & 2,87 & 4,62 & 2,6 & 4,35 \\
\hline Mediana & 3,75 & 4,83 & 3,1 & 4,8 & 2,82 & 4,61 & 2,3 & 4,4 \\
\hline Desv. Típica & 0,73 & 0,34 & 0,92 & 0,29 & 0,62 & 0,19 & 0,71 & 0,41 \\
\hline Mínimo & 2,17 & 4,17 & 1,8 & 4,2 & 2 & 4,43 & 2 & 3,8 \\
\hline Máximo & 4,5 & 5 & 4,4 & 5 & 3,86 & 5 & 3,8 & 5 \\
\hline Significación & 0,005 & 0,002 & 0,000 & & 0,000 \\
\hline
\end{tabular}

Fuente: elaboración propia.

El desarrollo de TICs en el ámbito de la fisioterapia se encuentra todavía en estadios iniciales. Según la OMS, es necesario desarrollar confianza en las nuevas tecnologías, tanto entre los profesionales de salud como entre los pacientes y ciudadanos. Es necesario por tanto, tener una actitud favorable por parte de los profesionales que permita la integración de estas 


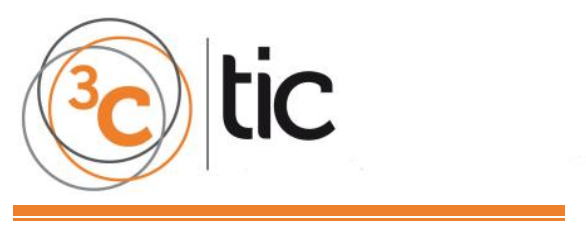

herramientas tanto en la investigación como en la experiencia clínica (World Health Organization, 2011).

Existen ejemplos de efectos beneficiosos en intervenciones basadas en Salud Electrónica, incluyendo entre otros efectos a la mejora de la adherencia a la actividad física. Según los resultados de este estudio, se puede observar también como un aumento en la cantidad y calidad de información proporcionada al paciente mejoras también en la satisfacción y motivación por la tarea, coincidiendo esta premisa con los resultados de este trabajo (Norman et al., 2004).

Según la OMS, existe una interrelación entre los diferentes factores que influyen en la adherencia a un tratamiento. El presente trabajo coincide con la premisa del trabajo de la OMS, donde concluyen que la compresión de la información es necesaria para lograr una adecuada motivación. Es complicado garantizar la implicación activa de un paciente en un proceso que desconoce, como afirman Montero et al. (2004), el conocimiento de las características de una enfermedad así como de la orientación del tratamiento permite mejorar la participación del paciente en el proceso.

No obstante, la comprensión del proceso por parte del paciente no garantiza su implicación, como afirman $\emptyset$ sterås et al. (2014) en su trabajo. Los usuarios necesitan factores motivantes que sustenten el hábito de cumplimiento de la prescripción de un tratamiento, quizá el uso de la aplicación diseñada puede ser un factor motivador en sí mismo. Existe evidencia de que la simple interacción con un Smartphone puede mejorar la motivación por una tarea y en consecuencia, la adherencia a una determinada intervención.

\section{CONCLUSIONES}

Los resultados del presente estudio reflejan que el uso de la app durante un periodo de tres semanas, a diferencia de las rutinas en formato papel, puede mejorar la adherencia a un tratamiento de ejercicio físico. Esta mejora se debe a que, cuando se analizan las puntuaciones de cada una de las variables de estudio: satisfacción, cantidad y comprensión de la información y motivación, en el formato informático (uso de la app), son significativamente superiores a las obtenidas por el formato en papel, siendo todas ellas elementos clave en la adherencia al tratamiento. No obstante, los resultados obtenidos no son extrapolables, puesto que el tamaño muestral y el tiempo de uso de ambos formatos son reducidos. Este trabajo, es un estudio piloto que refleja las posibilidades que las tecnologías de la información y comunicación podrían tener en el ámbito de la fisioterapia. Es necesario continuar esta línea de investigación para poder alcanzar resultados más concluyentes que permitan establecer el potencial de las TICs en este campo. 


\section{REFERENCIAS BIBLIOGRÁFICAS}

Galán-Rodas, E., y Zamora, A. (2014). La historia clínica electrónica como herramienta de gestión y mejora del proceso de atención de salud en Costa Rica. Acta Médica Costarricense, 56(1), 35-36.

Jiménez, C.E., Fernández, R., Zurita, F., Linares, D., y Farías, A. (2014). Programas de Educación en Salud y Entrenamiento de la Fuerza en adultos mayores con artrosis de cadera leve a moderada. Revista médica de Chile, 142(4), 436-442.

Montero, M., García, R.F., y Ríos, M.D. (2004). Un análisis de la adherencia al tratamiento en fisioterapia. Fisioterapia, 26(6), 333-339.

Oviedo, E., y Fernández, A. (2010). Tecnologías de la información y la comunicación en el sector salud: oportunidades y desafíos para reducir inequidades en América Latina y el Caribe. CEPAL.

Norman, G. J., Zabinski, M. F., Adams, M. A., Rosenberg, D. E., Yaroch, A. L., y Atienza, A. A. (2007). A review of eHealth interventions for physical activity and dietary behavior change. American journal of preventive medicine, 33(4), 336-345.

Peña, A. N., Juan, J. C., y Moreno, N. A. (2010). La interacción comunicativa en el cuidado de la salud. Rev Esp Com Sal, 1(2), 113-29.

Østerås, N., Hagen, K. B., Grotle, M., Sand-Svartrud, A. L., Mowinckel, P., Aas, E., \& Kjeken, I. (2014). Exercise programme with telephone follow-up for people with hand osteoarthritis-protocol for a randomised controlled trial. BMC musculoskeletal disorders, 15(1), 1.

Reed, J. L., Prince, S. A., Cole, C. A., Nerenberg, K. A., Hiremath, S., Tulloch, H. E., ... y Pipe, A. L. (2015). E-health physical activity interventions and moderate-to-vigorous intensity physical activity levels among working-age women: a systematic review protocol. Systematic reviews, 4(1), 1.

World Health Organization. (2011). Global Observatory for eHealth series. Retrieved March, 4, 2011.

Zurita Ortega, F., Fernández García, R., Cepero González, M., Zagalaz Sánchez, M. L., Valverde Cepeda, M., y Ramírez Domínguez, P. (2009). The relationship between pain and physical activity in older adults that begin a program of physical activity. 


\section{ASPECTOS BÁSICOS PARA UNA ENSEÑANZA E-LEARNING DE CALIDAD EN LA EDUCACIÓN

\section{BASIC ASPECTS FOR A LEARNING OF QUALITY IN THE HIGHER EDUCATION}

Juan Miguel Torres Martín ${ }^{1}$

1. Máster en Tecnología Educativa. Universidad de Murcia.

E-mail: ajuanmiftv@hotmail.com

Torres Martín, J.M. (2016). Aspectos básicos para una enseñanza e-learning de calidad en la Educación Superior. 3C TIC: Cuadernos de desarrollo aplicados a las TIC, 5(3), 8-32. DOI: <http://dx.doi.org/10.17993/3ctic.2016.53.8-32/>. 


\section{RESUMEN}

En el presente artículo vamos a tratar la importancia de los diferentes aspectos que contribuyen en una enseñanza e-learning en el ámbito educativo superior. Para ello, trataremos diferentes conceptos esenciales para que una enseñanza de este tipo sea de una calidad óptima.

El desarrollo de la Web 2.0, el concepto de educación abierta y los recursos educativos abiertos de fácil acceso han proporcionado elementos esenciales para el enriquecimiento de las plataformas virtuales actuales. Dichas plataformas permiten un acercamiento entre los alumnos y los profesores de la institución, y a su vez, el propio alumno puede llegar a ser completamente autónomo creando un entorno personalizado de aprendizaje. Para esto, hablaremos de la posibilidad que tiene el alumno en utilizar una cantidad de recursos y herramientas que permiten a este usuario interactuar construyendo su propio conocimiento.

La era de las Tecnologías de la Información y de la Comunicación ha cambiado la forma de concebir la educación superior en España y también, a nivel internacional, promoviéndose un intercambio de conocimientos a nivel global nunca alcanzados con anterioridad.

En el artículo que exponemos, apreciaremos la importancia de la educación e-learning y la gestión del conocimiento, su evolución y sus posibles limitaciones. Para esto, nos basaremos en los argumentos e investigaciones desarrolladas por diferentes profesionales de la rama educativa de los últimos tiempos.

\section{ABSTRACT}

In this article we will address the importance of the different aspects that contribute in an elearning higher education. To do this, we will speak different essential concepts for teaching of this type based in optimum quality.

The development of Web 2.0, the concept of open learning and open educational resources easily accessible, have provided essential elements for the enrichment of existing virtual platforms. These platforms enable a rapprochement between the students and teachers of the institution and in turn, the students themselves can become completely autonomous thereby creating a personalized learning environment. For this, we will discuss the possibility for students to use a number of resources and tools that enable the user to interact constructing their own knowledge.

The era of Information Technology and Communication has changed the way of thinking about higher education in Spain and at the international level, promoting an exchange of knowledge at global level never reached before.

In the article, we appreciate the importance of education e-learning and knowledge management, its evolution and its possible limitations. For this, we rely on the arguments and research carried out by different professionals from the educational branch of recent times. 


\section{PALABRAS CLAVE}

Web 2.0, educación abierta, Enseñanza e-learning, Recursos Educativos Abiertos (REA).

\section{KEYWORDS}

Web 2.0, Open education, e-learning, Open Educational Resources (OER). 


\section{INTRODUCCIÓN}

El concepto de Web 2.0 comienza a evolucionar a partir del año 2000 permitiendo compartir información mediante la red y para que los propios usuarios hagan uso de la misma, de manera participativa (Bartolomé y Grané, 2009). Podemos ir construyendo conocimientos entre los distintos usuarios de forma colaborativa y mediante el uso de la red, utilizándose para ello diferentes herramientas que permiten a dichos usuarios participar activamente. Para esto, este concepto permite dejar de lado el papel de un lector que simplemente busca información para crear su propio conocimiento sin participar en la construcción del mismo (Requena, 2008).

Teniendo en cuenta esta idea, comienzan a aparecer conceptos relacionados con el término de la Web 2.0, que permiten aprovechar sus ventajas y la capacidad de interactuar mediante el uso de la red en diferentes áreas, tales como la Empresa 2.0 o E-learning 2.0, o bien, el que más nos interesa en este caso, la educación 2.0 (Garrido, Almenara, Graván, Sardi, Palazio, Febres y del Carmen, 2009). De esta forma, se busca el intercambio de ideas y la posibilidad de compartir una información útil para otros usuarios.

El concepto de Web 2.0 acoge una cantidad de cualidades que permiten al usuario participar en la red de forma continua y generar conocimientos. Tal como señala Requena (2008), "el resultado del contacto de las personas con estos nuevos avances es el de expandir la capacidad de crear, compartir y dominar el conocimiento". Como vemos, la Web 2.0 ha dado un impulso a la concepción de la educación en el S. XXI en la que participa las Tecnologías de la Información y de la Comunicación (TIC).

En esta línea, podemos aprovechar la oportunidad que nos ofrece la Web 2.0 desde que Tim O'Reilly impulsara esta forma de navegar por la red en el año 2004. Desde entonces, mediante las herramientas y los recursos que proporciona este tipo de web participamos en una nueva forma de comunicarnos y de compartir información por todo el mundo (Bartolomé y Grané, 2009). Las redes sociales, las wikis o los blogs de diferentes temáticas son solo algunos ejemplos actuales de la importancia de este nuevo concepto, gracias al cual la sociedad se ha globalizado. De hecho, las redes sociales son ejemplos actuales de los que más hemos oído hablar siendo posible, gracias a la Web 2.0 y estando las mismas disponibles para el ámbito de las relaciones sociales o bien, dentro del ámbito educativo entre otros aspectos (Castañeda y Gutiérrez, 2010). Las redes sociales han marcado una tendencia que se fundamenta en el intercambio continuo de la información mediante la red.

Como podemos apreciar, esta nueva tendencia del uso de la información disponible en la red iniciada a comienzos de la década 2000, marca una nueva revolución en el mundo de la informática en el que cada usuario conectado en cualquier parte del mundo puede compartir una multitud de recursos de forma libre y gratuita con otros usuarios (De la Torre, 2006).

El uso generalizado de la Web 2.0 ha contribuido a que los usuarios puedan construir, modificar, corregir y compartir el conocimiento desde cualquier ámbito o perspectiva. Un ejemplo claro de esto último es la Wikipedia, la famosa enciclopedia basada en la construcción de un conocimiento que es añadido y mejorado por el intercambio de 


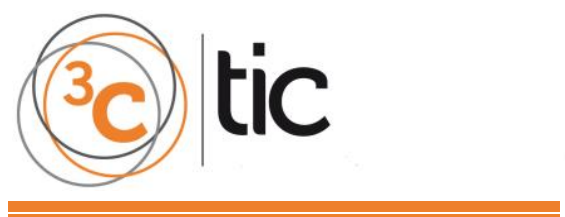

información entre los usuarios de la red de forma constante (Pagola, 2010). Según Pérez, de San y Sánchez (2012), la principal ventaja de este avance se relaciona con la mejora de la calidad de la información y de la comunicación interactiva entre los ciudadanos mediante la red y en mundo de la educación superior.

Cano (2013) expresa las principales características de la Web 1.0 y su evolución el actual hacia concepto de la Web 2.0 adentrándose también, en un nuevo concepto que está aún por llegar, la Web 3.0. La web 3.0 consiste en una tendencia del uso de la red más avanzada que la actual web 2.0, y se prevé que a lo largo de la década de 2010-2020 se perfeccione su uso. De esta forma, Vaquerizo-García (2012) indica que la web 3.0 baraja la posibilidad de usar nuevas formas de comunicación y de acceso a contenidos disponibles en la red de forma aún más inmediata desde cualquier dispositivo. De esta forma, expone una experiencia docente donde la utilización de las herramientas que actualmente se dispone en la red interviene de manera positiva en la calidad educativa. Sin embargo, Cano (2013) va más allá y profundiza en el concepto de Web 3.0 y contempla el uso de la inteligencia artificial como facilitadora de la interacción en la reden un futuro.

En la figura 1 (Cano, 2013) se aprecia de forma resumida la diferencia entre la web 1.0 en la que el usuario no interactúa y simplemente navega en la red para leer la información sin poder construirla e intercambiarla con otros usuarios de manera eficaz, y por otro lado, el concepto de web 2.0 mediante el cual, estamos constantemente construyendo el conocimiento en colaboración con otros usuarios a través del uso compartido de la información en red:

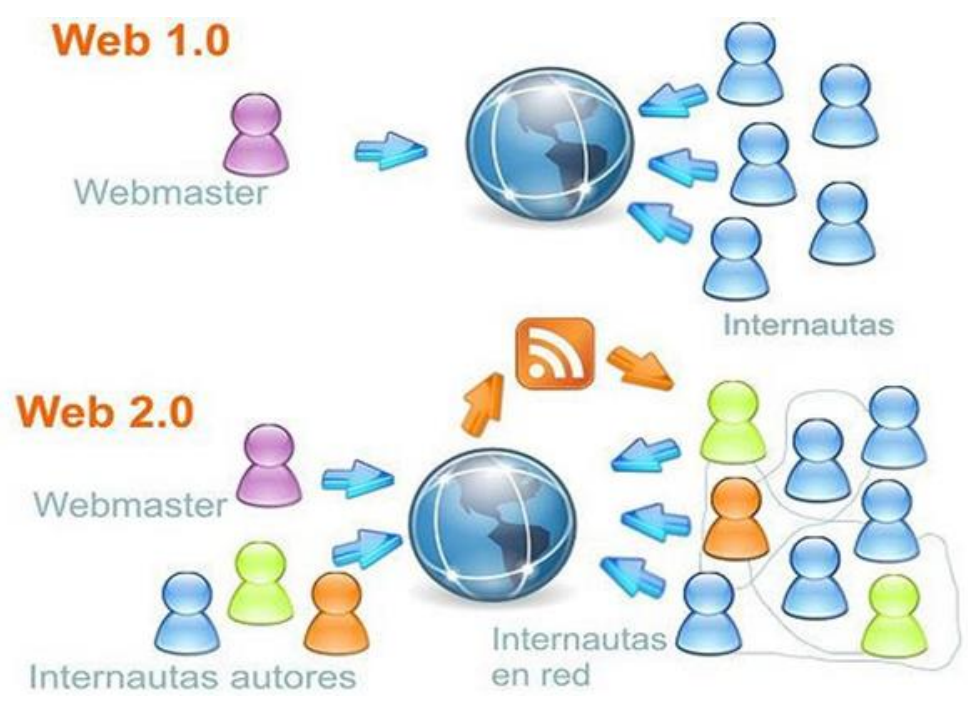

Figura 1. Concepto y evolución de web 1.0 a Web 2.0, Cano (2013). Fuente: http://comenzandodecero.com/definicion-de-web-2-0/ 


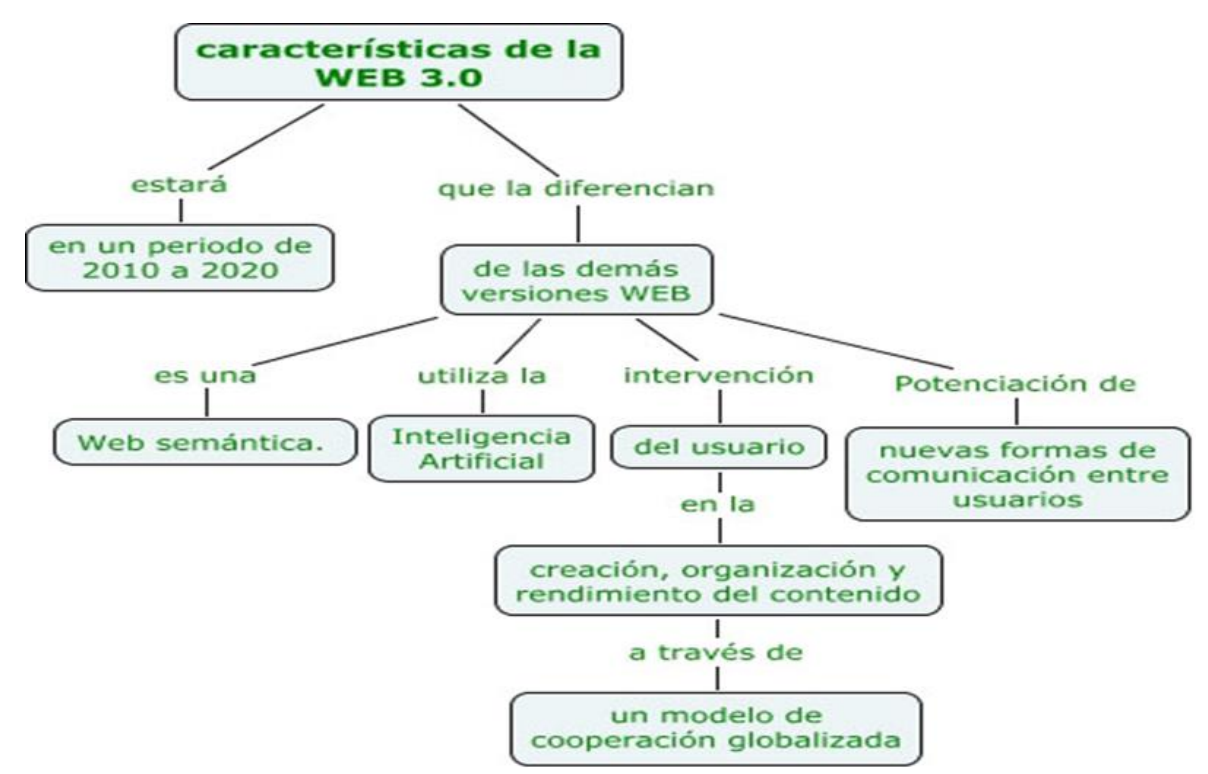

Figura 2. Concepto y evolución de web 2.0 a Web 3.0, Cano (2013).

Fuente: http://comenzandodecero.com/definicion-de-web-2-0/

En la actualidad, podemos mejorar aspectos de la web 2.0 antes de hablar de una tendencia hacia la web 3.0 (Freire, 2007), como por ejemplo, la puesta en marcha de nuevas aplicaciones y herramientas que pueden desarrollar y ampliar aún más la Web 2.0, permitiendo participar a los usuarios de manera más sencilla. "La web 2.0 puede entenderse como un facilitador de un cambio de paradigma en los procesos de aprendizaje" Freire (2011, p. 1). Como vemos, este autor comienza a hablarnos de la importancia que ofrecen las distintas herramientas de la Web 2.0 en el mundo de la educación.

Debemos tener en cuenta que el concepto Web 2.0, además de influir de forma bastante significativa en el ámbito educativo, también está presente en otras ramas como el mundo laboral, en la cual se ha ofrecido diversas herramientas durante la última década y gracias a la nueva era de internet (Fundació per a la motivació dels recursos humans, 2008). No obstante, la educación superior sigue siendo la rama en la que las plataformas virtuales, la enseñanza e-learning y las herramientas derivadas de la web 2.0 evolucionan de la forma más rápida, integradora y eficaz (Area, 2009).

Según Álvarez (2009), la web 2.0 ha originado la enseñanza e-learning, y con ello las actuales plataformas y entornos virtuales disponibles mediante la educación superior. En el presente informe podríamos adentrarnos en las características de las plataformas virtuales, sus tipologías y también, en los Entornos Personales de Aprendizaje (PLE). Esto último, los PLE son creados por los propios alumnos gracias a la disponibilidad de recursos y herramientas que pueden ser utilizados para fomentar y construir su propio conocimiento. No obstante, estos aspectos no son objeto de investigación (mirar bloque II del presente informe) y nuestro estudio no se relaciona directamente con dichos aspectos. Por esto, hemos decidido no profundizar en esos detalles. Sin embargo, debemos tener en cuenta que la creación de la Web 2.0 ha permitido también crear nuevos proyectos ambiciosos en la actualidad que permiten compartir conocimientos de transmisión libre a escala mundial (González, 2009) Este aspecto lo tendremos bastante en cuenta en el presente informe. 


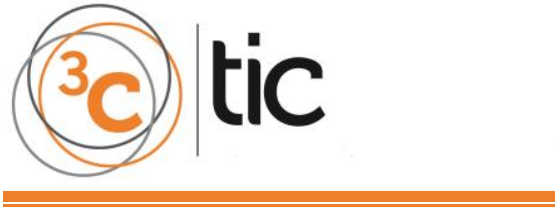

El término de Web 2.0 ha generado no solo un cambio educativo sino también, un cambio social. Las relaciones sociales y las formas de comunicarnos se han modificado en muchos aspectos en la última década (Flores, 2009). Hemos evolucionado en cuanto a la forma de conocer gente y de comunicarnos. La variedad de dispositivos electrónicos que surgen en nuestros días han colaborado de forma significativa en este desarrollo social (Herreros, 2008).

Siguiendo esta línea, "la web 2.0 es una plataforma de redes sociales de información en sentido amplio y general concerniente a muchos campos del conocimiento y de la vida real", (Herreros, 2008, p. 347). Como podemos apreciar, este autor denomina a la Web 2.0 como una gran plataforma de redes sociales, es decir, la Web 2.0 ha mejorado las comunicaciones y las relaciones entre los usuarios de la red. Podríamos hacer referencia a este concepto como si de una gran red social se tratase.

Según Castañeda, González y Serrano (2011), existen distintas tipologías entre las distintas redes sociales (online) de las que disponemos para usar en la actualidad mediante la utilización de Internet. Estas redes sociales pueden variar según su organización y su finalidad. De esta forma, García, Portillo, Romo y Benito (2007) nos habla de una nueva generación que ha nacido en la era de la Web 2.0. Esta generación denominada como nativos digitales incluyen en sus vidas desde edades muy tempranas las nuevas tecnologías creciendo y evolucionando con las mismas. Como vemos, el concepto del cual hemos hablado, abarca distintos aspectos de nuestras vidas y ha venido para quedarse y evolucionar con nosotros, haciéndonos la vida más cómoda accediendo a la información y al conocimiento de manera más sencilla.

Para concluir, hacemos referencia a la nueva alfabetización digital relacionada con el uso de las nuevas herramientas que ofrece la Web 2.0 y la importancia de la participación de los usuarios en la mejora de este concepto en la actualidad, "ligado a conceptos de alfabetización y lenguaje audiovisual que todavía hoy son necesarios en ámbitos educativos, y atado también a la idea de participación de la Web 2.0" (Bartolomé y Grané, 2009, p. 2).

\section{EDUCACIÓN ABIERTA}

En la educación abierta participa de forma activa tanto el alumnado como el profesorado, teniendo disponible para ello herramientas y recursos en la red. Esto permite un aprendizaje de lo más pleno y enriquecedor posible (Gea, Montes, Rojas, Marín, Cañas, Blanco y Gutiérrez, 2013). De esta forma, se garantiza una mayor eficacia en el aprendizaje de nuevos conocimientos y en la autonomía de los propios alumnos.

La educación abierta aprovecha los recursos y las herramientas que ofrece la Web 2.0 y pone al alcance de los alumnos del ámbito educativo superior el acceso al aprendizaje de forma enriquecedora sin necesidad de desplazarse necesariamente a un lugar físico (Salinas, 2013).

Siguiendo las aportaciones de uno de los grandes impulsores de la educación abierta en el ámbito de la educación superior, Downes (2007), debemos resaltar la importancia de la 
disponibilidad de los recursos en una educación abierta. Estos recursos deben tener unas características que sean algo más que las simples imágenes o textos, deben intervenir otros apoyos fundamentales para el sistema educativo como la disponibilidad de conferencias llevadas a cabo por expertos, por ejemplo. También, la realización de intercambios de estudiantes a nivel internacional, entre otros aspectos fundamentales que nos indican la importancia de la transmisión de contenidos basados en experiencias fomentado así la globalización del conocimiento.

Según Salinas (2002), para que un aprendizaje sea flexible debe cumplir una serie de características como una flexibilidad apreciable en el lugar, en el tiempo, en los métodos y en los distintos ritmos de aprendizaje de los alumnos. La flexibilidad de la educación se basa en el protagonismo del alumno, siendo el profesor un agente que ofrece contenidos que facilitan el buen desarrollo del aprendizaje. De esta forma, se debe cumplir el objetivo fundamental de la educación abierta, el cual se relaciona con la autonomía plena en el aprendizaje de estos alumnos (Area, 2003).

Según Rodés, Podetti, Custodio, Fager, Alonzo y Pérez (2014), en la educación abierta los usuarios tienen la posibilidad de disponer de una gran variedad de recursos para fomentar y construir sus propios conocimientos. Por esto, hacemos referencia a los Recursos Educativos Abiertos (REA) cuando hablamos de una educación abierta en el ámbito de la enseñanza superior. Para afirmar esto último, debemos tener en cuenta lo que Geser (2007) nos indica al respecto, "se entiende que los recursos de educación abierta (OER) comprenden contenidos para enseñar y aprender, herramientas y servicios basados en software y licencias" (Geser, 2007, p. 5). De esta manera, se puede apreciar la importancia de los OER en el ámbito de la educación superior y por ello, volveremos a hablar detalladamente en el siguiente apartado del presente artículo.

Según Peré, Perera y Canuti (2011), los Recursos Educativos Abiertos (REA) han sido reconocidos por distintas organizaciones mundiales como la OCDE o la UNESCO entre otras, debido al papel que juegan en la transmisión libre de conocimientos así como la libertad que otorga al usuario de construir su propio conocimiento partiendo de las publicaciones disponibles en la red. Esto quiere decir que estos recursos fomentan el desarrollo educativo de los países que más lo necesitan (Geser, 2007), y por esto, esta tendencia relacionada con la transmisión de contenidos libres es avalada por los distintos organismos internacionales. Según este autor, debemos tener en cuenta que al hablar de conocimientos libres, o bien, contenidos libres dispuestos en una educación abierta, se permite un aprendizaje también libre y abierto para cualquier ciudadano del mundo. Todo esto, siempre y cuando tengamos disponible una conexión a Internet.

Según Parra y Oblitas (2011), cuando hablamos de educación abierta, debemos hacer referencia a un nuevo modelo en la transmisión de contenidos, una nueva forma de generar conocimientos, una forma innovadora de compartir y construir el conocimiento. Esto se debe a que una educación abierta es simplemente una educación igualitaria al alcance de todos los que quieran acceder de la forma más cómoda e inmediata posible (Cookson, 2012). Una revolución en la transmisión del conocimiento y en la difusión de la información que hasta hace unos años era impensable conseguir. 
D'antoni (2007) nos habla en este caso de la importancia de la educación abierta y sus recursos en el ámbito de la educación superior. De esta manera, deja reflejada la importancia de una educación fundamentada en un derecho de todos los ciudadanos. De esta forma, se expresa en la obra de este autor el inicio de este tipo de educación a la cual todos podemos acceder de la misma forma a los mismos conocimientos. Gracias a la educación abierta y a los recursos que ofrece la misma, nace el concepto e-learning que ha ido evolucionando en la última década para darle respuesta a las necesidades de los alumnos de la enseñanza superior tanto en España como en otros países del mundo (Álvarez, 2009).

Para concluir, podemos apreciar en la siguiente página y como parte fundamental de la educación abierta, la importancia del concepto de aprendizaje abierto. En torno a este concepto gira todo lo que hemos visto en el presente apartado, y a partir del cual podríamos obtener más detalles si profundizamos en dicho concepto. La base de la educación abierta se relaciona directamente con un aprendizaje eficaz y constructivo para el alumno.

\section{RECURSOS EDUCATIVOS ABIERTOS (REA)}

Estrechamente unido al concepto de Educación Abierta, hacemos referencia al concepto de Recursos Educativos Abiertos (REA) el cual, trataremos con profundidad en el presente apartado.

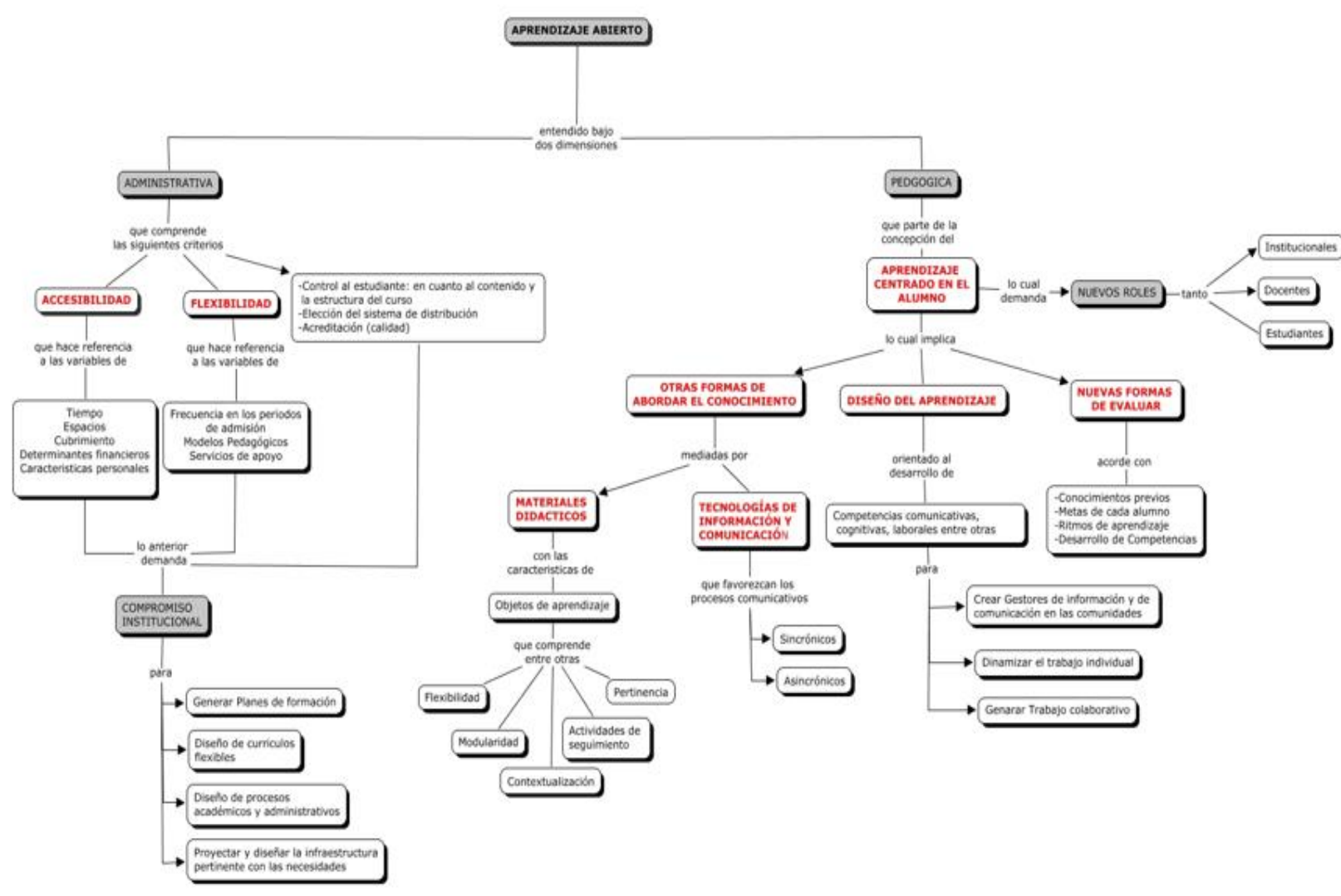

Figura 3. Esquema del Aprendizaje Abierto en el ámbito de la educación superior. Fuente: http://culturadigitalpucp.blogspot.com.es/2012/05/educacion-abierta.html 
Para empezar, debemos destacar la cantidad de información que podemos encontrar disponible en la red de forma gratuita pudiendo aprovecharse la misma, por cualquier usuario, como enriquecimiento personal (Ledo, Alfonso, Peña y Hernández, 2014). Esta información disponible es más habitual en la educación superior y disponemos de diferentes organizaciones a nivel internacional encargadas de administrar y organizar todos estos contenidos (González y Hernández, 2013).

García y Uribe (2009) expresan en su artículo la importancia de cumplir con unos estándares o requisitos en el momento de compartir los Recursos Educativos Abiertos en la red. De esta forma, podremos crear plataformas virtuales y compartir la información de manera más rápida, seleccionando una temática para ello. También, podemos disponer del tipo de herramientas necesarias para que la información sea aprovechada lo mejor posible.

Siguiendo esta línea, según López (2008), los Recursos Educativos Abiertos (REA) se organizan en tres apartados fundamentales (tipología). En primer lugar, nos habla de los contenidos educativos que abarcan cursos completos, imágenes, vídeos y publicaciones, entre otros contenidos. En un segundo lugar, este mismo autor nos habla de otro tipo de REA fundamental en la educación superior. Nos referimos a las herramientas necesarias para organizar y transferir todos esos contenidos. Y la tercera tipología de los REA se relaciona con los recursos de implementación, es decir, con la necesidad de publicar los contenidos bajo las licencias de propiedad intelectual. Como vemos, estos tres tipos de Recursos Educativos Abiertos (REA) se organizan y se transfieren siguiendo unas características fundamentales para que el éxito en la red sea posible.

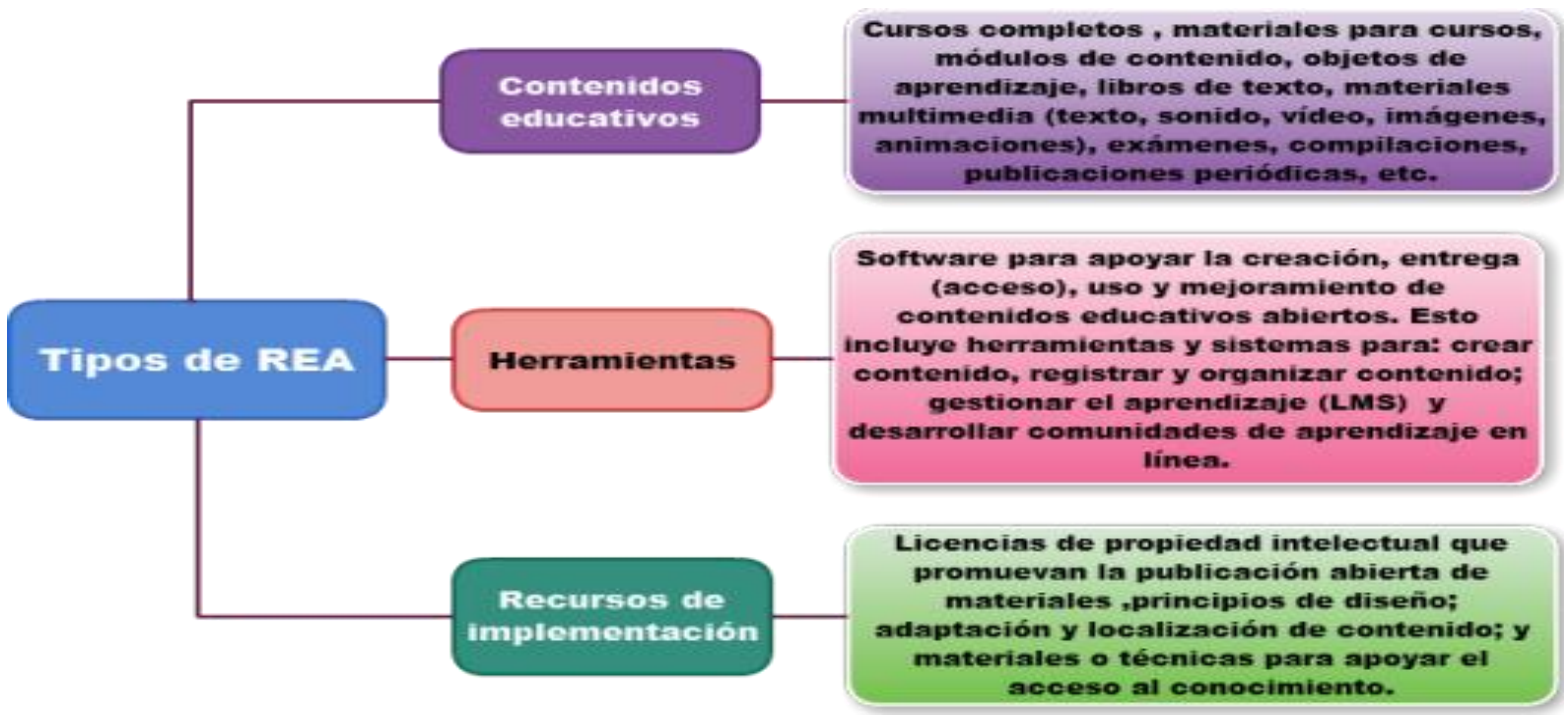

Figura 4. Tipología de los REA.

Fuente: https://ugalblog.wordpress.com/2013/10/18/compartir-conocimiento-recursoseducativos-abiertos-rea/

Los Recursos Educativos Abiertos, conocidos como Open Educational Resource (OER) en inglés a nivel internacional, comienzan a clasificarse en el año 2002 por la UNESCO (Parra y Oblitas, 2011). Gracias a los recursos depositados en la red de forma libre por profesionales del campo de la educación superior, se forman y se comienzan a desarrollar proyectos emprendedores que crecen a la par de la construcción y creación de estos recursos. Los REA 


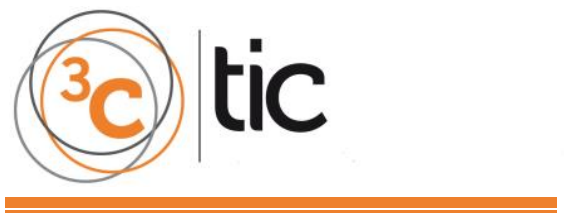

establecen la base para hacer posible la transmisión libre de conocimientos en la educación superior a nivel internacional. Para hacer posible esto, se siguen unos requisitos básicos y esenciales para poder mantener una calidad óptima en la publicaciones de los contenidos en la red (Montes, Rodríguez, González y Gea, 2012).

Según la UNESCO (2005), los recursos educativos de libre acceso ofrecen estrategias para una correcta y adecuada educación, favoreciendo la interacción y propiciando la libre transmisión de diferentes tipos de conocimientos. De esta forma, se fomentan a su vez las capacidades de los usuarios. La UNESCO es una de las grandes organizaciones que a nivel internacional se encarga de organizar el conocimiento para que todos los usuarios independientemente del país en el que vivan puedan acceder libremente al mismo.

Siguiendo esta línea, Sicilia (2007) propone las vías (y los formatos) por las cuales los docentes pueden compartir de la forma más efectiva sus publicaciones a nivel internacional. Es decir, siguiendo un formato adecuado, o bien unas sencillas indicaciones los profesionales de la rama educativa, contribuyen en la transmisión de los conocimientos en el nivel educativo superior. De esta manera, se cumple con lo que propone la UNESCO (2005) en cuanto a la gestión del conocimiento, es decir, se transmite el conocimiento a todos los sectores de la sociedad, "la noción de sociedades del conocimiento no se puede reducir a una visión exclusiva de los países del Norte, ya que parece constituir también un nuevo enfoque de desarrollo pertinente para los países del Sur" (UNESCO, 2005, p.7).

Según Prendes, Gutiérrez y Martínez (2010), los Recursos Educativos Abiertos tienen cada vez una mayor importancia en el ámbito de la educación superior. Se crean contenidos que pueden ser temas, pruebas, glosarios, entre otros, que permiten a los usuarios de la red disfrutar y disponer de estos materiales de manera libre.

Para poder entender como ha llegado hasta la actualidad la difusión de los REA, la UNESCO fundó en el año 2002 el primer "foro mundial sobre recursos educativos de libre acceso", con los que se explora el impacto de dichos materiales en los países en vías de desarrollo. En ese mismo año la UNESCO crea el término "Recursos Educativos Abiertos" y se comienza a propagar diversos materiales a nivel internacional.

En el año 2005, la UNESCO creó, junto con la fundación de William y Flora Hewlett, una "wiki mundial comunitario sobre recursos educativos de libre accedo". Finalmente, con la colación de diferentes instituciones europeas, entre los que encontramos: ICDE, la institución de miembros del ICDE, la Universidad Abierta del Reino Unido y la UNESCO, coordinado por la Universidad de Duisburg-Essen promueven la creación de OPAL (Open Educational Quality), en la que mejoran la calidad de los recursos educativos ofrecidos con mayor innovación (Smith y Casserly, 2006).

Según Pagola (2010) y centrándonos en el concepto de Recursos Educativos Abiertos, cabe destacar que existen otros ejemplos en los que podemos apreciar la libre transmisión del conocimiento. Uno de estos ejemplos es la enciclopedia virtual más visitada en el mundo y que cumple una función relacionada completamente con la construcción de recursos por los propios usuarios que crean de forma colaborativa y que comparten a nivel internacional. Hacemos referencia en este caso, a la Wikipedia (Adell, 2007). 
Según Starobinas (2013), no se pretende eliminar los libros didácticos aunque sí debemos considerarlos insuficientes para una educación adecuada y plena. Este autor colabora en la idea de fomentar la educación mediante la participación de múltiples instituciones como la UNESCO antes mencionada, el Instituto de Tecnología de Massachussetts, la fundación Willian y Flora Helett o bien, los componentes que forman la OPAL. Uno de los principales objetivos que recogen estas organizaciones a nivel mundial las cuales, apuestan por el conocimiento libre, es llegar no solo a los usuarios pertenecientes a la educación superior sino también, expandir estos recursos a todos aquellos que quieran formarse y aprender independientemente de la edad que disponga, es decir, se pretende apostar por la creación de contenidos libres destinado para todas las edades (López, 2008). Siguiendo esta línea y teniendo en cuenta a uno de los autores más relevantes en el tema de la transmisión del conocimiento libre en la educación superior, Downes (2007) enriquece el concepto de Recursos Educativos Abiertos (REA), "a priori pensar que los OER abarcan objetos físicos estáticos o recursos digitales tales como textos, imágenes, gráficos y multimedias" (Downes, 2007, p.3).

Además de esto, contamos con las ideas de Johnstone (2005), pues este autor amplía las características del concepto Recursos Educativos Abiertos (REA). De esta forma, se complementa las aportaciones que posteriormente añade Downes (2007), categorizando los Recursos Educativos Abiertos en distintos tipos según su disponibilidad y función.

Según Johnstone (2005), en un primer lugar disponemos de los recursos de aprendizajes que abarcan cursos completos, módulos de contenidos, herramientas y comunidades virtuales entre otros aspectos. En un segundo lugar, nos habla de los recursos necesarios para apoyar a los profesores, es decir, se centra en este caso en las herramientas y en los materiales que intervienen en la creación de contenidos por parte de los profesores. $Y$ en tercer lugar, este autor nos habla de los recursos que aseguran la calidad de la educación y de las prácticas educativas.

Valverde (2010) elabora posteriormente otra clasificación de los Recursos Educativos Abiertos (REA). De esta forma, este autor organiza los REA, en un primer apartado, en contenidos de aprendizaje que abarcan los cursos, los módulos o los materiales. En un segundo apartado tiene en cuenta las herramientas tecnológicas, como la creación de distintos software que ayuden a mejorar la calidad y gestión de los contenidos producidos y, en un tercer apartado se incluyen los recursos de implementación, como las licencias de propiedad intelectual.

Si nos fijamos, Johnstone (2005) y Valverde (2010) guardan una mayor similitud entre sus clasificaciones respecto a las aportaciones de Downes (2007). Según Santana (2013), la idea de la propagación del conocimiento libre y gratuito por todo el mundo se relaciona directamente con el acceso a la cultura y a la formación que necesitan en muchas ocasiones los ciudadanos de aquellos países menos favorecidos económicamente. Es decir, se garantiza una igualdad de oportunidades, ya que de esta forma se considera la educación realmente como un derecho universal del que todo el mundo dispone mediante el acceso a la red (coincide la idea con lo propuesto por la UNESCO, 2005). 


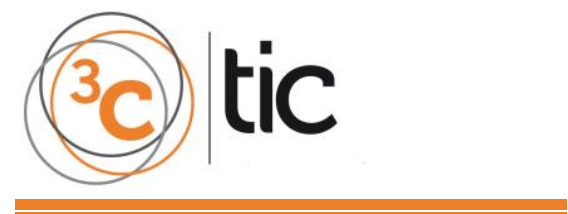

Santana (2013) afirma que estos Recursos Educativos Abiertos (REA) involucran tanto a profesores como a los alumnos en cuanto a la adaptación y uso de contenidos libres. De esta manera, se pueden formar a los propios docentes para que sean éstos los que diseñen los REA. Esta tendencia de generar recursos educativos forma parte de una revolución educativa en cuanto a las tecnologías digitales, para así producir un cambio en la sociedad educativa actual.

Según Prendes, Gutiérrez y Martínez (2010) se habla de las 4R. Una forma clara y concisa de expresar la forma de utilizar los Recursos Educativos Abiertos. Partiendo de esto, se habla de reutilizar, revisar, remezclar y redestribuir. Acciones que permiten un mayor aprovechamiento de los materiales que disponemos en la red. Uno de los principales objetivos de los profesores y educadores es fomentar y proporcionar la educación y los recursos entre sus alumnos. En este sentido, podemos incluir dentro de este alumnado a otros profesionales y educadores, pues son aprendices de estos conocimientos, contenidos y herramientas que proporcionan sus compañeros de profesión del resto del mundo.

Para concluir, expondremos a continuación la figura, que recoge las cinco características básicas en las que se basan los Recursos Educativos Abiertos (REA) que disponemos en la red.

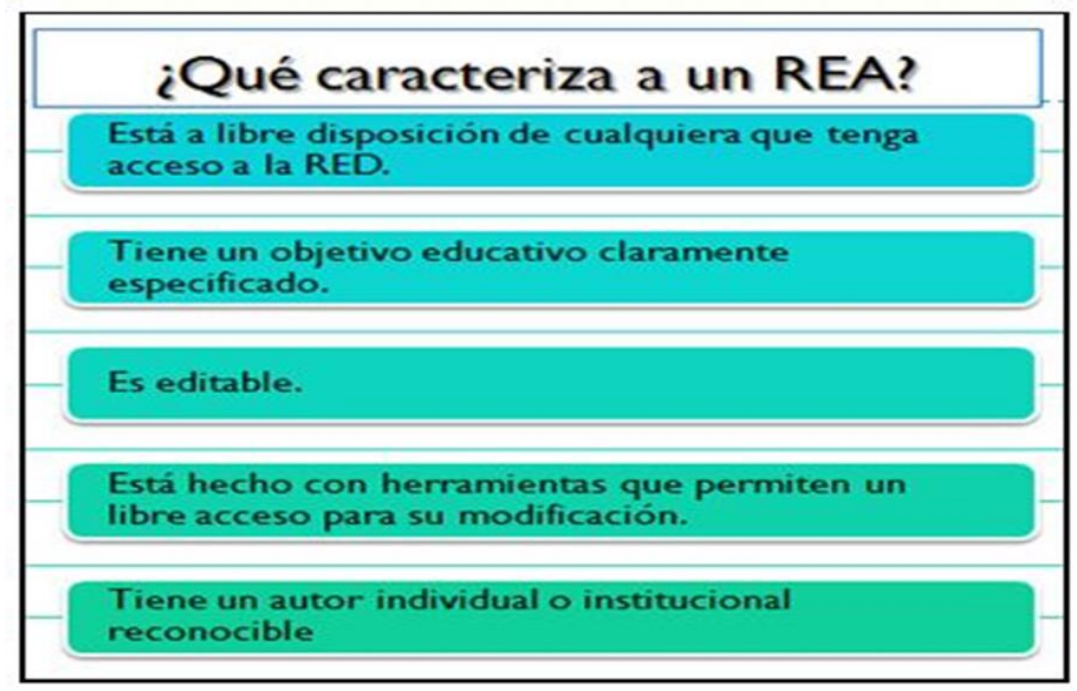

Figura 5. Características básicas de los Recursos Educativos Abiertos (REA).

Fuente:http://eportafoliomeneses.blogspot.com.es/2014/02/construyendo-un-espacio-decomunicacion.html

\section{E-LEARNING Y SU EVOLUCIÓN}

La enseñanza e-learning se basa en la transmisión de contenidos (compartir conocimientos) mediante una metodología que guarda una estrecha relación con la virtualidad (Álvarez, 2009). Su pilar básico gira en torno al estilo de enseñanza que ofrecen actualmente muchos centros de educación superior (también se aplica en niveles educativos medios, en menor medida) utilizándose para ello, plataformas virtuales en muchos casos (Almenara, 2006). El profesorado puede seguir y evaluar el aprendizaje de estos alumnos de forma continua y de manera dinámica sin la necesidad de compartir un espacio físico. 


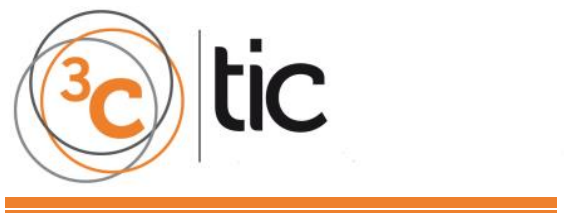

Según Schneckenberg (2004), la aparición del concepto de e-learning en la educación superior ha traído una renovación constante en la enseñanza de contenidos por parte de las universidades a nivel internacional. De esta forma, la educación superior se ha podido acercar a los alumnos como nunca antes había ocurrido, pudiendo integrarse al ritmo de vida de los mismos. Este autor deja reflejada la evolución de este concepto en su obra, mediante la cual indica la inversión y la rentabilidad que supone este reciente método de enseñanza que ha ido evolucionando desde los comienzos de la pasada década. Por esto, a medida que el concepto e-learning ha ido evolucionando, se han integrado los términos necesarios para su funcionamiento como el Aprendizaje Abierto o Educación Abierta. "Los conceptos relacionados con el cambio en el sector de la educación, que han sido iniciados por las nuevas tecnologías, incluyen desde la digitalización de la educación, la corporación y comercialización de las universidades en un nuevo mercado competitivo" (Schneckenberg, 2004 , p. 147). Como vemos, la revolución en el mundo de la educación superior va de la mano de la revolución tecnológica, es decir, avanza de forma unida hacia una mayor calidad educativa y una mayor competitividad.

Siguiendo esta línea, Area y Segura (2009) nos dice que las universidades deben invertir en innovación tecnológica para que sea posible una enseñanza virtual (e-learning). No obstante, una educación en modalidad e-learning supone un coste inferior al invertido de forma presencial. Además de las ventajas económicas que supone para las universidades este tipo de enseñanza, Area y Segura (2009) destacan los aspectos positivos que esto implica para la sociedad, tratándose de aquella sociedad dispuesta a formarse a través de una enseñanza completa e innovadora, como la que permite la modalidad e-learning.

Según Rubio (2003), la enseñanza e-learning se ofrece mediante plataformas y entorno virtuales, es decir, se crea entre la institución (el profesorado) y los alumnos en unas aulas de carácter virtual que permiten una interacción constante entre los usuarios. De esta manera, los conocimientos impartidos pueden llegar fácilmente a distintos lugares e incluso, a diferentes países del mundo de la misma forma.

Como vemos, la educación e-learning ha ido evolucionando a lo largo de los últimos años hasta llegar a la enseñanza virtual que conocemos actualmente en la educación superior, tanto en España como a nivel Internacional (Albert y Ros, 2008). Esta enseñanza virtual se ofrece mediante distintas plataformas virtuales y se aprovechan las diferentes herramientas que ofrecen actualmente la web 2.0 (Álvarez, 2009).

Manzuoli y Roig (2015) han llevado a cabo de forma reciente una investigación en la que muestra la importancia de la enseñanza e-learning en la educación superior en nuestros días. Mediante la misma, se presentan en las encuestas rellenadas por los participantes el cambio de roles dentro de este tipo de enseñanza.

Siguiendo esta línea, podemos apreciar que mediante la enseñanza e-learning no se excluyen a alumnos por motivos de lejanía al centro educativo. Por esto, la enseñanza e-learning se ha ido fortaleciendo en la última década (Zapata, 2002). Y gracias a este fenómeno, el alumno puede crear su propio espacio de aprendizaje, por el cual accede de manera más sencilla al conocimiento (Adell y Castañeda, 2010). Este espacio es conocido como los Entornos 


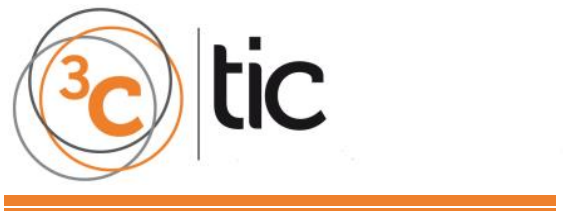

Personales de Aprendizajes (PLE). Los PLE se crean gracias a la disponibilidad de las diversas herramientas y recursos que los alumnos encuentran en la red para construir su propio conocimiento de forma autónoma (Cabero-Almenara, 2006).

Area y Segura (2009) también expresan la importancia de la labor del profesorado para redirigir a sus alumnos en cuanto a la búsqueda de la información útil que está disponible en la red. Aunque los alumnos tengan a su disposición desde cualquier lugar o mediante cualquier dispositivo con acceso a Internet una gran cantidad de información, los mismos deben ser capaces de seleccionar aquellos datos más relevantes o aquellos que guardan una mayor relación con el tema de contenidos que se imparten en las aulas virtuales. Como vemos, la enseñanza e-learning permite una mayor autonomía a los alumnos.

La propia universidad como institución puede crear una red exclusiva en la que los accesos a la red del propio centro permitan crear una comunidad exclusiva entre usuarios (Molina y Ramos, 2015). Esto se relaciona con las plataformas telemáticas que se habilitan en los espacios universitarios con el fin de establecerse un intercambio de conocimientos entre los miembros que colaboran en una misma institución.

Además de la enseñanza e-learning, mediante la cual destaca la virtualidad y el aprovechamiento de los recursos disponibles en la red, podemos apreciar autores que defienden una enseñanza semipresencial (blended learning), como es el caso de García (2004). Este autor hace referencia a la educación semipresencial como un estilo de enseñanza que se sitúa en medio de la presencialidad física y la completa virtualidad. No obstante, crea su propio estilo de enseñanza que aporta a los alumnos un aprendizaje completo basada en recursos tecnológicos y el trato presencial de las instituciones ante sus alumnos. Además, también encontramos a otros autores como Lizárraga, Colado, Zatarain, Pérez y Sánchez (2013) que nos hablan de la enseñanza blended learning y exponen estudios realizados en la educación superior sobre este tipo de enseñanza expresando a su vez, las opiniones de los alumnos.

Siguiendo esta línea, Pina (2004) presenta una crítica en la que describe una serie de aspectos negativos que se relacionan con la enseñanza e-learning. No obstante, en su obra apuesta por un estilo de enseñanza Blended learning considerando que dicho estilo es el más beneficioso para un aprendizaje activo y enriquecedor.

Frente a estos argumentos, Bartolomé (2001) nos habla acerca de la importancia de la educación presencial y tradicional en el ámbito educativo superior. No obstante, también nos explica las características esenciales de los otros modelos de educación y aboga por aquel que sea el más completo y el que más aproveche los recursos disponibles para un aprendizaje de lo más enriquecedor posible.

Sin embargo, Bartolomé (2001) advierte un posible fracaso de la enseñanza e-learning si no se toman las medidas necesarias para aprovechar de la mejor forma este nuevo concepto de enseñanza-aprendizaje. Estamos ante un artículo sostenido en la crítica hacia un hecho actual, mediante el cual se encuentra en auge en la educación superior y muestra claros avances en la calidad educativa. 


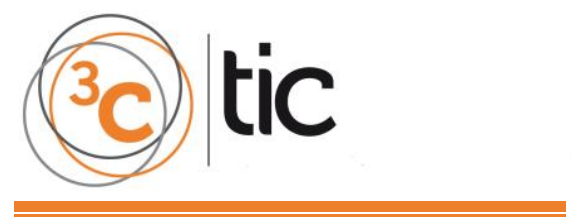

Cejudo (2012) muestra desde otra expectativa la evolución de la enseñanza e-learning. Para esto, este autor se basa en tres etapas fundamentales que abarcan el inicio del concepto hasta la actualidad y que a su vez, dicha clasificación la relaciona con la evolución de la Web 1.0 hasta la Web 3.0. Siguiendo este orden, Cejudo (2012) nos habla de tres etapas: elearning 1.0 , e-learning 2.0 y e-learning 3.0.

Teniendo en cuenta las aportaciones de Sánchez (2013) y Pina (2004) respecto a la enseñanza Blended learning y a su vez, las aportaciones de Cejudo (2012) respecto a la evolución del concepto de e-learning, hemos selecciónado la siguiente imagen:

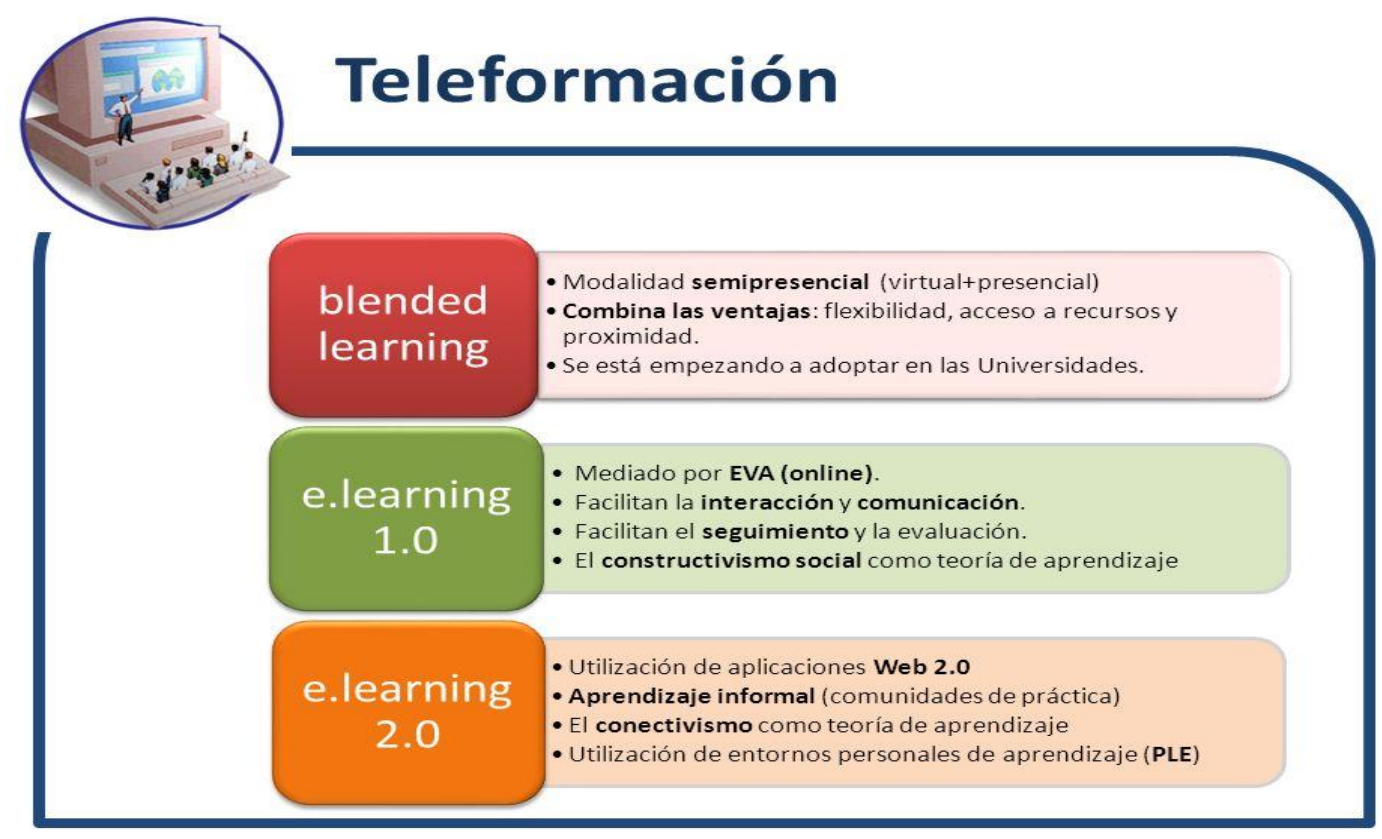

Figura 6. Blended learning y e-learning.

Fuente: http://slideplayer.es/slide/1022313/

Lara y Duart, (2005) hace referencia a la evolución de la enseñanza e-learning desde comienzos de la década de los noventa marcando un proceso de cambio y transformación acorde al desarrollo tecnológico hasta nuestros días. De esta forma, estos autores reflejan aquellos escasos recursos que disponían los usuarios de la enseñanza virtual hace unos veinte años y su evolución hasta nuestros días.

Como vemos, el concepto de e-learning es muy amplio en la actualidad y se trabaja tanto en España como a nivel internacional. En el ámbito internacional disponemos de diversos autores como Koper (2006), Downes, (2007), McLoughlin, y Lee (2007) o bien, O’Malley, Vavoula, Glew, Taylor, Sharples, y Lefrere (2003) entre otros, que han realizado estudios sobre este estilo de enseñanza en el ámbito de la educación superior. De hecho, ya hemos hablado de algunos de ellos con anterioridad. No obstante, debemos destacar, por ejemplo, la obra de McLoughlin, y Lee (2007), la cual expresa la importancia de la enseñanza de la educación virtual (e-learning) para la creación de nuevos proyectos de cara al futuro, haciendo referencia a la aparición de un nuevo paradigma pedagógico. 


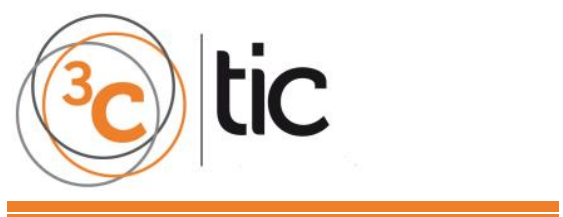

A continuación expondremos una imagen en la que reflejamos la importancia del concepto de e-learning y su tipología:

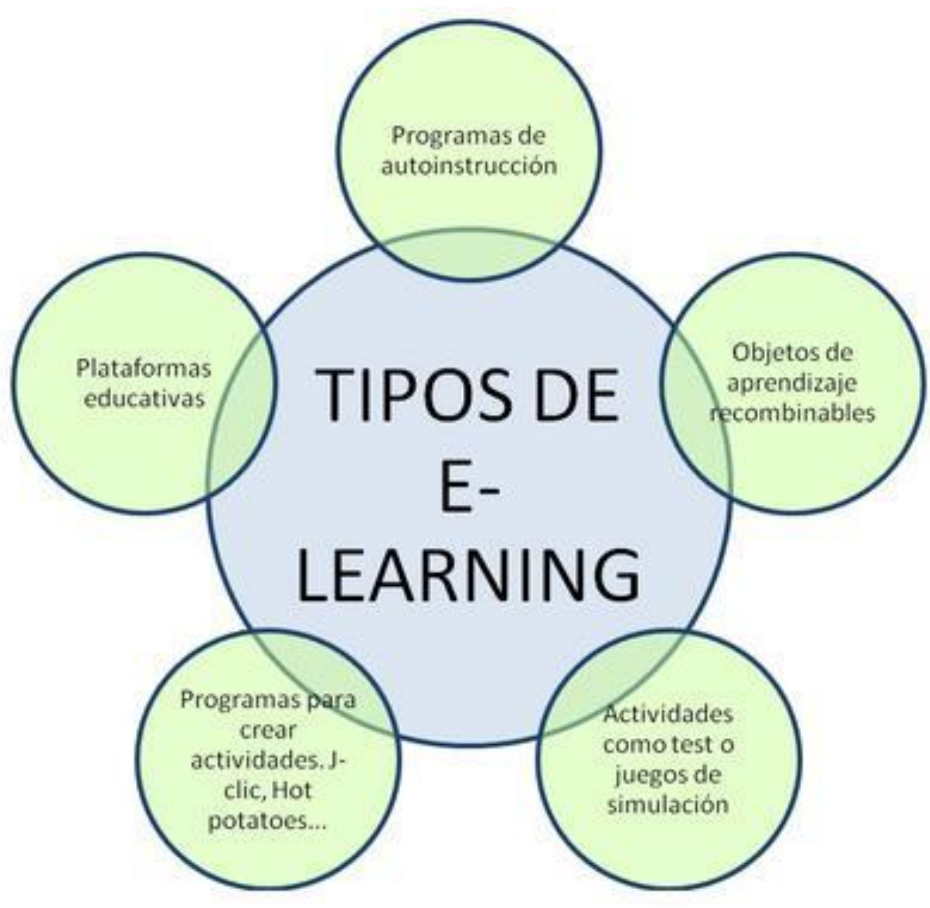

Figura 7. Tipos de e-learning.

Fuente: http://socialmente2011b.wikispaces.com/Aprendizaje+en+Red

\subsection{LA IMPORTANCIA DE LAS LICENCIAS QUE RESERVAN EL DERECHO DE LA PROPIEDAD INTELECTUAL}

Dentro de la enseñanza e-learning, debemos hacer referencia a las licencias que permiten reservar los derechos de la propiedad intelectual de todos aquellos contenidos de autores que mediante el uso de la red trasmiten sus conocimientos. Partiendo de esto, ya hemos hecho referencia en más de una ocasión a la importancia de proteger la propiedad intelectual de las publicaciones en apartados anteriores del presente informe. Uno de estos autores, López (2008), trata que dentro del apartado de los Recursos Educativos Abiertos (REA) hemos destacado la importancia de estas licencias para reservar el derecho de la propiedad intelectual (p.15). Siguiendo los argumentos de este autor, hablamos de la tipología de los REA teniendo en cuenta los recursos de implementación, es decir, la necesidad de publicar los contenidos bajo las licencias de la propiedad intelectual.

Una de las licencias más empleadas en la difusión de contenidos de forma libre y gratuita en el ámbito educativo superior trata de la licencia de Creative Commons. Esta licencia en concreto, permite publicar materiales y difundir conocimientos de libre acceso pudiendo

pedir información los autores de los mismos, estar protegidos ante posibles plagios o de un mal uso de la información que ofrecen a los usuarios. De esta forma, estos autores se encuentran respaldados bajo las leyes de la propiedad intelectual. Toda esta información 
viene detallada en la propia página web de Creative Commons ${ }^{1}$, en la cual se especifica con detalles los derechos y los requisitos necesarios para poder publicar de forma adecuada una obra.

El hecho de compartir libremente contenidos y conocimientos a nivel internacional no quiere decir que no se proteja el trabajo y el esfuerzo de los autores. Por esto, es bastante común y generalizado encontrarnos con la etiqueta de "Creative Commons" en los contenidos que se comparten en la educación superior, a diferencia de muchos otros contenidos que se publican en la red con el afán de compartir también conocimientos y recursos, pero no se aprecia en los mismos una clara protección de la información divulgada. De hecho, muchos de los cursos que ofrecen las plataformas de MOOC carecen de licencias que reserven los derechos de autor (Fernández, 2014).

Parra y Oblitas (2011) expresan la importancia de hacer públicos los trabajos bajo las licencias que reservan el derecho de autor. Esto se debe a cuestiones de formalidad llegando a proteger las publicaciones sin coste alguno para los autores. De esta manera, se garantizan los derechos de los trabajos publicados en la red de manera sencilla.

La facilidad del uso de la licencia de Creative Commons y la importancia de su manejo permite difundir las publicaciones de muchos investigadores mediante la red, haciendo posible el disfrute común de todos los usuarios. Por otro lado, otros autores como Prendes, Gutiérrez y Martínez, (2010) han dejado reflejado en su trabajo la importancia del uso adecuado de esta licencia cuando se realizan publicaciones para compartir en la red.

Aunque menos común, también disponemos de otros tipos de licencias que nos ayudan a mantener protegido aquellos trabajos y materiales que queremos publicar libremente. Una de estas licencias es el Copyleft, y se caracteriza por ser la antecesora a la licencia Creative Commons (ambas guardan una estrecha relación) que anteriormente explicamos con detalles (Fuentes, Linares y Pardo, 2013).

Según la fundación de Copyleft ${ }^{2}$ esta licencia es utilizada también, para la protección de los contenidos o de materiales redactados por diferentes investigadores. Estamos ante una licencia que se emplea llevando a cabo una serie de requisitos o de estatutos ${ }^{3}$ que aconsejan y guían al usuario, hacia su correcta utilización. De esta forma, el autor se garantiza de forma gratuita que sus publicaciones no se empleen para usos no deseados por el mismo.

Una tercera licencia que podemos utilizar para proteger nuestras publicaciones en la red, trata del Copyright, la cual se emplea también para la protección de los trabajos que los diferentes usuarios realizan y desean compartir con los demás. No obstante, en este caso se requiere una autorización previa del autor para usar sus obras. Este tipo de licencia ha sido destinada con mayor frecuencia a reservar los derechos de autor de obras literarias y

\footnotetext{
${ }^{1}$ https://creativecommons.org/licenses/?lang=es ES

${ }^{2}$ http://fundacioncopyleft.org/

${ }^{3}$ http://fundacioncopyleft.org/es/4/estatutos
} 


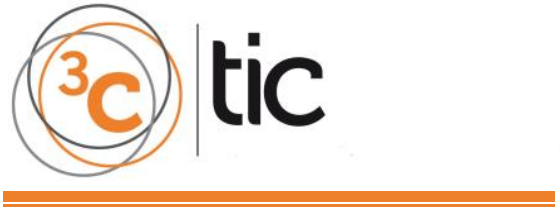

musicales. Normalmente, el autor debe invertir económicamente para compartir sus obras (Vercelli, 2003). Por esto, no se considera que su uso sea gratuito como las otras licencias mencionadas con anterioridad.

Como hemos visto, la protección de los trabajos de todos aquellos autores que quieran compartir sus conocimientos y sus experiencias mediante la red está garantizada usando una de esta licencia que hemos explicado detalladamente.

\section{CONCLUSIONES}

Debemos tener en cuenta de forma resumida los aspectos principales que hemos trabajado hasta el momento. Haremos un breve viaje que recoge las principales características de la Web 2.0, la Educación Abierta, los Recursos Educativos Abiertos (REA) y la evolución del concepto de e-learning, que hemos trabajado con profundidad.

La Web 2.0 evoluciona mediante el uso de las Tecnologías de la Información y de la Comunicación (TIC) haciendo partícipe al usuario en todo momento. De esta forma, hemos visto este concepto y su importancia en la educación superior actual. La Web 2.0 ha mejorado nuestra calidad de vida, en mayor medida, y también hemos visto cómo ha influenciado dicho concepto de manera positiva en otras ramas como en lo laboral. La Web 2.0 es una tendencia que aporta los ingredientes necesarios para mejorar la educación a escala mundial, evolucionando hacia el concepto de la Web 3.0.

Este primer apartado de este capítulo hace referencia a la base de la educación virtual y a la aparición de nuevos conceptos en el ámbito educativo, que transforman casi por completo la manera de construir el conocimiento en la educación superior. Por esto, este concepto se ha tenido en cuenta desde el comienzo de este primer apartado.

Luego, hicimos referencia a la importancia de la educación abierta. Este tipo de educación hace posible la transmisión del conocimiento libre mediante el uso de la red, un fenómeno que permite transmitir conocimientos a los diferentes rincones del Mundo. Una educación basada en la importancia de transmitir el conocimiento como fin principal, y este fin está sostenido por las distintas investigaciones que hemos expuesto en este trabajo. Tal como hemos visto, este concepto es fundamental y marca una revolución en la transmisión del conocimiento de la educación superior actual.

En este primer capítulo, también hemos trabajado la importancia de los Recursos Educativos Abiertos (REA). Otro concepto que nutre a los distintos usuarios de la red a nivel internacional de recursos y materiales para trabajar y construir un aprendizaje de calidad. Esto permite el libre acceso al conocimiento y los autores de los trabajos publicados en red fomentan el mismo y lo transmite a los ciudadanos de cualquier país del mundo.

Siguiendo esta línea, hemos hablado de la evolución del concepto de e-learning. Este concepto en concreto, marca un nuevo estilo de enseñanza en el sistema educativo superior tanto en España como en otros muchos países del mundo. La evolución del concepto elearning no pudiera haberse llevado a cabo de forma satisfactoria, tal como hemos expuesto 
en este trabajo, sin las aportaciones de los otros conceptos que hemos trabajado con anterioridad.

Como hemos visto, el modelo de enseñanza virtual (e-learning) está respaldado por numerosos investigadores en la actualidad y mejora de forma significativa el acceso a la educación superior. De hecho, una de las mejoras más importantes se relaciona con la ventaja de no tener que asistir necesariamente a un lugar físico como a las aulas de la institución en la que se imparte el conocimiento.

La enseñanza e-learning es un fenómeno global y marca una nueva tendencia en el sistema educativo. Hemos estudiado de forma exhaustiva sus ventajas y sus beneficios en el mundo de la educación actual.

En este trabajo hemos tratado diferentes conceptos relacionados con el desarrollo de las tecnologías y la educación. Conceptos necesarios para mejorar no solo la calidad educativa sino también, para mejorar nuestra calidad de vida. 


\section{REFERENCIAS BIBLIOGRÁFICAS}

Adell, J., y Castañeda, L. (2010). "Los Entornos Personales de Aprendizaje (PLEs): una nueva manera de entender el aprendizaje". En Roig Vila, R. y Fiorucci, M. (Eds.) Claves para la investigación en innovación y calidad educativas. La integración de las Tecnologías de la Información y la Comunicación y la Interculturalidad en las aulas. Stumenti di ricerca per l'innovaziones e la qualità in ámbito educativo. La Tecnologie dell'informazione e della Comunicaziones e l'interculturalità nella scuola. Alcoy: Marfil - Roma TRE Universita degli studi.

Adell, J. (2007). Wikis en educación. J. Cabero \& J. Barroso (Eds.), 323-333. Recuperado de: $<$ http://201.151.86.184/cete/snovo/pdf investigaciones/wikis en educacion.pdf/>.

Álvarez, R. B. (2009). El e-learning, una respuesta educativa a las demandas de las sociedades del siglo XXI. Pixel-Bit: Revista de medios y educación, (35), 87-96. Recuperado de: $<$ http://dialnet.unirioja.es/servlet/articulo?codigo $=3040865 />$.

Albert, M.E., y Ros, M.Z. (2008). Estrategias de aprendizaje y eLearning. Un apunte para la fundamentación del diseño educativo en los entornos virtuales de aprendizaje: Consideraciones para la reflexión y el debate. Introducción al estudio de las estrategias y estilos de aprendizaje. RED: Revista de Educación a Distancia, (19), 3. Recuperado de: $<$ https://scholar.google.es/scholar?q=related:cEyAVAFqDWUJ:scholar.google.com/\&hl =es\&as $\mathrm{sdt}=0,5 />$.

Area, M. (2009). Introducción a la tecnología educativa. Manual electrónico. Universidad de La Laguna (España). Recuperado de: <http://bibliotecadigital.org/bitstream/001/415/5/Introducci\%C3\%B3n\%20a\%20la\%20 tecnolog\%C3\%ADa\%20educativa.pdf/>.

Almenara, J. C. (2006). Bases pedagógicas del e-learning. DIM: Didáctica, Innovación y Multimedia (6). <http://www.raco.cat/index.php/DIM/article/view/56479/65901/>.

Bartolomé, A. y Grané, M. (2009). Herramientas digitales en una web ampliada. En J. De Pablos (Coord.), Tecnología educativa. La formación del profesorado en la era de Internet, 351-390. Málaga: Aljibe. Recuperado de: <http://www.Imi.ub.es/eroo/docs/abp mgo 2008.pdf/>.

Boyle, J. (2008). The public domain: Enclosing the commons of the mind. The bull classics. Recuperado de: $<$ https://books.google.es/books?hl=es\&lr=\&id=bv5ABAAAQBAJ\&oi=fnd\&pg=PT4\&dq= Boyle,+J.+(2008).+The+public+domain:+Enclosing+the+commons+of+the+mind.+the+b ull+classics.\&ots=0g8VkmjXZz\&sig=mSXNNKpErrpsKEM4wtAl70Z5VsA\#v=onepage\& $q \&$ $\mathrm{f=false} />$. 
Castañeda, L., \& Gutiérrez, I. (2010). Redes sociales y otros tejidos online para conectar personas. Aprendizaje con Redes Sociales. Tejidos educativos en los nuevos entornos. Sevilla: MAD Eduforma. Recuperado de: <http://mc142.uib.es:8080/rid=1MX54C554WJ3R5J-2WQ/Redes sociales\%20y\%20otros\%20tejidos\%20online.pdf/>.

Cabero-Almenara, J. (2006). Comunidades virtuales para el aprendizaje. Su utilización en la enseñanza. Edutec: Revista electrónica de tecnología educativa, (20),1. Recuperado de: <http://edutec.rediris.es/Revelec2/revelec20/cabero20.pdf/>.

Castañeda, L., \& Adell, J. (2011). El desarrollo profesional de los docentes en entornos personales de aprendizaje (PLE). Recuperado de: $<$ https://digitum.um.es/xmlui/bitstream/10201/24647/1/CastanedaAdell2011preprint .pdf/>.

Cookson, P. S. (2012). Acceso y equidad en la educación a distancia: investigación, desarrollo y criterios de calidad. Revista Electrónica de Investigación Educativa, 4(2). Recuperado de: <http://redie.uabc.mx/index.php/redie/article/view/66/118/>.

D'antoni, S. (2007). Recursos educativos abiertos y contenidos para la educación superior abiertos. RUSC. Universities and Knowledge Society Journal, 4(1). Recuperado de: <http://www.raco.cat/index.php/RUSC/article/viewArticle/58128/0/>.

De la Torre, A. (2006). Web Educativa 2.0. Edutec. Revista electrónica de tecnología educativa, (20). Recuperado de: <http://www.edutec.es/revista/index.php/edutece/article/view/515/>.

Ferran Ferrer, N., y Santos-Hermosa, G. (2012). Recursos educativos abiertos: Acceso a través de repositorios y uso educacional. Profesional de la Informacion. ISSN, 1386-6710. Recuperado de:<http://openaccess.uoc.edu/webapps/o2/bitstream/10609/13601/1/SantosFerran-Abadal.pdf/>.

Fernández, F. R. (2014). La realización de material audiovisual para los cursos masivos en abierto (MOOC): cuestiones legales no resueltas en el ámbito de la propiedad intelectual. IDP. Revista de Internet, Derecho y Política, (19), 78-91. Recuperado de: <http://elcrps.uoc.edu/index.php/idp/article/view/n19-ramon/n19-ramon-es/>.

Freire, J. (2007). Los retos y oportunidades de la web 2.0 para las universidades. La Gran Guía de los Blogs 2008, 82-90. Recuperado de: $<$ http://www.udc.gal/dep/bave/ifreire/pdf blog/Web\%202.0\%20y\%20universidades\% 20(JuanFreire GranGuiaBlogs).pdf/>.

Flores Vivar, J.M. (2009). Nuevos modelos de comunicación, perfiles y tendencias en las redes sociales. Recuperado de: <http://rabida.uhu.es/dspace/handle/10272/2843/>. 
Fuentes, I.L.L., Linares, A.M.S., y Pardo, D.M. (2013). Propiedad intelectual: derechos de autor, copyright y copyleft. Serie Científica, 6(3). Recuperado de: $<$ http://publicaciones.uci.cu/index.php/SC/article/view/1098/662/>.

García, F., Portillo, J., Romo, J., y Benito, M. (2007). Nativos digitales y modelos de aprendizaje. In SPDECE. Recuperado de: <http://ftp.informatik.rwthaachen.de/Publications/CEUR-WS/Vol-318/Garcia.pdf/>.

García, J.C.L., y Uribe, F.G.P. (2009). I Conferencia Internacional de Educación en Tecnología de Información y Comunicación. Recuperado de: $<$ http://www.paginaspersonales.unam.mx/files/154/Proyectos colaborativos en inte rnet.pdf/>.

Gea, M., Montes, R., Rojas, B., Marin, A., Cañas, A., Blanco, I., y Gutierrez, C. (2013). Formación abierta sobre modelos de enseñanza masivos: nuevas tendencias hacia el aprendizaje social. In IV Congreso Internacional sobre Calidad y Accesibilidad de la Formación Virtual, 17-19. Recuperado de: <https://Isi.ugr.es/ rosana/investigacion/files/abiertaUGR CAFVIF2013.pdf/>.

González-Fernández-Villavicencio, N. (2009). Qué puede hacer la biblioteca 2.0 por la inclusión digital. Educación y biblioteca, 21(172), 107-113. Recuperado de: <http://ftp.informatik.rwth-aachen.de/Publications/CEUR-WS/Vol-318/Garcia.pdf/>.

González, Z., \& Hernándezll, G. M. (2013). Recursos educativos abiertos. Recuperado de: <http://www.medigraphic.com/pdfs/educacion/cem-2013/cem133p.pdf/>.

Herreros, M. C. (2008). La Web 2.0 como red social de comunicación e información. Estudios sobre el mensaje periodístico, (14), 345-361. Recuperado de: <http://dialnet.unirioja.es/servlet/articulo?codigo=2898201/>.

Ledo, M. J. V., Alfonso, I. R., Peña, G. Z., \& Hernández, G. M. (2014). Búsqueda Temática Digital: Recursos de Educativos Abiertos (REA).Educación Médica Superior, 27(3).Recuperado de: <http://www.medigraphic.com/pdfs/educacion/cem2013/cem133p.pdf/>.

López, J.C. (2008). Recursos Educativos Abiertos (REA). EDUTEKA. Recuperado de: $<$ http://www.eduteka.org/OER.php/>.

Lizárraga, R.E., Colado, A.Z., Zatarain, R.M., Pérez, L.N., y Sánchez, O.V.G. (2013). Percepción de los estudiantes acerca de la implementación de la modalidad educativa blendedlearning en la Educación Superior. Revista Electrónica de Investigación en Educación Superior, 1(1). 
$<$ http://sistemanodalsinaloa.gob.mx/archivoscomprobatorios/ 10 articulosrevistasarb itraje/168.pdf/>.

Manzuoli, C. H., \& Roig, A. E. (2015). Construcción de conocimiento en educación virtual: Nuevos roles, nuevos cambios. RED-Revista de Educación a Distancia, 15(45).Recuperado de: <http://www.um.es/ead/red/45/hennig.pdf/>.

Moreira, M.A. (2003). ¿Qué aporta Internet al cambio pedagógico en la educación superior?. Universidad de la Laguna. Recuperado de: <http://www.tecnologiaedu.us.es/cursos/29/html/bibliovir/pdf/a12.pdf/>.

Montes, R., Rodriguez-Pina, G., González, M., y Gea, M. (2012). Enseñanza online y Recursos de Aprendizaje Abiertos: Recomendaciones de procedimientos basados en modelos de calidad. En III Congreso Iberoamericano sobre Calidad y Accesibilidad de la Formación Virtual. Recuperado de: <http://edunetworks.ugr.es/oertest/output/CAFVIR 2012.pdf/>.

O'Reilly, T. (2006). Qué es Web 2.0. Patrones del diseño y modelos del negocio para la siguiente generación del software. Boletín de la Sociedad de la Información: Tecnología e Innovación, 177-201. Recuperado de: <http://elchinorarodemadera.com/wpcontent/uploads/2013/03/Web2punto0 by Tim OReilly.pdf/>.

Pagola, L. (2010). Wikipedia en el mundo académico: Generación Google y estrategias docentes para colaborar en la construcción de conocimiento. Publicación de las Jornadas de Informática y educación de la UNVM. Recuperado de: http://mediatecalibre.cl/wp-content/files flutter/1308533730textopagolawikimania100412181648-phpapp01.pdf/>.

Peré, N., Perera, P., y Canuti, M.L. (2011). Cultura de colaboración: ¿Qué implica compartir y utilizar recursos educativos abiertos?. Jornadas de intercambio docentes, 2.

Recuperado de:

$<$ http://www.cse.edu.uy/sites/progresa.cse.edu.uy/files/culturacolaboracion-pereperera-canuti.pdf/>.

Pérez, T.S., de San, M.V.D.H., y Sánchez, J.A.P. (2012). Posibilidades de Wikipedia en la docencia universitaria: elaboración colaborativa de conocimiento. Ibersid: revista de sistemas de información y documentación, 5, 89-97. Recuperado de: $<$ http://www.ibersid.eu/ojs/index.php/ibersid/article/viewArticle/3915/>.

Reig-Hernández, D. (2010). El futuro de la educación superior, algunas claves. REIRE. Revista d'Innovació i Recerca en Educació, 3(2), 98-113. Recuperado de: $<$ http://www.raco.cat/index.php/REIRE/article/viewArticle/196168/0/>. 
Requena, S.R.H. (2008). El modelo constructivista con las nuevas tecnologías, aplicado en el proceso de aprendizaje. RUSC. Universities and Knowledge Society Journal, 5(2), 6. Recuperado de: $<$ http://dialnet.unirioja.es/servlet/articulo?codigo=2799725/>.

Rodés, V., Podetti, M., Custodio, C., Fager, J., Alonzo, L.P., y Pérez, A. (2014). El desafío del acceso a la educación superior: ecosistema de aprendizaje para la educación abierta. Recuperado de: <http://200.0.206.212/handle/10786/722/>.

Rosario, J. (2005). La Tecnología de la Información y la Comunicación (TIC). Su uso como Herramienta para el Fortalecimiento y el Desarrollo de la Educación Virtual. ARCHIVO del Observatorio para la CiberSociedad, 17. Recuperado de: $<$ http://www.cibersociedad.net/archivo/articulo.php?art=218/>.

Rubio, M.J. (2003). Enfoques y modelos de evaluación del e-learning. Recuperado de: $<$ http://www.uv.es/RELIEVE/v9n2/RELIEVEv9n2 1.pdf/>.

Santos-Hermosa, G., Ferran-Ferrer, N., y Abadal, E. (2012). Recursos educativos abiertos: repositorios y uso. El profesional de la información, 21(2), 136-145. Recuperado de: $<$ http://accesoabierto.net/sites/accesoabierto.net/files/Santos-Ferran-AbadalEPI.pdf/>.

Schneckenberg, D. (2004). El "e-learning" transforma la educación superior. Educar, (33), 143-156. Recuperado de: <http://ddd.uab.cat/pub/educar/0211819Xn33/0211819Xn33p143.pdf/>.

Sicilia, M.Á. (2007). Más allá de los contenidos: compartiendo el diseño de los recursos educativos abiertos. RUSC. Universities and Knowledge Society Journal, 4(1). Recuperado de: <http://www.raco.cat/index.php/RUSC/article/view/58132/68224/>.

UNESCO, I.M. (2005). Hacia las sociedades del conocimiento. Publicaciones Unesco. París. Recuperado de: <http://unesdoc.unesco.org/images/0014/001419/141908s.pdf/>.

Vaquerizo-García, M.B. (2012). Enseñanza-aprendizaje con Web 2.0 y 3.0. Revista de Comunicación Vivat Academia. ISSN 1575-2844. Recuperado de: <http://www.vivatacademia.net/h/numeros/n117E/PDFs/MBVaqu.pdf/>.

Vercelli, A. (2003). Creative Commons y la profundidad del Copyright. En. red. ando: reflexió $i$ anàlisi sobre la vida a Internet, (enero). Recuperado de: <http://eprints.rclis.org/9970/1/profcopy.pdf/>.

Zapata, D. (2002). Contextualización de la enseñanza virtual en la educación superior. Bogotá, DC: Instituto Co. Recuperado de: $<$ http://blade1.uniquindio.edu.co/uniquindio/ntic/lineamientos/nuevos\%20libros/arc 88.pdf/>. 


\section{ALGORITMO DE BOOTH EN FORMA DE DÍGITOS SIGNADOS}

\section{BOOTH ALGORITHM IN SIGNED-DIGIT REPRESENTATION}

Jesús Ayuso Pérez ${ }^{1}$

1. Compositor musical y desarrollador software. Licenciado en Ingeniería Informática por la Universidad Carlos III de Madrid (UC3M). E-mail: ayusoperez@terra.com

Ayuso Pérez, J. (2016). Algoritmo de Booth en forma de dígitos signados. 3C TIC: Cuadernos de desarrollo aplicados a las TIC, 5(3), 33-43. DOI: <http://dx.doi.org/10.17993/3ctic.2016.53.33-43/>. 


\section{RESUMEN}

El algoritmo dado por Andrew Donald Booth en 1950 para la multiplicación puede interpretarse de la forma clásica: una manera de reducir las secuencias de 1s consecutivas existentes en la representación binaria de un número, o puede mirarse más desde el prisma en que lo hacen técnicas como la representación NAF, donde se entiende que, en lugar de apostar por una representación binaria del número se tiene una representación ternaria, que cumple la propiedad (o se espera que cumpla) de tener más 0s que la representación binaria clásica. En ambos enfoques el aumento de rendimiento se obtiene debido a que, en el esquema algorítmico de Booth, cuando el número contra el que se opera tiene un 0 en la $i$ esima posición. En ese i-esimo paso algorítmico nos ahorramos los cálculos (o parte de ellos), de ahí que en este documento vayamos a optimizar esos casos donde, según el prisma por el que miremos, compactamos las secuencias consecutivas de $1 \mathrm{~s}$ o la representación ternaria tenga más 0s que la binaria.

\section{ABSTRACT}

The algorithm given by Andrew Donald Booth in 1950 for multiplication, can be interpreted in the classic way: a way to reduce existing sequences consecutive $1 \mathrm{~s}$ in the binary representation of a number. Or you can look more from the prism they do techniques such as NAF representation: where it is understood that instead of opting for a binary representation of the number, it is a ternary representation, which meets the property (or is expected to meet) having more 0 s than classical binary representation. In both approaches, the performance increase is achieved because, in the algorithmic scheme Booth, when the number against which it has a 0 in the ith position operates in the $i$-th algorithmic step, we saved the calculations (or part thereof). Hence in this paper we are going to optimize those cases where, according to the prism through which we look, we compact sequences of consecutive $1 \mathrm{~s}$ or 0 s ternary representation has more than binary.

\section{PALABRAS CLAVE}

Booth, algoritmo, multiplicación, inverso, dígitos signados.

\section{KEYWORDS}

Booth, algorithm, multiplication, inverse, signed-digit. 


\section{INTRODUCCIÓN}

Como adelantábamos, el concepto de Booth basa su potencia en la posibilidad de reducir las operaciones que componen cierto cálculo eliminando secuencias de 1s consecutivos en la representación binaria, o usando una representación ternaria de un mayor ratio de 0s, apoyándose en la operación inversa, a la que compone el cálculo, para absorber el efecto algebraico de operar por la secuencia completa de 1s. Lo que Booth no notó en su algoritmo fue lo que ocurría ante una secuencia de 1s que consta de un único 1. Claro, si es un solo 1 , no es una secuencia de 1s (tal vez sí, depende de cómo se defina), y en ese caso, no tratado por Booth, su algoritmo decrementa el rendimiento.

Por otra parte, si lo enfocamos más desde el prisma de la representación ternaria, más concretamente la representación NAF, eliminamos ese efecto negativo o ese caso no tratado por Booth. No obstante, tampoco es una solución que pueda terminar de satisfacernos siempre, o de encajarnos en cualquier situación, ya que la gran virtud de la representación $\mathrm{NAF}$, que es que garantiza el óptimo, es decir: no existe una representación del número que tenga mayor número de $0 \mathrm{~s}$, es también su punto débil, ya que para garantizar esa optimalidad se puede volver un cálculo bastante pesado, de cara a agilizar o a ser aplicado el concepto de Booth a operaciones ligeras. En cambio, de la manera elegante e implementativa con la que Booth dio a conocer su concepto, su algoritmo puede ser incrustado sin ese coste de tener que calcular otra representación de los números.

\section{METODOLOGÍA}

Bien, vamos a tratar de ilustrar exactamente la problemática del concepto de Booth. Para que se vea mejor, vamos a intentar mostrarlo con una operación sencilla: de la adición, en nuestro caso algebraico, suma entre enteros.

Antes de nada, repasemos la tabla 1, dada por Booth para reducir el número de operaciones necesarias, apoyándonos en esa invertibilidad de la primitiva con la que se construye nuestra operación:

Tabla 1. Tabla de acciones de Booth.

\begin{tabular}{|c|c|c|c|}
\hline bit menos significativo & bit extra & Interpretación & Acción \\
\hline $\mathbf{0}$ & $\mathbf{0}$ & intermedio cadena de 0s & ninguna \\
\hline $\mathbf{0}$ & $\mathbf{1}$ & final cadena de $1 \mathrm{~s}$ & operación \\
\hline $\mathbf{1}$ & $\mathbf{0}$ & comienzo cadena de 1s & $\begin{array}{c}\text { operación inversa / } \\
\text { inverso misma operación }\end{array}$ \\
\hline $\mathbf{1}$ & $\mathbf{1}$ & intermedio cadena de 1s & ninguna \\
\hline
\end{tabular}

Partiendo de la tabla anterior, el algoritmo de Booth, como figura en la referencia bibliográfica 'Booth algorithm operations addition and subtraction', aplicado a la suma de dos números, $a$ y $b$, de longitud $n$ quedaría: 
result $=\mathrm{a}$

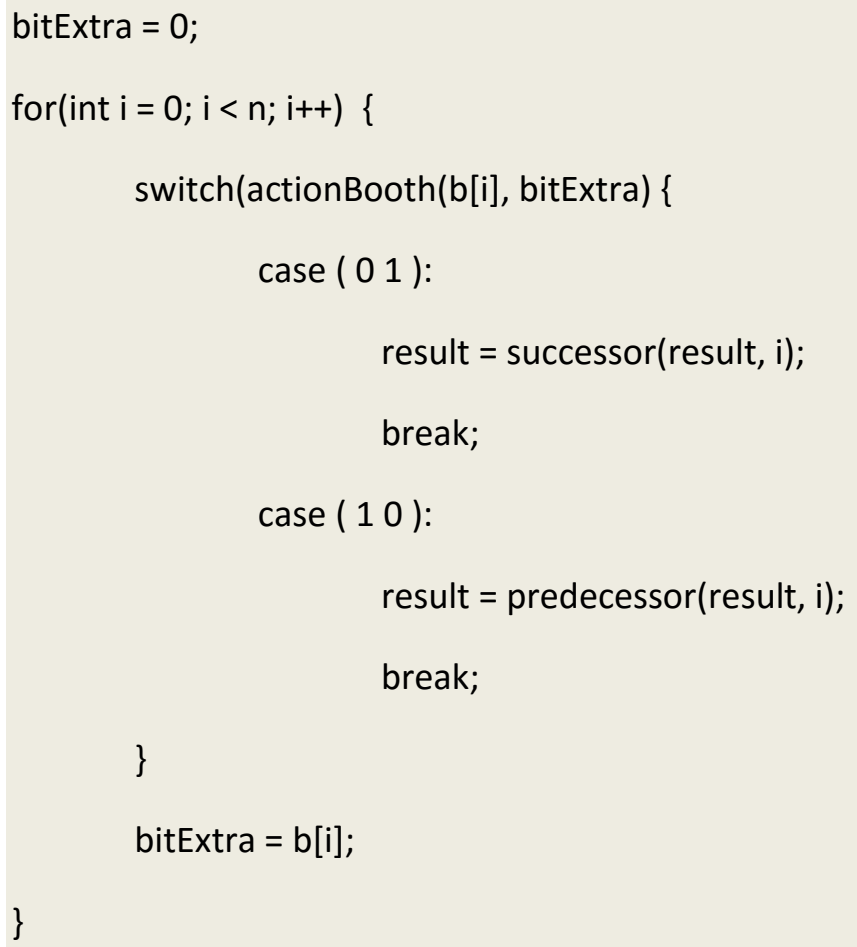

Figura 1. Algoritmo de suma 2.

Fuente: elaboración propia.

Pues bien, imaginemos que en el algoritmo anterior nos encontramos con un valor de $b$ que respeta la siguiente distribución:

\section{$01010101 \ldots 01010101$}

Si nos fijamos, el algoritmo de Booth, tal y como él lo definió, al operar contra un número cuya distribución de 1s fuera esa relación intercalada de 1s y 0s, lo que haría sería: comienza el algoritmo, el bit extra de Booth, contiene un 0 y el primer bit del número es 1, luego actúa en función de lo que dice la tabla de Booth para: ' $1 \mathbf{0}$ ', es decir, comienzo de secuencia de 1s; luego opera por la operación inversa. Acto seguido, en la siguiente iteración, el bit extra de Booth vale 1 , y el siguiente bit del operando es 0 , luego se actúa para ' $0 \mathbf{~}^{\prime}$ ', con lo que se opera de manera natural. Y así constantemente.

Volvamos ahora al algoritmo inicial de suma, descrito en 'Booth algorithm operations addition and subtraction', basado en la primitiva de sucesor. Tenía este esquema:

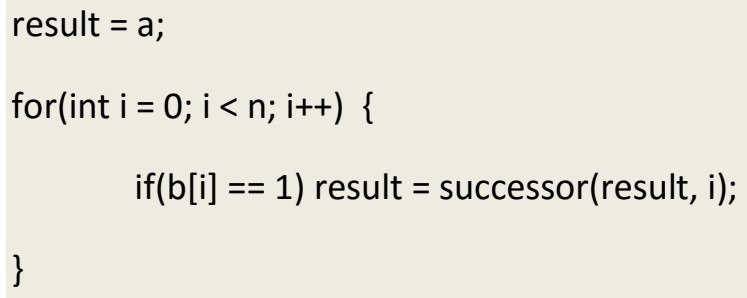

Figura 2. Algoritmo de suma 1.

Fuente: elaboración propia. 
Si nos fijamos, el anterior algoritmo únicamente opera en caso de que el i-esimo bit del operando sea 1. Luego nos encontramos con que el algoritmo definido por Booth, para este caso, acaba realizando justo el doble de operaciones que el esquema clásico. Si lo miramos desde el prisma de que, el concepto de Booth se basa en el uso de una representación ternaria (como se hace en la representación NAF). Podríamos explicarlo de manera que el algoritmo de Booth acaba representando el número binario con esa relación intercalada de 1 s y 0 s de la siguiente manera:

$$
1-11-11-11-1 \ldots \quad 1-11-11-11-1
$$

Donde vemos claramente que, para ese caso, el concepto de Booth no trabaja con un número que tiene más 0s en su representación, sino justo lo contrario, acaba eliminando todos los Os que había en la representación del operando.

Pensemos ahora que, en muchos casos, para muchos valores de ese supuesto $b$, podemos encontrarnos con un 1 suelto en alguno de los $n$ bits que lo representan. Dándose ese problema, no constantemente, como ocurre en el peor caso expuesto, pero sí en muchas ocasiones. Pues bien, para evitar esa casuística, la de estar ante un único 1, se puede modificar el algoritmo de Booth, de manera que sea capaz de detectar esas situaciones y, ante ellas, se realice una sola operación (1 suma para el caso que nos ocupa), como haría el algoritmo clásico. Para ello simplemente lo que se hace es:

1. Llevar 2 bits extras, en lugar de uno.

2. Contemplar 2 bits del operando, en lugar de uno. Serán el $i$-esimo y, dependiendo de si estamos en un recorrido right-to-left o left-to-right, el i-esimo + 1 o el i-esimo - 1 , respectivamente.

Sabiendo lo anterior, se puede fácilmente modificar la tabla 1 dada por Booth, para absorber esos casos, y realizar como decimos sólo una operación. La tabla, para un recorrido de derecha a izquierda, $y$ entiendo que lo que denotamos como $x$ toma un valor perteneciente al conjunto $\{0,1\}$, sería:

Tabla 2. Tabla ampliada de acciones de Booth.

\begin{tabular}{|c|c|c|c|}
\hline 2 bits menos significativos & bits extras & Interpretación & Acción \\
\hline$\times 0$ & $0 x$ & intermedio cadena de 0s & ninguna \\
\hline$\times 0$ & 10 & cadena de un 1 dejada atrás & ninguna \\
\hline 00 & 11 & final cadena de 1s & operación \\
\hline 11 & $0 x$ & cadena de un 1 & operación \\
\hline & $0 x$ & comienzo cadena de 1s & operación inversa \\
\hline & & & $\begin{array}{c}\text { inverso misma } \\
\text { operación }\end{array}$ \\
\hline & $1 \times$ & intermedio cadena de 1s & ninguna \\
\hline
\end{tabular}

Fuente: elaboración propia. 
Con lo anterior, describimos un nuevo algoritmo de suma de dos números, $a$ y $b$, de longitud n, como:

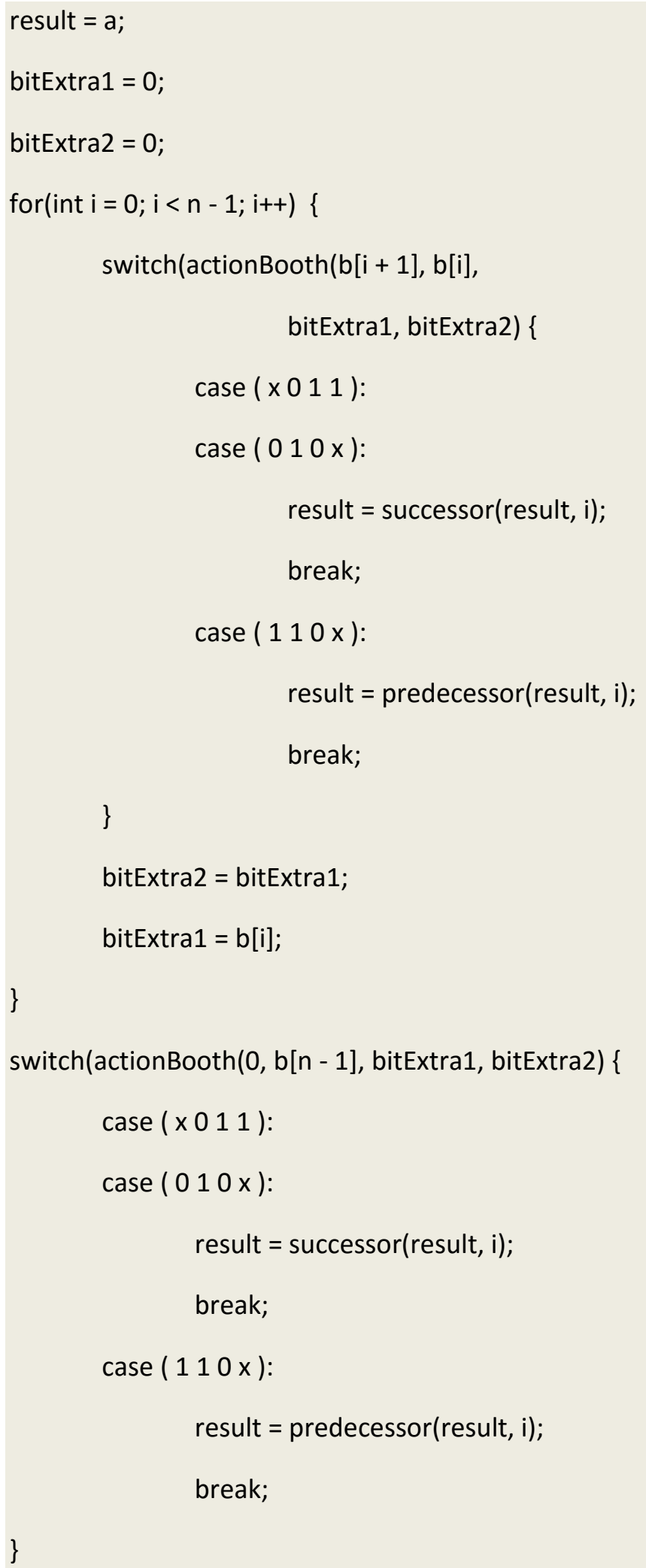

Figura 3. Algoritmo de suma 3.

Fuente: elaboración propia. 
Véase que, para no acabar indexando la estructura que contiene los bits de los que consta nuestro operando $b$, realizamos nuestro bucle hasta $n-1$, en lugar de hasta $n$, como estábamos haciendo hasta ahora. Por ello, al salir del bucle, tenemos un último switch donde tratamos la última iteración en la cual sabemos que no existe bit $(n+1)$-esimo.

Pero lo destacable del algoritmo anterior es la forma en la que, con una simple modificación del algoritmo dado por Booth, conseguimos evitar ese peor caso donde no mejoramos el rendimiento de las técnicas clásicas, sin tener que recurrir a representaciones ternarias precalculadas, como sería en caso de utilizar la representación NAF.

Entremos ya en el caso de mirar el concepto de Booth como una representación ternaria de los números, en lugar de representarlos en binario, como se ha hecho siempre en el mundo de la Computabilidad. En concreto, con la alternativa óptima, la representación NAF. Primero daremos una posible implementación para calcular esa representación ternaria de un operando.

La representación Non-Adjacent Form, NAF, como decimos, lo que hace es llevarse un entero de la forma binaria habitual a un sistema ternario de dígitos signados donde se cumple la propiedad, y es la propiedad culpable de su interés, pues es la responsable del incremento del rendimiento, de que: la representación NAF de un entero $b$ tiene menos dígitos diferentes de cero que su representación binaria.

Una implementación del algoritmo de transformación NAF para obtener la representación ternaria de $b$ con una longitud de $n$ bits podría ser:

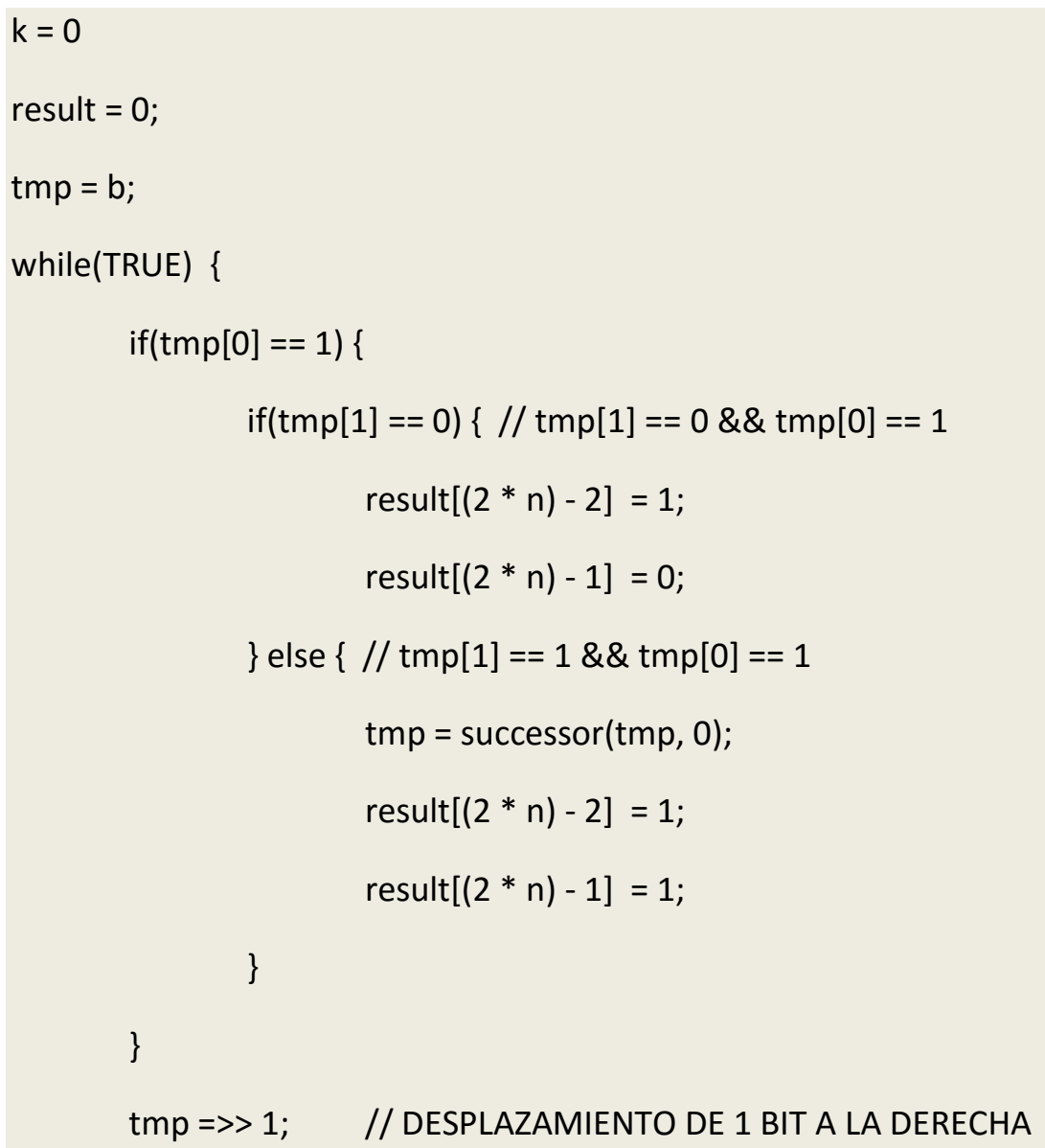




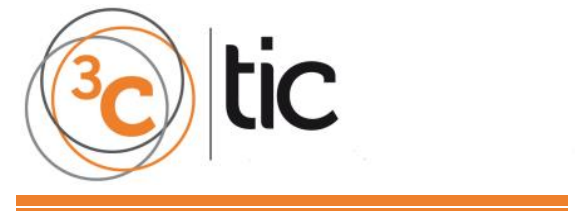

if(tmp == 0) break;

DOI: http://dx.doi.org/10.17993/3ctic.2016.53.33-43

$k++$;

result => 2; // DESPLAZAMIENTO DE 2 BITS A LA DERECHA

\}

return $\mathrm{k}$;

Figura 4. Algoritmo de cálculo de representación NAF.

Fuente: elaboración propia.

En el algoritmo expuesto en la figura 4, entenderemos que la variable result tiene un tamaño de $2 * n$, ya que para almacenar 1 dígito ternario requeriremos de 2 bits. Además, como vemos, devuelve dicha representación ternaria en la variable result y también retorna el valor de un entero $k$. Ese entero $k$ determinará el número de dígitos ternarios de los que constará nuestra nueva representación del operando. Destacamos que etiquetamos el algoritmo con el nombre calcNAF.

Otro detalle a resaltar es que, el anterior algoritmo de cálculo de la representación NAF está asociado al recorrido left-to-right. En nuestro caso, como vamos a utilizar un recorrido rightto-left, vamos a requerir de un posterior ajuste. Algo así:

$k=$ calcNAF(b, b_naf);

for(int $i=k+1 ; i<n ; i++)$

\section{b_naf =>> 2; // DESPLAZAMIENTO DE 2 BITS A LA DERECHA}

Figura 5. Algoritmo de ajuste NAF para recorrido right-to-left.

Fuente: elaboración propia.

Como aventurábamos, intentar calcular la representación ternaria en operaciones muy ligeras, por ejemplo, de alguno de los 2 operandos de los que consta una operación de suma de 2 enteros, no tiene demasiado sentido, ya que el coste de obtener dicha representación puede ser ya igual o más pesado que la propia operación de adición. Sin embargo, imaginémonos que la operación de suma se produce dentro de un contexto modular, y además, que tendremos que realizar cientos o miles de sumas y restas bajo un módulo (como es el caso de, por ejemplo, operaciones como la exponenciación modular). Entonces, representar dicho módulo $m$ en por ejemplo NAF, sí podría tener mucho sentido. Por ello, expondremos una solución que detalla cómo conjugar esa técnica con el algoritmo de reducción basado en Booth. Tendríamos que la suma de dos números, $a$ y $b$, de longitud $n$, módulo $m$, quedaría:

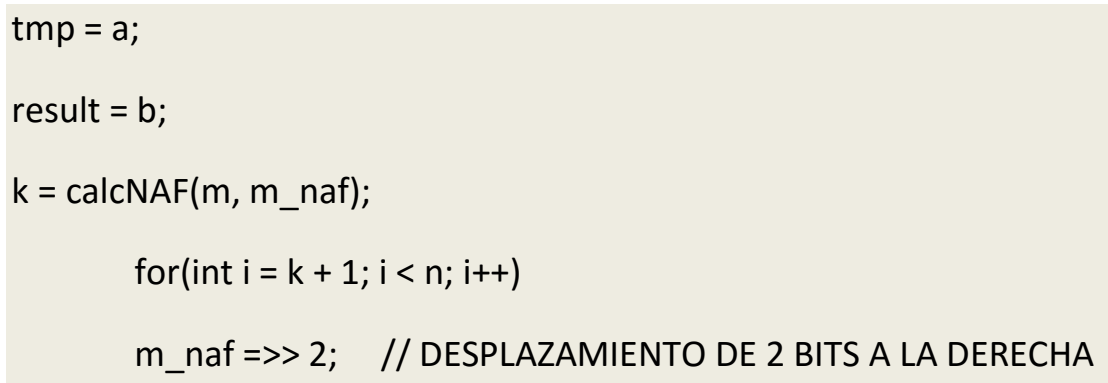


int $\mathrm{i}=0$;

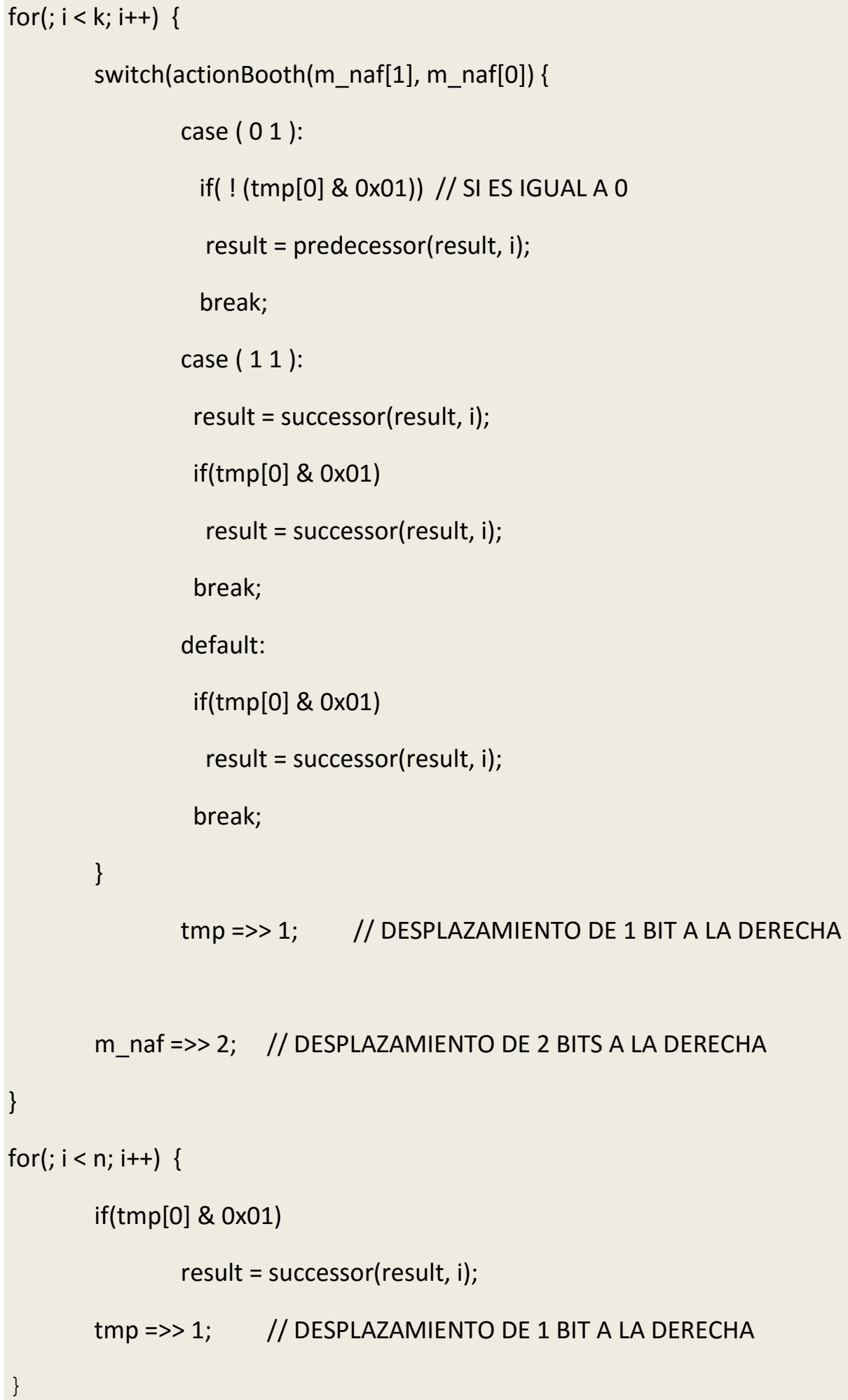

Figura 6. Algoritmo de suma modular 3.

Fuente: elaboración propia.

Entendemos que la función calcNAF deja la representación ternaria del módulo $m$ en la variable llamada $m \_n a f$, además de devolver el número de dígitos ternarios de los que consta dicha variable. Como hemos adelantado, en nuestra implementación física, dicha variable se 


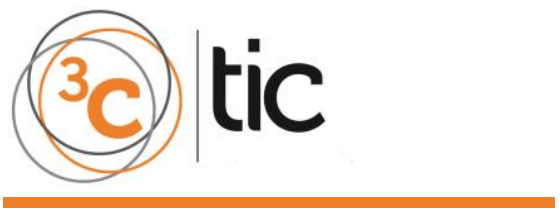

acabará traduciendo por una variable con el doble de bits de nuestro operando, es decir, para nuestro caso $2 * n$. Pues bien, requerimos 2 bits por cada dígito binario del módulo que es representado en un dígito signado. De ahí que, como podemos observar en el código existente sobre este párrafo, al término de cada iteración desplazamos 2 bits el valor de $m_{-}$naf, para encuadrar los 2 siguientes bits que contienen el valor del próximo dígito ternario, y en cambio, en el caso de la variable tmp únicamente nos movemos 1 solo bit, ya que ésta sí contiene una representación binaria.

Obviamente, se podría aplicar simultáneamente la mejora que soluciona el peor caso del algoritmo de Booth, con la anterior técnica de reducción de módulo basada en la representación NAF. En la descripción anterior sólo hemos contemplado el proceso de cancelación entre los incrementos de la adición y los decrementos de la reducción debido al módulo.

\section{RESULTADOS Y DISCUSIÓN}

El aplicar el concepto de Booth en cualquier operación que se construya sobre una sucesión de cómputos de otra operación invertible que compone a la primera, no siempre nos garantiza una mejora en el rendimiento, o un número menor de operaciones para converger al resultado final. Dependiendo de la distribución de los bits de los que constan nuestros operandos, podemos no siempre estar realizando el menor número de cálculos necesarios. Para evitar esto tendremos que afrontar la optimización en base a varios criterios: la sobrecarga de utilizar representaciones de números que garanticen una mayor distribución de 0 s, como es el caso de NAF, y el evitar el fallo del algoritmo dado por Booth al afrontar un 1 individual entre los bits de los números.

En conclusión, la idea propuesta por Booth basa su rendimiento en un factor estadístico de la distribución de los 1s en la representación binaria de un número. Existen representaciones ternarias, que garantizan un mayor ratio de 0 s, que la representación binaria, pero igualmente el rendimiento estará supeditado a esa probabilidad de que el operando se pueda expresar con un menor número de cruces entre la operación algebraica y su inversa, refiriéndonos, claro está, a la que compone a aquella que estamos calculando. 


\section{REFERENCIAS BIBLIOGRÁFICAS}

Ayuso, J. (2015). Booth algorithm operations addition and subtraction, 3C TIC, 4(2), 113-119.

Ayuso, J. (2015). Booth algorithm modular arithmetic operations of addition and subtraction, 3C TIC, 4(3), 222-229.

Booth, A.D. (1945). A method of calculating reciprocal spacings for X-ray reflections from a monoclinic crystal. J. Sci. Instr, Vol. 22, p. 74.

Booth, A.D. y Britten, K.H.V. (1947). General Considerations in the Design of an Electronic Computer. Princeton.

Booth, A.D. (1951). A signed binary multiplication technique. Q.J. Mech. and Appl. Math, 4(2), 236-240

Burks, A., Goldstein, H. and Von Neumann, J. (946). Logical Design of an Electronic Computing Instrument. Princeton.

W. Reitwiesner, G. (1960). Binary Arithmetic, 231-308. 


\title{
MODELO DE RED DE COMUNICACIÓN A TRAVÉS DE LA APLICACIÓN DE NUEVAS TECNOLOGÍAS PARA EL FORTALECIMIENTO DE ACCESO INTERNET
}

\section{MODEL OF COMMUNICATION SYSTEM THROUGH NEW TECHNOLOGIES APPLICATION FOR STRENGTHENING OF INTERNET ACCESS}

\author{
Christian Ruperto Caicedo Plùa ${ }^{1}$ \\ Roberto Wellington Acuña Caicedo ${ }^{2}$ \\ Antonieta Del Carmen Rodríguez González ${ }^{3}$ \\ Kleber Plutarco Castro Valeriano ${ }^{4}$
}

1. Ingeniero en Computación y Redes, Magister en Gerencia Educativa e Investigación, Docente Titular de la Universidad Estatal del Sur de Manabí. E-mail: christiancaicedoplua@hotmail.com

2. Ingeniero en Sistemas, Magister en Docencia Universitaria e Investigación Educativa, Magister en Sistemas de Información Gerencial. E-mail: roberec2000@hotmail.com

3. Licenciada en Ciencias de la Educación mención Inglés, Tecnólogo en Computación Administrativa, Magister en Enseñanza del Idioma Inglés. E-mail: antojipi2006@hotmail.com

4. Ingeniero en Computación y Redes. Universidad Estatal del Sur de Manabí, Empresa Netlife.S.A. Jipijapa. E-mail: kpcv@hotmail.com

Caicedo Plúa, C.R., Acuña Caicedo, R.W., Rodríguez González, A.C. y Castro Valeriano, K.P. (2016). Modelo de red de comunicación a través de la aplicación de nuevas tecnologías para el fortalecimiento de acceso a Internet. 3C TIC: Cuadernos de desarrollo aplicados a las TIC, 5(3), 44-64. DOI: <http://dx.doi.org/10.17993/3ctic.2016.53.44-64/>. 


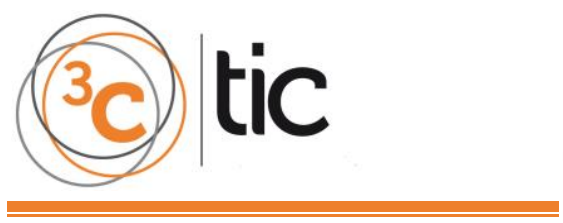

\section{RESUMEN}

Actualmente, las telecomunicaciones son de gran importancia para el desarrollo de las personas y las empresas. El objetivo del presente trabajo es el desarrollo de la propuesta de un método para mejorar la calidad del Internet y ampliar su cobertura, en la que se realizó el análisis de la estructura actual de la red de fibra óptica y la identificación de la misma. El proyecto, cuyo campo investigativo fue la empresa Netlife del cantón Jipijapa, Ecuador, versó sobre el diseño técnico de una red de fibra óptica FTTH con tecnología Gpon aplicando técnicas de microsanjado, ya que el sistema actual no satisface todas las necesidades de los clientes. Como antecedente, se tiene que en la última milla se utilizan cables de cobre o coaxial hasta ingresar al domicilio del abonado causando esto un cuello de botella en este tipo de redes. Para el desarrollo de la propuesta se obtuvieron referencias de diferentes estudiosos del tema. De la misma manera, fue de vital importancia la realización de encuestas y entrevistas a algunos componentes del campo de análisis. Se concluyó con la solución a través del desarrollo de un diseño técnico de esta red y su simulación mediante el software openSimMPLS-bin-v1.1, Permitiendo cumplir las normas técnicas establecidas para el diseño.

\section{ABSTRACT}

Nowadays, the telecommunication systems are very important for the development of an enterprise. The main objective of this research was accomplished succesfully. So, it was designed a proposal based of a method to improve the quality and expand internet coverage. In this context, the analysis of the current structure of the optic fiber network was performed. The place of the present Project was Netlife Company from Jipijapa CantonEcuador. It was performed a technical design of an optic fiber. This means FTTH network with GPON technology using techniques micropit as the current system does not reach all the needs of customers. In the last mile were used copper or coaxial cables to enter the subscriber's home causing this a bottleneck in such networks. For the development of the proposal references of different researchers were obtained. Likewise, it was paramount to perform surveys and interviews with some components of the research field. As a conclusion, the solution of this research problem was the development of a technical design of the network through OpenSimMPLS-bin-v1.1 software. So, the objectives of the investigation was accomplished succesfully by means of the technical requirements for design.

\section{PALABRAS CLAVE}

Fibra Óptica, telecomunicaciones, microsanjado, redes.

\section{KEY WORDS}

Fiber optics, telecommunications, microtrenching, network. 


\section{INTRODUCCIÓN}

En la actualidad, las empresas que proveen servicios de Internet en el Sur de Manabí no cuentan con una red de fibra óptica FTTH (Fiber To The Home- fibra hasta el hogar) con tecnología Gpon (Gigabit-capable Passive Optical Network- Red Óptica Pasiva con Capacidad de Gigabit) que soporte las exigencias y consumo de ancho de banda de acuerdo a los servicios brindados a los usuarios, y que se adapte a las normas y políticas urbanísticas que proponen los Gobiernos Autónomos Descentralizados en el Ecuador con estructuras de redes subterráneas, todo ello enmarcado en el PNBV y la concepción de tener ciudades completamente digitales (Smart City) (Caicedo, 2015).

Investigaciones realizadas indican que las redes pasivas FTTH como el termino lo deriva (fibra óptica hasta el hogar) es una de las mejores soluciones para fortalecer los servicios mejorando el ancho de banda. Esto es debido a que su estructura está conformada por equipos ópticos que permiten transportar grandes cantidades de información a través de pulsos de luz a distancias sumamente extensas y sin peligro de perdida de datos o caída de sistemas en líneas (Castillo Jaramillo \& Figueroa Torres, Determinación de la demanda, dimensionamiento y diseño de una red de servicios de telecomunicaciones, mediante la tecnología de acceso FTTH en el cantón Gualaceo para la empresa CNT EP (Doctoral dissertation)., 2013). Saltos Montaño (2011) expresa que, de igual manera a arquitectura de las redes FTTH, tiene un sinnúmero de ventajas con la tecnología actual y futura, ya que su gran capacidad de trasmisión de datos e inmunidad ante las interferencias electromagnéticas y baja atenuación en grandes distancias, es uno de los conductores de información más eficientes y seguros en el medio también por el peso y tamaño de los equipos ópticos ya que tienen un fácil manejo, manipulación e instalación (Calle Méndez y Machado Tapia, 2015).

La tecnólogas PON (Passive Optical Network), por consiguiente, son las redes ópticas pasivas que no necesitan de equipos electrónicos para su funcionamiento, además, esta estructura de red elimina el uso de repetidores y fuentes de poder intermedias dentro de la red que son las encargadas de amplificar las señales para lleguen al destino deseado. Esta arquitectura solo necesita de splitters y de acopladores que fusionen las señales luz que se transporta en las líneas de fibra óptica (Gaona Román y Santillán Sarmiento, 2013). De igual manera, la arquitectura GPON es una de las tecnologías más actuales que se pueda implementar en las redes de telecomunicaciones, pues su equipamiento de componentes ópticos pasivos en su infraestructura, tiene la capacidad de soportar velocidades superiores a $1 \mathrm{Gbit} / \mathrm{s}$ y además, es capaz de transportar frecuencias de Ethernet, ATM y TDM. Es decir con esta arquitectura se puede proveer servicios de triple play (Chacón Jimbo \& Villavicencio Fernández, 2014).

El medio físico par de cobre es el más utilizados en muchos países de Latinoamérica, y por el proceso de evolución tecnológica cada vez se necesitan más decenas de Mbps para satisfacer las necesidades de los usuarios, donde los estándares de transmisión asimétricas de datos como lo es el ADSL solo soportan velocidades de $1.5 \mathrm{Mbps} / 512 \mathrm{Kbps}$ en distancias de $3 \mathrm{a} 5 \mathrm{~km}$ como máximo, y esto dependiendo de los equipos de la planta central y también de los pares 
conectados en las troncales (Añazco Aguilar, 2013). Intriago Núñez, Castillo Chang, y Fiallos, (2013) explican que, por lo que la familia de redes de acceso FTTX y en especial, la FTTH son consideradas como redes de banda ancha, ya que por su arquitectura de la fibra óptica desde la central hasta el domicilio del cliente permite transportar grandes cantidades de información a velocidades binarias muy elevadas. Además, esta familia FTTX permite la utilización y configuración de topologías de red en árbol, estrella en bus y anillo que brindan seguridad absoluta en las redes (Rodríguez Zambrano, 2012). De tal forma que las redes de acceso GPON, debido a la necesidad del aumento del ancho de banda y el trafico IP, presenta un estándar como lo es ITU-T G.984, el cual es muy potente y eficiente ya que soporta multiservicios de datos, voz, video y la tasa de transferencia simétrica es de $622 \mathrm{Mbps}$ a $1.25 \mathrm{Gbps}$ y la tasa asimétrica es de $2.5 \mathrm{Gbps}$ en dwonlink y $1.25 \mathrm{Gbps}$ en uplink (Ojeda Sotomayor, 2011).

Las redes FTTH con tecnologías GPON están diseñadas para adaptarse a las tecnologías futuras y de esta manera proporcionar un ancho de banda casi ilimitado, que permita relacionar el internet con las cosas de nuestros hogares y llegar a la altura de las conocidas ciudades inteligentes, donde las personas vivan en un mundo digital sin limitaciones tecnológicas (Vargas Guzhñay, 2014).

En lo que respecta al tendido de redes de fibra óptica con métodos subterráneos aplicando técnica de microsanjado, son muy utilizados en sectores urbanos e inter - urbanos donde las calzadas asfálticas están en perfecto estado para su instalación. Este método reduce costos de infraestructuras subterráneas, eliminando los ductos o canalizaciones tradicionales que requiere de más tiempo y financiamiento a la empresa (Miranda Pozo, 2010). Las técnicas de microsanjado consisten en diseñar un micro - ducto de diámetros muy pequeños entre 15 a $20 \mathrm{~mm}$ de ancho y con una profundidad de 10 a $25 \mathrm{~cm}$ donde se va a ubicar la fibra óptica recubierta de aislantes para su protección. Este sistemas es uno de los más económico y seguros en lo que corresponde los tendidos subterráneos (Castillo Chang \& Intriago Nuñez, 2012).Este trabajo se propone la elaboración del diseño técnico de una red de fibra óptica FTTH con tecnología Gpon aplicando técnicas de microsanjado para la empresa Netlife, localizada en la zona urbana del Cantón Jipijapa.

\section{METODOLOGÍA}

La elaboración de un modelo de diseño técnico de una red de fibra óptica FTTH con tecnología Gpon aplicando técnicas de microsanjado para la empresa Netlife, localizada en la zona urbana del cantón Jipijapa es un método innovador de acuerdo a la realidad del entorno que permite identificar nuevas formas de uso de la tecnología. 


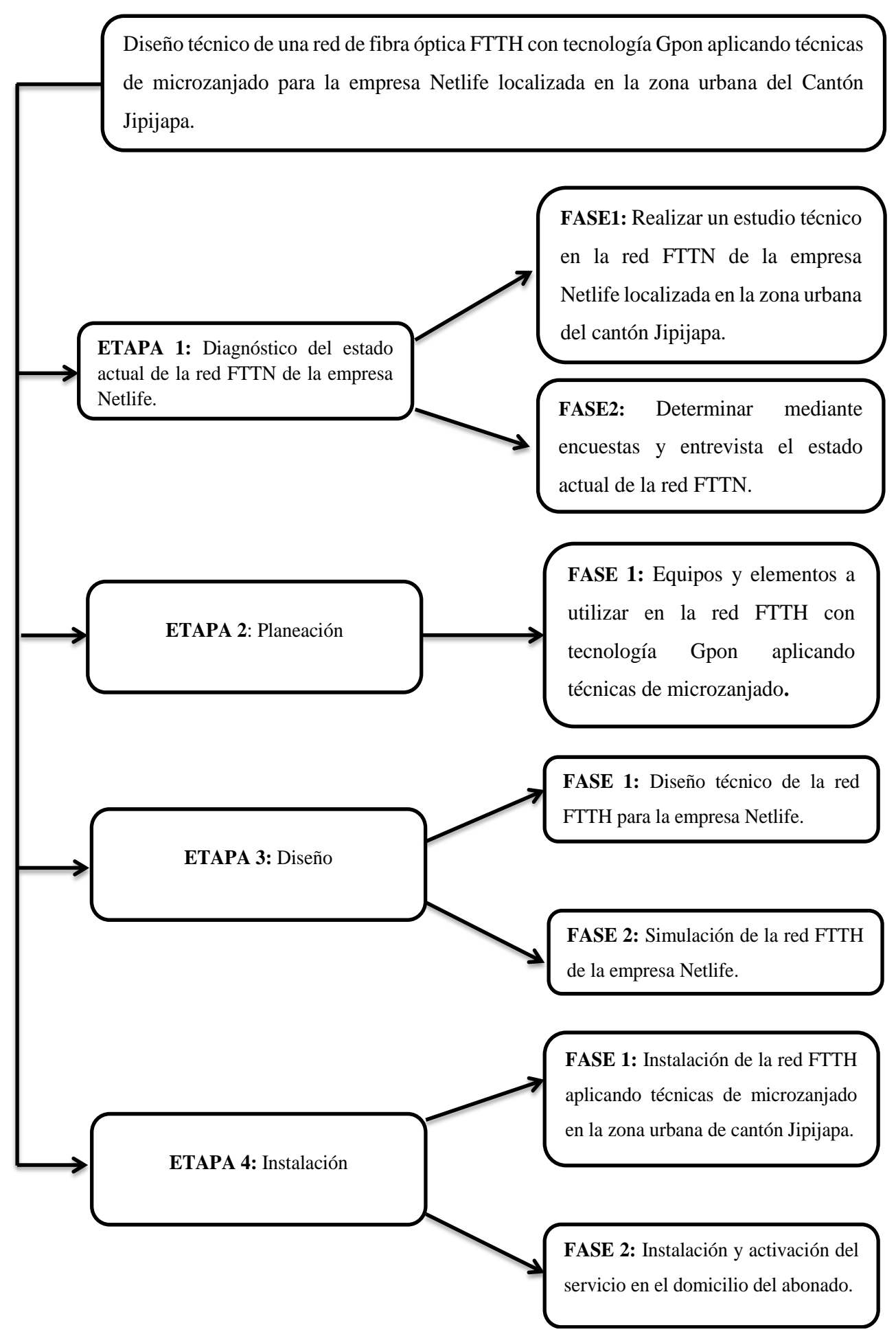

Figura 1. Esquema gráfico del diseño.

A pesar que la empresa Netlife ofrece un Internet de muy buena calidad con un soporte técnico que cubre en su totalidad los fallos que se presentan diariamente, se opta la necesidad de buscar nuevas estrategias para el mejoramiento la calidad del servicio debido al 
aumento de ancho de banda que solicitan los clientes por el uso del Internet. Así, se incentiva a la empresa a implementar una nueva red de fibra óptica de alta velocidad. El servicio de Internet que ofrece Netlife lo provee a través de una red FTTN donde la fibra óptica llega hasta un nodo de dispersión donde un equipo activo denominado DSLAM convierte las señales luz a digitales, en cual en la última milla se transporta con un cable multipar de cobre hasta el domicilio del cliente con un máximo de ancho de banda $30 \mathrm{Mb}$ asimétricos. Por esta razón, se cumple ciertos parámetros para la elaboración de un diseño técnico de una red FTTH con tecnología Gpon aplicando técnicas de microsanjado para mejorar la calidad del servicio que provee empresa Netlife.

\section{ESTUDIO TÉCNICO DE LA RED FTTN DE LA EMPRESA NETLIFE LOCALIZADA EN LA ZONA URBANA DEL CANTÓN JIPIJAPA}

Argüello Moscoso y Burneo Echeverría, (2013) indican que la tecnología PON es la que actualmente utiliza la red de la empresa Netlife, que provee el servicio de Internet en la zona urbana del cantón Jipijapa con la arquitectura FTTN. En esta zona, la fibra óptica parte de un nodo central y llega al nodo o armario dispersión donde se convierten las señales en luz a señales digitales a través de un conversor pasivo que se conecta al DSLAM, el cual reparte la señal digital atreves de cables de cobres que llegan al domicilio de los clientes donde un receptor o modem router recibe la señal del Internet. Hinojosa Erazo, (2014) explica que el sistema de tendido que utiliza la red FTTN es el holgado por su infraestructura, ya que tiene varios años en el mercado, se encuentra en un estado deteriorado, en la que los fallos que presenta frecuentemente se ocasionan por el mal estado de la misma y por la saturación de redes que utilizan el mismo sistema con los postes de alumbrado público. Vega, (2010) explica que, la tecnología ADSL está diseñada para que la capacidad de bajada o descarga sea mayor que la de subida, donde el ancho de banda como máximo $30 \mathrm{Mb}$ asimétricos.

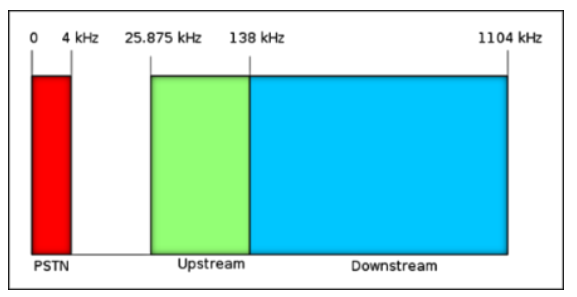

Figura 1. Frecuencias usadas en ADSL. Fuente: elaboración propia.

En la ilustración 2, el área roja es aquella usada para la voz en la Red Telefónica Conmutada (PSTN), el verde es para subida de datos (upstream), y el azul es para descarga de datos (downstream). Entre los equipos existentes en la empresa tenemos: nodo central, nodo o armario de dispersión de la red FTTN, conversor pasivo óptico, equipo activo DSLAM, regletas multipar de las cajas de repartidoras o mangas de cobre, cajas repartidoras de diez pares y modem router ADSL. 


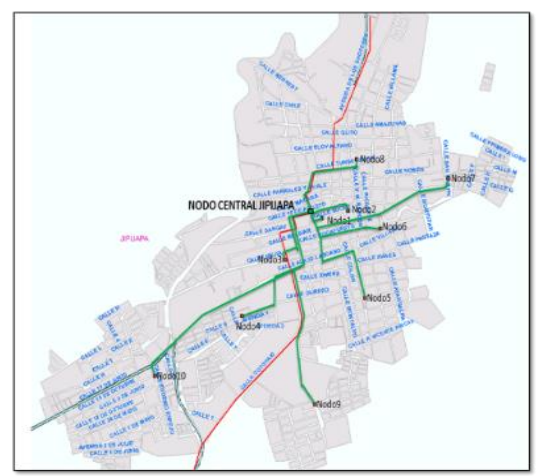

Figura 2. Red FTTN de la zona urbana.

Fuente: elaboración propia.

La red FTTN está compuesta por un nodo central y diez armarios o nodos localizando en zona urbana del cantón Jipijapa. Ésta consta de 785 clientes activos en la actualidad y tiene capacidad de soportar a 816 clientes según la estructura y equipos instalados.

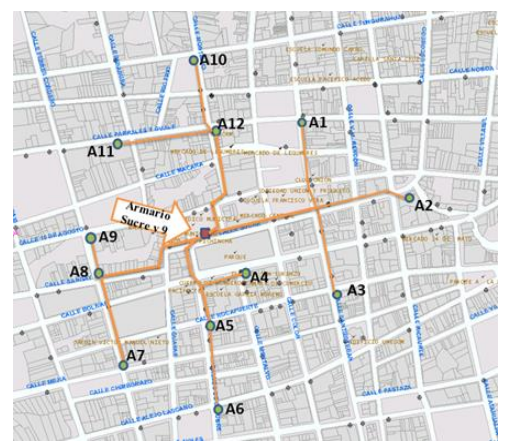

Figura 3. Nodo 1, Red Sucre y 9 De Octubre.

Fuente: elaboración propia.

La red del nodo 1 está compuesta por dos DSLAM de 48 puertos que son los que provee la señal del internet. Se reparte en 12 cajas de dispersión o magas de diez pares que utilizan como medio de transmisión cables multipar de cobre y tiene un total de 86 clientes activos en la actualidad.

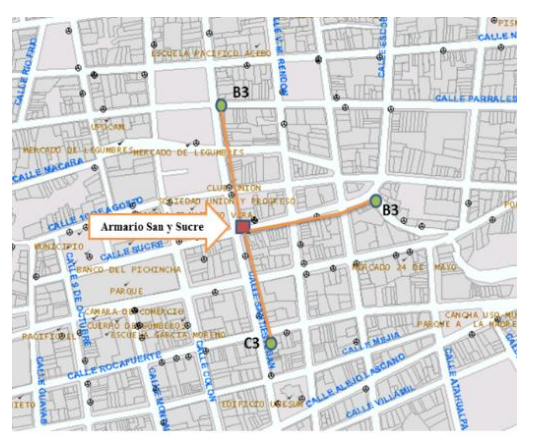

Figura 4. Nodo 2, Red Santisteban y Sucre.

Fuente: elaboración propia. 
La red del nodo 2 está compuesta por un DSLAM de 48 puertos que son los que provee la señal del Internet donde se reparte en 3 cajas de dispersión o magas de diez pares que utilizan como medio de transmisión cables multipar de cobre y tiene un total de 33 clientes activos en la actualidad.

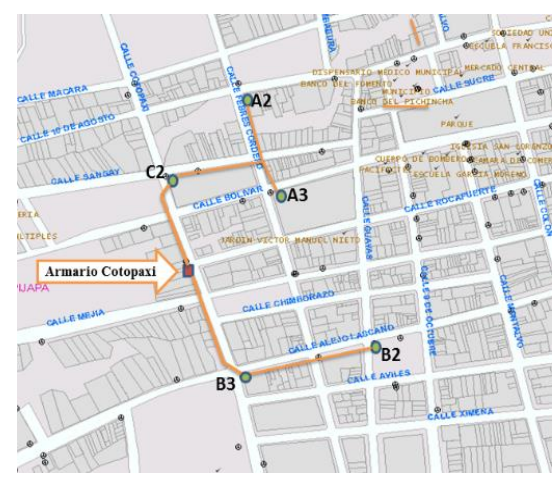

Figura 5. Nodo 3, Red Cotopaxi y Rocafuerte.

Fuente: elaboración propia.

La red del nodo 3 está compuesta por un DSLAM de 48 puertos que son los que provee la señal del internet donde se reparte en 5 cajas de dispersión o magas de diez pares que utilizan como medio de transmisión cables multipar de cobre y tiene un total de 38 clientes activos en la actualidad.

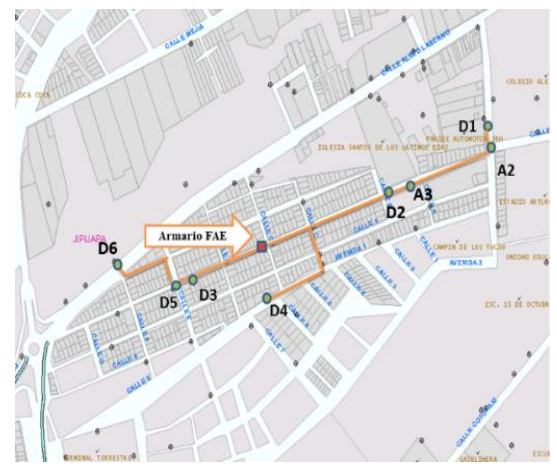

Figura 6. Nodo 4, Red Ciudadela La Fae.

Fuente: elaboración propia.

La red del nodo 4 está compuesta por un DSLAM de 48 y otro de 24 puertos que son los que provee la señal del Internet donde se reparte en 8 cajas de dispersión o magas de diez pares que utilizan como medio de transmisión cables multipar de cobre y tiene un total de 49 clientes activos en la actualidad. 

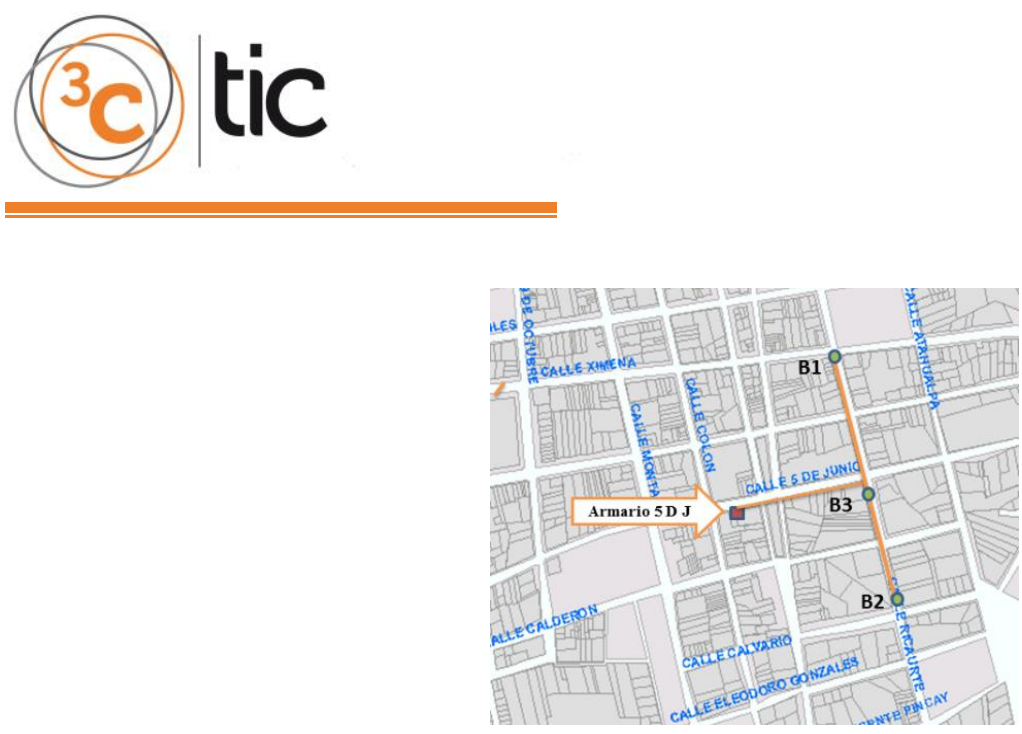

Figura 7. Nodo 5, Red Colon y 5 de junio.

Fuente: elaboración propia.

La red del nodo 5 está compuesta por un DSLAM de 48 y otro de 24 puertos que son los que proveen la señal del Internet, donde se reparte en 3 cajas de dispersión o magas de diez pares que utilizan como medio de transmisión cables multipar de cobre y tiene un total de 55 clientes activos en la actualidad.

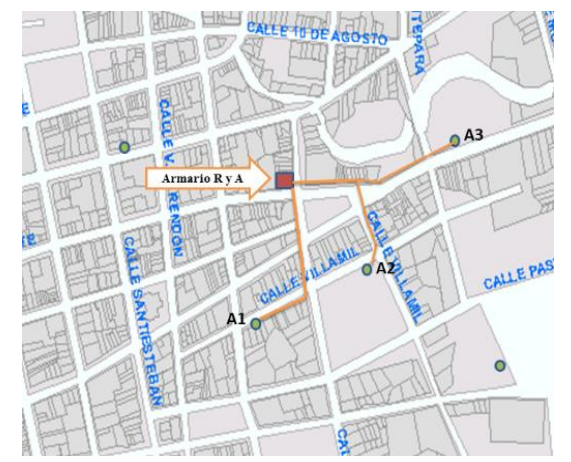

Figura 8. Nodo 6, Red Rocafuerte y Atahualpa.

Fuente: elaboración propia.

La red del nodo 6 está compuesta por un DSLAM de 24 puertos que son los que provee la señal del internet donde se reparte en 3 cajas de dispersión o magas de diez pares que utilizan como medio de transmisión cables multipar de cobre y tiene un total de 17 clientes activos en la actualidad.

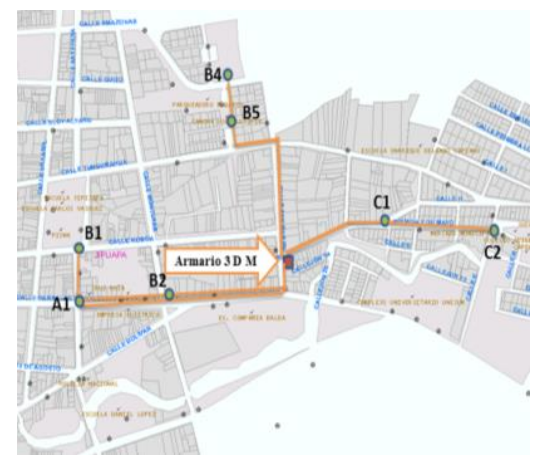

Figura 9. Nodo 7, Red Ciudadela 3 de Mayo.

Fuente: elaboración propia. 
La red del nodo 7 está compuesta por un DSLAM de 48 y otro de 24 puertos que son los que provee la señal del internet donde se reparte en 7 cajas de dispersión o magas de diez pares que utilizan como medio de transmisión cables multipar de cobre y tiene un total de 67 clientes activos en la actualidad.

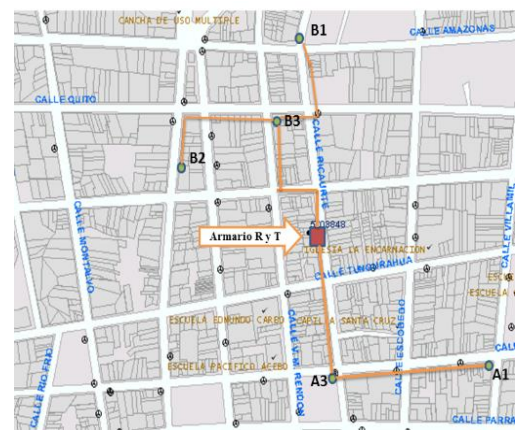

Figura 10. Nodo 8, Red Ricaurte y Tungurahua.

Fuente: elaboración propia.

La red del nodo 8 está compuesta por un DSLAM de 48 puertos que son los que provee la señal del internet donde se reparte en 5 cajas de dispersión o magas de diez pares que utilizan como medio de transmisión cables multipar de cobre y tiene un total de 40 clientes activos en la actualidad.

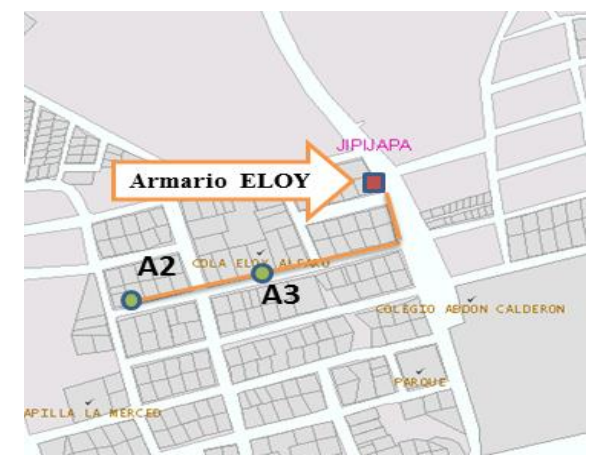

Figura 11. Nodo 9, Red Ciudadela Eloy Alfaro.

Fuente: elaboración propia.

La red del nodo 9 está compuesta por un DSLAM de 24 puertos que son los que provee la señal del internet donde se reparte en 2 cajas de dispersión o magas de diez pares que utilizan como medio de transmisión cables multipar de cobre y tiene un total de 20 clientes activos en la actualidad. 

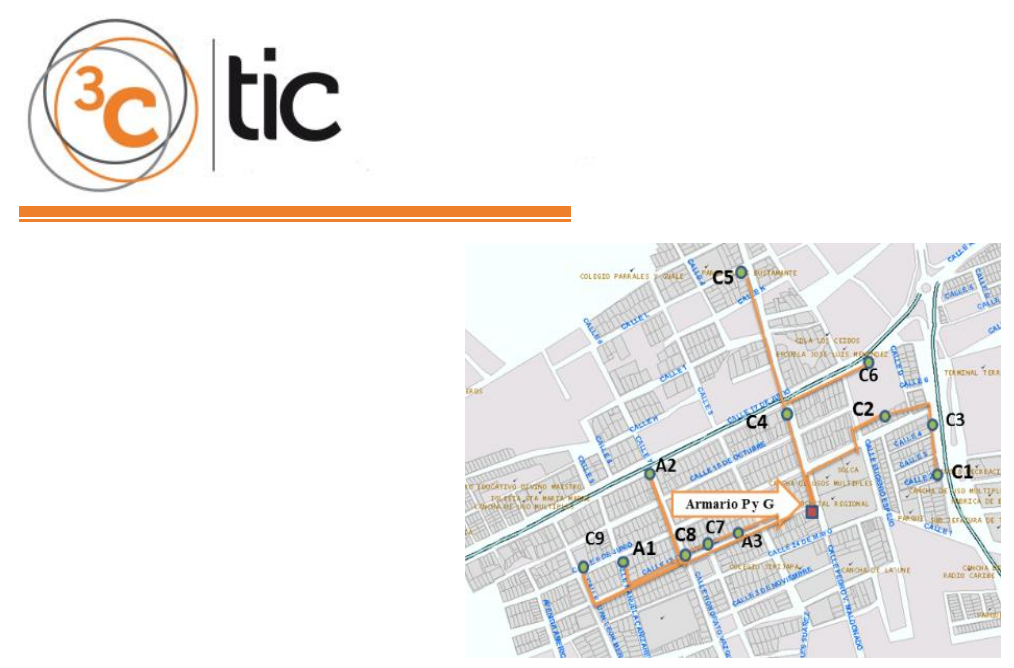

DOI: http://dx.doi.org/10.17993/3ctic.2016.53.44-64

Figura 12. Nodo 10, Red ciudadela Parrales y Guale.

Fuente: elaboración propia.

La red del nodo 10 está compuesta por dos DSLAM de 48 puertos que son los que provee la señal del internet donde se reparte en 12 cajas de dispersión o magas de diez pares que utilizan como medio de transmisión cables multipar de cobre y tiene un total de 96 clientes activos en la actualidad.

\section{TECNOLOGÍA GPON EN LA ARQUITECTURA FTTH}

En su tesis, Castillo Jaramillo y Figueroa Torres, (2013), indican que la tecnología Gpon es la evolución de la tecnología Pon, pero esta capacidad de Gigabit aplicando la arquitectura FTTH es llevar un hilo de fibra óptica a cada domicilio de los clientes aprovechando el gran ancho de banda que soporta esta red proporcionando servicios triple play (Datos, voz y video).

Tabla 1. PON con capacidad de 1 Gigabit (GPON).

\begin{tabular}{|c|c|c|}
\hline GPON & Unid. & $\begin{array}{l}\text { PON con capacidad de } 1 \\
\text { Gigabit (GPON) } \\
\text { 10G-PON (GPON) }\end{array}$ \\
\hline Protocolo & & Ethernet, TDM, TDMA \\
\hline Servicios & & $\begin{array}{l}\text {-Voz, datos y video } \\
\text {-Triple uso } \\
\text {-Intercambio de archivos, } \\
\text { aprendizaje remoto, } \\
\text { tele-medicina, IPTV, vídeo } \\
\text { bajo demanda }\end{array}$ \\
\hline $\begin{array}{l}\text { Distancia } \\
\text { física } \\
\text { máxima. }\end{array}$ & $\mathrm{Km}$ & Máximo 20km (OLT a ONT) \\
\hline $\begin{array}{l}\text { Relación de } \\
\text { División }\end{array}$ & & $\begin{array}{llll}\text { hasta } & 1 \times 64 & \text { (por hilo } \\
\text { óptico) } & & & \end{array}$ \\
\hline $\begin{array}{l}\text { Velocidad de } \\
\text { transferencia } \\
\text { de bits } \\
\text { nominal }\end{array}$ & & Descendente \\
\hline
\end{tabular}




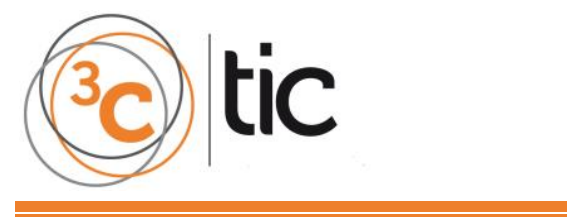

\begin{tabular}{|l|l|l|l|}
\hline Asimétricos & Gbit/s & 10 & 2.5 \\
\hline Simétricos & Gbit/s & 10 & 10 \\
\hline ORL MÁX & dB & $>32$ & $>32$ \\
\hline
\end{tabular}

Fuente: elaboración propia.

Las arquitecturas FTTH utilizan las longitudes de onda (1310, 1490 y $1550 \mathrm{~nm}$ ) y transportan simultáneamente diferente información y en varias direcciones sobre la misma fibra.

El cable de fibra óptica transporta las señales ópticas entre la central y el divisor, lo cual permite conectar varios ONTs a la misma fibra de entrada. Se requiere un ONT para cada abonado y proporciona conexiones para los distintos servicios (voz, datos y vídeo).

Dado que un OLT presta servicio hasta un número de 32 abonados en PON y 64 con GPON, normalmente se necesitan muchos OLTs que salgan dela misma Central para servir a una comunidad. Hay diferentes arquitecturas para conectar abonados a la PON y GPON, la más sencilla utiliza un divisor único pero también pueden emplearse múltiples divisores.

En su tesis, Vargas Guzhñay, (2014) expone que, en una red FTTH puede haber un divisor o varios divisores en cascada, en función de la topología. La recomendación G.984 de la ITU-T permite relaciones de división de hasta 31, mientras que la recomendación G.984.6 amplía la relación hasta 64. Independientemente de la topología, el divisor debe satisfacer el presupuesto de pérdida óptica permitido.

\section{RESULTADOS}

La nueva red FTTH con tecnología Gpon utiliza la topología en anillo partiendo desde en nodo central, realizando un recorrido por cado uno de los FDH (concentrador de distribución de fibra). De esta forma, se ordena con una fibra de 48 hilos el cual alimenta a los splitters $1 \times 4$ que divide las señales para los splitters de $1 \times 16$ y, finalmente, llegando al ONT.

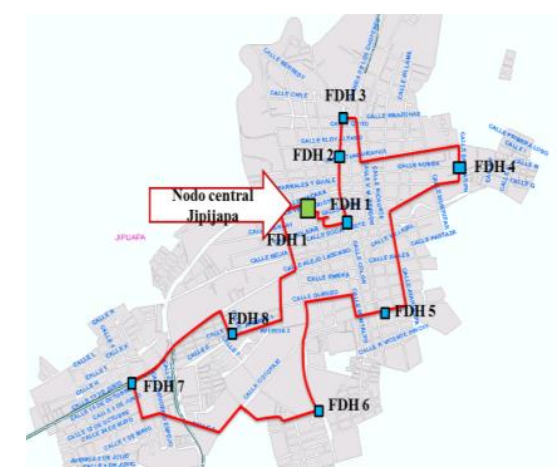

Figura 13. Diseño técnico de la red FTTH para la empresa Netlife. Fuente: elaboración propia.

La estructura de la red FTTH está diseñada para soportar un total de 1.648 clientes con planificación a expandirse con la instalación de más equipos en la misma red. 
Ubicación de los componentes de la red FTTH con tecnología GPON.

Nodo Central: Calle 10 de agosto entre Imbabura y Febres cordero.

FDH 1: Calles Bolívar y Montalvo

FDH 2: Santisteban y Tungurahua

FDH 3: Amazonas y Colon.

FDH 4: Ciudadela 3 de Mayo

FDH 5: Calles 5 de Junio y Colon

FDH 6: Ciudadela Eloy Alfaro

FDH 7: Ciudadela la Fae.

FDH 8: Ciudadela Parrales y Guale

Red FTTH con tecnología GPON estructurada por nodos FDH.

Cada FDH (concentrador de distribución de fibra) utiliza una topología tipo árbol o de ramificación la cual está integrada de equipos pasivos ópticos y empalmes que se reparte la señal en diferentes sectores de cantón.

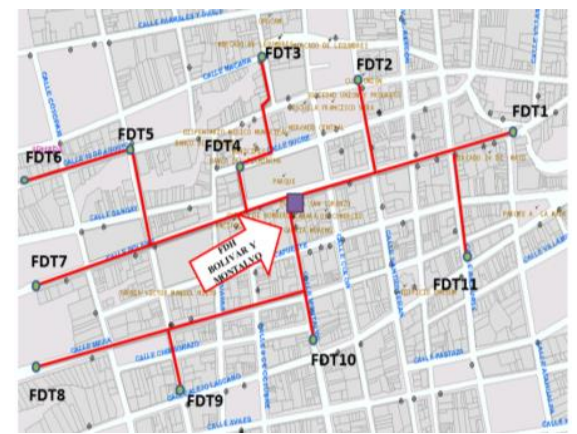

Figura 14. FDH 1. Red Calles Bolívar y Montalvo.

Fuente: elaboración propia.

La red del FDH 1 está compuesta 4 splitters $1 x 4$ y 13 de 1x16, los cuales reparten la señal a 11 FDT (terminal de distribución de fibra) en los diferentes puntos lotizados el en sector con un cable de fibra óptica de 6 hilos donde utiliza la técnica de sangrado fibra para alimentar cada FDT.

Esta red tiene capacidad de soportar 208 clientes correspondientes a su estructura presentada. 


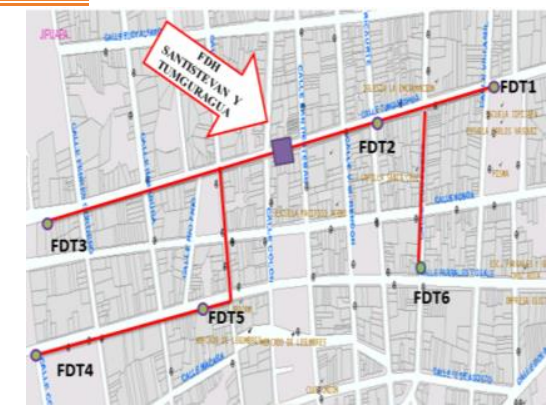

Figura 15. FDH 2. Santisteban y Tungurahua.

Fuente: elaboración propia.

La red del FDH 2 está compuesta 3 splitters $1 x 4$ y 9 de 1x16, los cuales reparten la señal a 6 FDT (terminal de distribución de fibra) en los diferentes puntos lotizados el en sector con un cable de fibra óptica de 6 hilos donde utiliza la técnica de sangrado fibra para alimentar cada FDT.

Esta red tiene capacidad de soportar 176 clientes correspondientes a su estructura presentada.

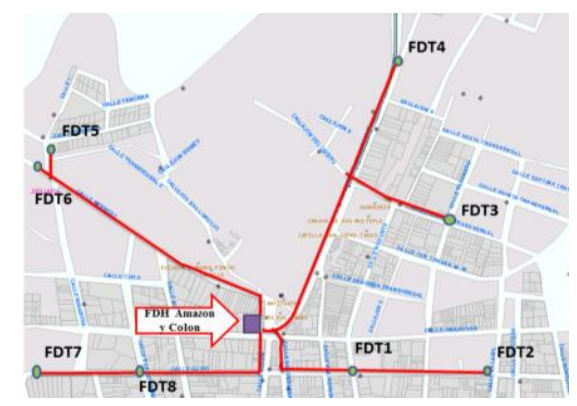

Figura 16. FDH 3. Red Amazonas y Colon.

Fuente: elaboración propia.

La red del FDH 3 está compuesta 4 splitters $1 \times 4$ y 11 de $1 \times 16$, los cuales reparten la señal a 8 FDT (terminal de distribución de fibra) en los diferentes puntos lotizados el en sector con un cable de fibra óptica de 6 hilos donde utiliza la técnica de sangrado fibra para alimentar cada FDT.

Esta red tiene capacidad de soportar 176 clientes correspondientes a su estructura presentada.

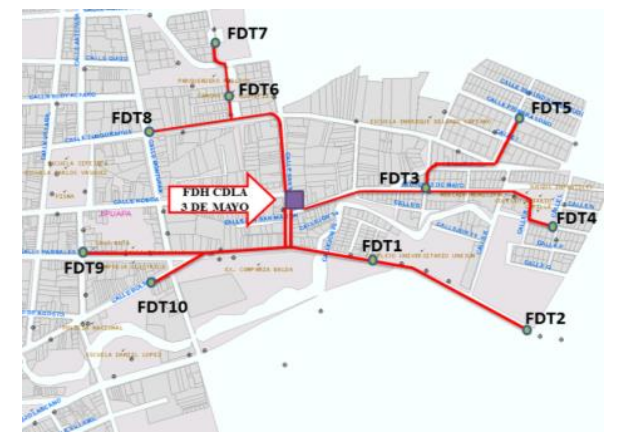

Figura 17. FDH 4. Red Ciudadela 3 de Mayo. Fuente: elaboración propia. 
La red del FDH 4 está compuesta 4 splitters $1 x 4$ y 13 de 1x16, los cuales reparten la señal a 10 FDT (terminal de distribución de fibra) en los diferentes puntos lotizados el en sector con un cable de fibra óptica de 6 hilos donde utiliza la técnica de sangrado fibra para alimentar cada FDT.

Esta red tiene capacidad de soportar 208 clientes correspondientes a su estructura presentada.

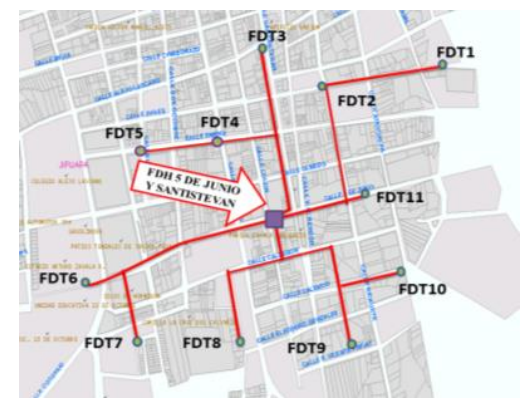

Figura 18. FDH 5. Red Calles 5 de Junio y Colon.

Fuente: elaboración propia.

La red del FDH 5 está compuesta 4 splitters $1 x 4$ y 14 de 1x16, los cuales reparten la señal a 11 FDT (terminal de distribución de fibra) en los diferentes puntos lotizados el en sector con un cable de fibra óptica de 6 hilos donde utiliza la técnica de sangrado fibra para alimentar cada FDT.

Esta red tiene capacidad de soportar 224 clientes correspondientes a su estructura presentada.

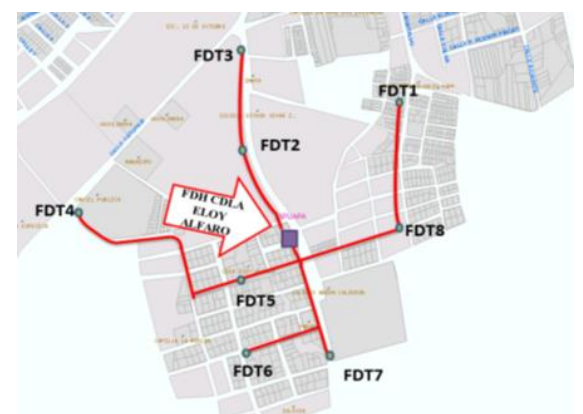

Figura 19. FDH 6. Red Ciudadela Eloy Alfaro.

Fuente: elaboración propia.

La red del FDH 6 está compuesta 3 splitters 1 x 4 y 12 de 1x16, los cuales reparten la señal a 9 FDT (terminal de distribución de fibra) en los diferentes puntos lotizados el en sector con un cable de fibra óptica de 6 hilos donde utiliza la técnica de sangrado fibra para alimentar cada FDT.

Esta red tiene capacidad de soportar 192 clientes correspondientes a su estructura presentada. 


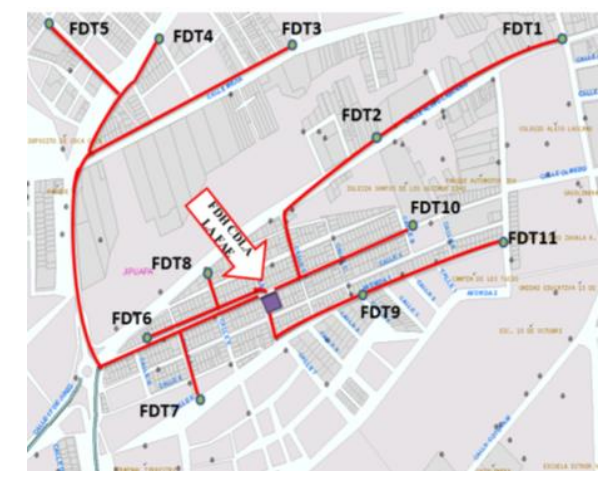

Figura 20. FDH 7. Red Ciudadela la Fae.

Fuente: elaboración propia.

La red del FDH 1 está compuesta 4 splitters $1 \times 4$ y 13 de 1x16, los cuales reparten la señal a 11 FDT (terminal de distribución de fibra) en los diferentes puntos lotizados el en sector con un cable de fibra óptica de 6 hilos donde utiliza la técnica de sangrado fibra para alimentar cada FDT.

Esta red tiene capacidad de soportar 208 clientes correspondientes a su estructura presentada.

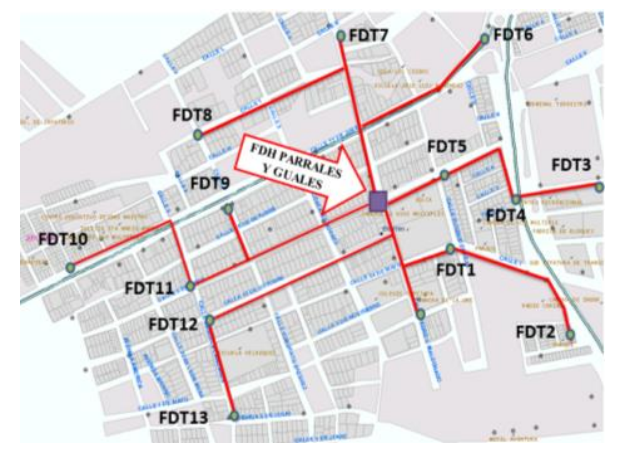

Figura 21. FDH 8. Red Ciudadela Parrales y Guale.

Fuente: elaboración propia.

La red del FDH 8 está compuesta 4 splitters $1 x 4$ y 16 de 1x16, los cuales reparten la señal a 13 FDT (terminal de distribución de fibra) en los diferentes puntos lotizados el en sector con un cable de fibra óptica de 6 hilos donde utiliza la técnica de sangrado fibra para alimentar cada FDT.

Esta red tiene capacidad de soportar 256 clientes correspondientes a su estructura presentada. 


\section{SIMULACIÓN DE LA RED FTTH DE LA EMPRESA NETLIFE}

La simulación de la red FTTH con tecnología Gpon se realizó con el software openSimMPLSbin-v1.1.

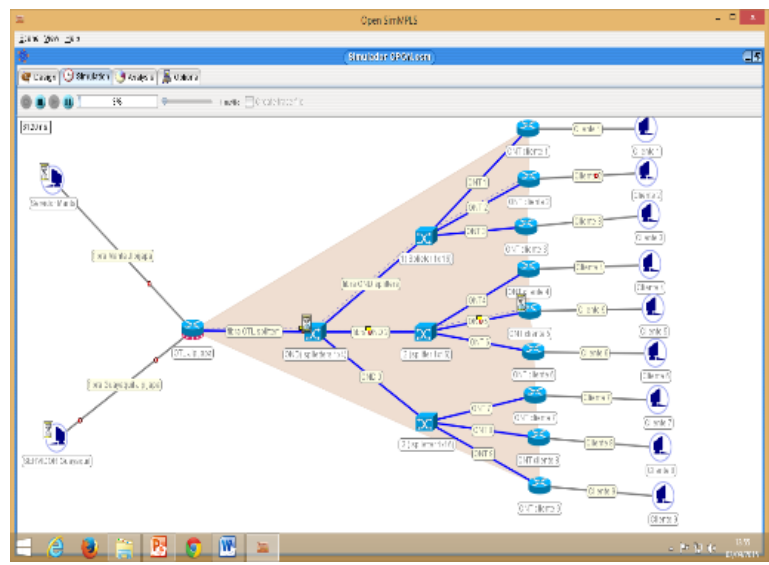

Figura 22. Simulador GPON.

Fuente: elaboración propia.

El proceso de instalación de la red FTTH con tecnología GPON aplicando las técnicas de microsanjado debe cumplir ciertos parámetros y especificaciones que requiere el diseño, para garantizar así la estructura de la red y proveer un servicio de internet de calidad.

Según Gómez Rodríguez, (2013), las micro zanjas constituyen una nueva y ventajosa técnica de construcción para canalizaciones de cables ópticos en suelo urbano. Se trata de canalizaciones de tamaño muy reducido que se construyen sobre asfalto o hormigón de manera rápida y económica.

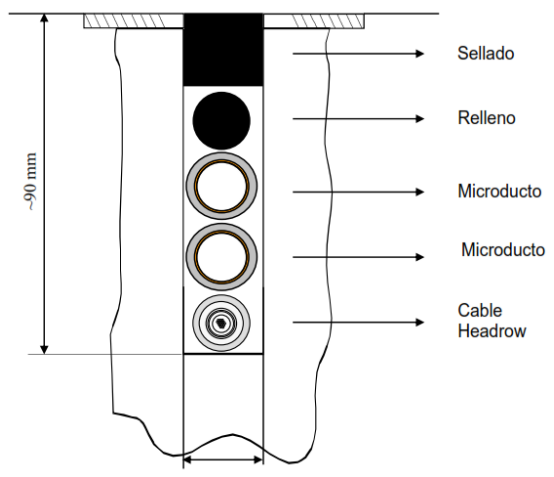

Figura 23. Sistema de microsanjado.

Fuente: elaboración propia.

- Su anchura puede variar entre 10 y $15 \mathrm{~mm}$.

- Su profundidad puede variar entre 10 y $25 \mathrm{~cm}$.

Admiten diversas arquitecturas y permiten incorporar uno o varios cables de fibra óptica directamente enterrados también, y uno o varios microductos vacíos disponibles para tender 
fibra posteriormente mediante técnicas de soplado que es el sistema que se utiliza en la redes FTTH.

El subsuelo urbano está repleto de servicios (agua, gas, comunicaciones, electricidad, etc.) y en muchos casos no existe documentación actualizada de sus trayectorias. El paso de un Geo radar ayuda a descubrir la existencia de estos servicios y elegir la mejor ruta. Estos servicios discurren a mayores profundidades que la micro zanja $(>50 \mathrm{~cm})$, sin embargo, conviene no construirla encima de ellos para facilitar sus eventuales mantenimientos.

El corte con una máquina de zanjado provista de una sierra circular de diamante se abre la micro zanja con una anchura de entre 10 y $15 \mathrm{~mm}$ y una profundidad de entre 10 y $26 \mathrm{~cm}$ (Cevallos Salazar \& Coronel Ayala, 2014).

Para el tendido de la fibra óptica se utilizan cables headrow que soportan grandes presiones provocadas por la dilatación del asfalto. De igual manera se sella la zanja con un material llamado bitumen (betún).

Pueden usarse arquetas sencillas para acotar una sección de reposición en caso de avería, habilitar un acceso para ramales la distancia entre estas arquetas depende del destino de la red, se trata de arquetas plásticas, estancas y con tapa de fundición (Caicedo, 2016).

- Entre 200 y 500 m en urbano.

- Entre 500 y $2000 \mathrm{~m}$ en interurbano.

\section{CONCLUSIONES}

El modelo para la elaboración de un diseño técnico de una red FTTH con tecnología Gpon, aplicando técnicas de microsanjado para la empresa Netlife está vinculado con los beneficios que brinda la empresa a la comunidad de la zona urbana del cantón Jipijapa. Por ello, es importante mejorar el servicio del Internet mediante la aplicación de nuevas tecnología en las redes de la empresa privada Netlife. De esta manera, se mejorará la calidad del servicio a través de un Internet de alta velocidad en la zona urbana del cantón, por lo que se determina la nueva estructura de red de la fibra óptica FTTH con tecnología aplicando técnica de microsanjado para zona urbana del cantón Jipijapa.

El diseño técnico fue estructurado basándose en el estudio técnico que se realizó en la red FTTN de la empresa Netlife, considerando la cantidad clientes activos localizados en el sector y reestructurando su geografía física con una arquitectura FTTH, donde se eliminan las extensiones de última milla de cobre por fibra óptica hasta el domicilio del cliente.

En esta red se implementa nueva tecnología Gpon que garantiza la calidad del servicio del Internet de alta velocidad en Gigabits, donde el ancho de banda que soporta es casi ilimitado y se lo utiliza para proveer múltiples servicios como datos voz y videos.

El tipo de tendido que se aplicó en el diseño técnico es el canalizado o subterráneo pero aplicando técnicas de microsanjado, al cual se realiza una micro zanja en un costado de las vías donde se introduce la fibra óptica y los micro ductos que son los que llegan hasta el 
domicilio del cliente. Los equipos instalados en la red FTTH se representaran gráficamente en planos para determinar la ubicación de cada elemento en el lugar específico. 


\section{REFERENCIAS BIBLIOGRÁFICAS}

Añazco Aguilar, C.O. (2013). Diseño básico de redes de acceso FTTH utilizando el estándar GPON (Doctoral dissertation). Guayaquil.

Argüello Moscoso, E., y Burneo Echeverría, P. (2013). Análisis técnico y financiero para migrar la red de acceso de cobre a una red GPON de la Corporación Nacional de Telecomunicaciones del Ecuador en el cantón Azogues (Doctoral dissertation). Azoguez.

Calle Méndez, C.A., y Machado Tapia, D.G. (2015). Estudio de factibilidad para la implementación de la red FTTH en la empresa Puntonet sucursal Cuenca. Cuenca.

Caicedo Plúa, C.R., Rodríguez Gonzales, A.C., Caicedo Plúa, F.J., Acuña Caicedo, R.W., y Delgado Pesantes, G.P. (2015). Plataforma virtual a través de una infraestructura basada en el sistema de gestión de aprendizajes. Sinapsis, Portoviejo.

Caicedo Plúa, C.R., Acuña Vásquez J.P., Rodríguez Gonzales, A.C., Caicedo Plúa, F.J., y Acuña Caicedo, R.W. (2016). Aplicativo móvil como estrategia de marketing para el impulso de la matriz productiva en el área turística. 3C Tecnología, 5(1), 41-3. ISSN: 2254 4143 .

Castillo Chang, P.R., e Intriago Nuñez, R.I. (2012). Diseño de una red sdh entre Quito y Tulcan para dar servicios de un stm-1 por medio de una señal agregada stm-4 y proveer a un centro de llamadas en cuenca de un e1 internacional hacia el nap de las. Cuenca.

Castillo Jaramillo, M.C., y Figueroa Torres, S.F. (2013). Determinación de la demanda, dimensionamiento y diseño de una red de servicios de telecomunicaciones, mediante la tecnología de acceso FTTH en el cantón Gualaceo para la empresa CNT EP (Doctoral dissertation). Gualaceo.

Cevallos Salazar, G.K., y Coronel Ayala, F.M. (2014). Diseño y Simulación de una red de acceso para brindar servicios Triple Play con tecnología FTTx en el centro de la ciudad de Ambato. Ambato: QUITO:EPN.

Chacón Jimbo, J.V., y Villavicencio Fernández, S.A. (2014). Procedimiento para la ampliación y puesta en operación de cabeceras GPON en la red de telecomunicaciones de ETAPA $E P$. Cuenca.

Gaona Román, L.A., y Santillán Sarmiento, L.P. (2013). Análisis de factibilidad del área técnica y diseño de una red FTTH GPON en el sector de Cumbayá (Doctoral dissertation). Cumbaya.

Gómez Rodríguez, C. (2013). Técnicas de Microzanja y el desarrollo de nuevas redes de comunicaciones. Ingeopres: Actualidad técnica de ingeniería civil, minería, geología y medio ambiente, pp. 33-35. 
Hinojosa Erazo, J.H. (2014). Diseño de una propuesta de red de acceso para brindar servicios de Internet, telefonía, datos y televisión a través de FTTH, para el sector de Iñaquito mediante la tecnología RFoG para un proveedor de CATV (Doctoral dissertation, QUITO/EPN.

Intriago Núñez, R., Castillo Chang, P., y Fiallos, H. (2013). Diseño de una red sdh entre quito y tulcán para dar servicios de un stm-1 y proveer a un centro de llamadas en cuenca de un e1 hacia el nap de las américas con tecnologías metro ethernet y tdmoip. Cuenca.

Miranda Pozo, M.V. (2010). Estudio y Diseño de la Red de Fibra Óptica mediante la Técnica de Microzanjado para la Empresa Telconet SA en el Centro de la Ciudad de Ambato. Ambato.

Ojeda Sotomayor, A.O. (2011). Estudio y diseño de una red FTTH en un campus universitario y una vivienda residencial. Lima Peru.

Quishpe Pérez, A.S., y Vinueza Estévez, N.S. (2010). Estudio de factibilidad de una red de acceso para servicios Triple Play en el sector central de la ciudad de lbarra, mediante la combinación de las tecnologías FTTX (FIBER TO THE X). Ibarra.

Rodríguez Zambrano, C.R. (2012). Diseño de una red FTTH para la renovación de los servicios de las operadoras telefónicas de Guayaquil (Doctoral dissertation). Guayaquil.

Saltos Montaño, A.P. (2011). Diseño de una red troncal de fibra óptica que enlace los poblados que se encuentran a lo largo de la carretera Ibarra. San Lorenzo, teniendo como nodo central a la población de Lita, para brindar servicios IP y TV por suscripción. Quito: QUITO/EPN.

Vargas Guzhñay, C.L. (2014). Estudio e investigación para realizar un análisis técnicoeconómico acerca de la factibilidad de implementación de redes FTTH en comparación con redes de cobre ADSL (Doctoral dissertation). Guayaquil.

Vega, N. (2010). Estudio de Banda Ancha en chile. Chile. 


\title{
SISTEMA PARA LA GESTIÓN DE
} INFORMACIÓN DE LOS SERVICIOS Y MEDIOS DE CÓMPUTO EN EL GRUPO EMPRESARIAL CONSTRUCCIONES GRANMA

\section{MANAGEMENT INFORMATION SYSTEM OF THE SERVICES AND COMPUTER RESOURCES IN THE GRUPO EMPRESARIAL CONSTRUCCIONES GRANMA}

\author{
Yudi Castro Blanco ${ }^{1}$ \\ Susana Teresa Carbonell Hernández ${ }^{2}$ \\ Eric Ismael Leonard Brizuela ${ }^{3}$
}

1. Máster en Informática aplicada. Profesora Asistente de la Universidad de Granma, Bayamo, Cuba. E-Mail: ycastrob@udg.co.cu

2. Ingeniero Informático. Especialista en el Grupo Empresarial Construcciones Granma, Bayamo, Cuba. E-mail: susana@dir.gecgr.co.cu

3. Ingeniero Informático. Profesor Asistente de la Universidad de Granma, Bayamo, Cuba. E-Mail: eleonardb@udg.co.cu

Castro Blanco, Y., Carbonell Hernández, S.T. y Leonard Brizuela, E.I. (2016). App vs papel como soporte para el usuario. Efectos de las Tics en la adherencia a un tratamiento de fisioterapia. 3C TIC: Cuadernos de desarrollo aplicados a las TIC, 5(3), 65-76. DOI: $<$ http://dx.doi.org/10.17993/3ctic.2016.53.65-76/>. 


\section{RESUMEN}

En el Grupo Empresarial Construcciones Granma, en Cuba, se lleva a cabo el registro del gran volumen de información relacionada con los servicios y medios de cómputo de los que se dispone en el grupo empresarial y en las siete empresas subordinadas. Entre los elementos que se controlan se encuentran las computadoras, sus periféricos, componentes internos y características técnicas, además, los cambios o reemplazos, mantenimientos que se realizan y aspectos de la seguridad informática como la actualización de los programas y las auditorias. Su procesamiento se realiza de forma manual, invirtiéndose mucho tiempo debido a que se requiere la consulta de diferentes documentos, lo que provoca retrasos en la entrega de informes de carácter nacional. Atendiendo a estas necesidades, la presente investigación tiene como objetivo desarrollar una aplicación web. Para su implementación, se empleó el framework Django en la programación de páginas dinámicas, Phyton como lenguaje del lado del servidor, HTML5 como lenguaje del lado del cliente, con soporte de base de datos en SQLite y la metodología de desarrollo Extreme Programing. Con su empleo se facilita el registro y procesamiento de la información de manera rápida, permitiendo una mayor consistencia, seguridad y elevando el nivel de eficiencia desde el punto de vista organizativo, de control y analítico.

\section{ABSTRACT}

In the Grupo Empresarial Construcciones Granma (GREMCO), is carried out the registration of a large information volume related to the services and computing resources which is available in the business group and at the seven subordinate companies. Among the elements that are controlled are computers, peripherals, internal components and technical characteristics, besides, the changes or replacements, maintenances that are accomplished and aspects of security informatics like the update of the programs and the auditing. Its processing is done manually, inverting a long time because it require to consult different documents provoking delays in information processing and the delivery of reports. Attending to this needs, this research aims to develop a web application. For its implementation, the Django framework was used in the programming of dynamic pages, Phyton like the language of the server side, HTML5 like the language in the customer side and with data base support SQLite and the methodology Extreme Programming. With its use is facilitate the recording and processing information, enabling greater consistency, security and raising the level of efficiency from the organizational point of view, control and analytical.

\section{PALABRAS CLAVE}

Aplicación web; gestión de servicio y medios de cómputo; gestión de información.

\section{KEY WORDS}

Web Application; service management and computer resources; Information Management. 


\section{INTRODUCCIÓN}

Desde que el hombre comenzó a comunicarse, vio la necesidad de recopilar y procesar información que con el tiempo se han ido perfeccionado gracias a los avances de la ciencia y la técnica, unidos al surgimiento de la computadora. Por eso, considera Aladro (2011) que los países desarrollados basan su crecimiento en la aplicación y la programación estratégica de las herramientas computacionales y han definido políticas que los inducirán a su permanencia en el dinamismo mundial de los próximos años. De este modo, la presencia de la computación en los sectores productivos es un factor determinante para su funcionamiento.

Nada ni nadie escapan al paradigma y la nueva sociedad que ha creado las telecomunicaciones, la informática e Internet, y el mundo de la construcción no es ninguna excepción. Según Ferrada y Serpell (2009), cada vez son más las empresas constructoras que se involucran en gestionar sus principales procesos de diseño, construcción e ingeniería empleando las tecnologías de la información y la comunicación para cumplir con calidad su encargo social.

En Cuba, el Ministerio de la Construcción es el organismo rector encargado de dirigir, ejecutar en lo que le compete y controlar la política del estado y el gobierno en cuanto a los servicios de diseño, ingeniería y construcción, producción de materiales de construcción y del sistema de la vivienda. Cumple un importante rol en el desarrollo del país, tanto cultural como económico, pues a través de la construcción se satisfacen las necesidades de infraestructura de la mayoría de las actividades económicas y sociales de la nación (MICONS, 2014).

El Grupo Empresarial Construcciones Granma (GREMCO) es una de las dependencias del Ministerio de la Construcción. El mismo cuenta con una alta productividad y eficiencia económica logrando construcciones competitivas, dotado de un personal motivado y elevado sentido de pertenencia. También cuenta con toda la industria modernizada y máxima calidad en las obras minimizando los daños en el entorno con una fuerte imagen corporativa que permite satisfacer a los clientes nacionales e internacionales.

La Dirección Técnica de GREMCO tiene como principal función gestionar toda la información referente a los servicios y medios de cómputo de los que se dispone en el grupo empresarial y en las siete empresas subordinadas. Entre ellas, se encuentran las computadoras, sus periféricos, componentes internos y sus características técnicas. Además se registran los cambios o remplazos y mantenimientos que se realizan y aspectos de la seguridad informática, como la actualización y autorización de los programas y las auditorias, incluyendo los servicios que se prestan. Todo el control que lleva a cabo constituye un criterio de medida a nivel nacional, lo que requiere la entrega de informes de forma periódica. Han sido detectadas algunas deficiencias en este proceso: 
- Se invierte mucho tiempo para su realización, pues se requiere la consulta de varios documentos, lo que implica que se puedan cometer errores.

- Los documentos son vulnerables a pérdida, sustracción y deterioro.

- La información es enviada por correo electrónico a la Dirección Nacional de Informática y Comunicaciones del Ministerio de la Construcción, y hasta tanto no llegue no puede consultarse la situación actual de la misma.

- Para conocer el estado de los equipos es necesario consultar informes aislados provocando demoras en el proceso.

- Se requiere de gran cantidad de papeles y no existe seguridad en los documentos pudiendo existir alteración por personal no autorizado.

- No se desarrollan comparaciones entre empresas para un mismo indicador por período, que muestre la situación actual de los componentes y equipos de forma general.

No se halló ninguna propuesta informática que realice una gestión detallada de los servicios y medios de cómputo. Se encontró la propuesta de un modelo para la gestión automatizada e integrada de controles de seguridad informática (Montesino, Baluja y Porvén, 2013) y una metodología para su implementación (Miranda, Valdés, Pérez, Portelles y Sánchez, 2016). Estos estudios permiten profundizar sobre una parte del proceso que se gestionada en GREMCO, los procederes en la seguridad informática, permitiendo realizarse un reevaluar de la manera en la que se realiza según los estándar internacional.

Según Vidal y Araña (2012) y Torres (2015) la gestión de la información es el proceso de organizar la información, evaluar, presentar, comparar los datos en un determinado contexto, controlar la calidad, veracidad, que sea oportuna, significativa, exacta, útil y que esté disponible en el momento que se le necesite. Teniendo en cuenta esta consideración y las deficiencias detectadas en GREMCO, se consideran necesarias nuevas formas de gestión, o sea, mecanismos más eficaces de almacenamiento y procesamiento de los datos.

En aras de solucionar la ineficiencia en el proceso de gestión de la información relacionada con los servicios y medios de cómputo en GREMCO, se propone en esta investigación desarrollar una aplicación web que lo realice de manera rápida y eficiencia.

\section{METODOLOGÍA}

Inicialmente, se hizo un estudio en GREMCO para constatar las deficiencias en la gestión de la información relacionada con los servicios y medios de cómputo y determinar la mejor vía para solucionarlo. Se utilizaron métodos y técnicas como el análisis y síntesis para recopilar y procesar la información necesaria, la revisión documental para conocer con claridad los datos que son de interés, la entrevista para obtener datos detallados sobre su procesamiento, y la observación para ver las funcionalidades del jefe de la dirección técnica. Se realizó una búsqueda de sistemas informáticos que pudieran emplearse para resolver las deficiencias 
detectadas, y al no encontrarse ninguno, se desarrolló una aplicación web con este objetivo que se ajustara a sus necesidades.

Para su desarrollo se hizo un estudio bibliográfico sobre las posibles herramientas, tecnologías y lenguajes a utilizarse (Gutiérrez, 2008; Hernández y Greguas, 2010) según sus prestaciones, tendencias actuales y novedades, con el fin de mantener la mayor integración posible y seleccionar las adecuadas. Se empleó el proceso de desarrollo para guiar la metodología Extreme Programing o como también se le conoce XP, ya que es una metodología ágil que se basa en la realimentación continua entre el cliente y el equipo de desarrollo, comunicación fluida entre todos los participantes y simplicidad en las soluciones (Díaz, 2009; Tinoco, Rosales y Salas, 2010; Escobar y Gualteros, 2013; Bagarotti, Meneses y Arias, 2013). Se implementó haciendo uso de los lenguajes de programación del lado del cliente HTML 5 (Gauchat, 2012) y del lado del servidor Python (Challenger, Díaz y Becerra, 2014), este último permite la creación de páginas web dinámicas y facilita la conexión a diferentes tipos de servidores de bases de datos. Para la maquetación se utilizó Bootstrap, pues permite crear interfaces web con CSS y Javascript (Lessin, 2013). Como gestor de base de datos se hizo uso de SQLite, ya que cuenta con un completo soporte para tablas e índices en un único archivo por base de datos, soporte transaccional, rapidez (dos veces más veloz que MySQL y PostgreSQL), escaso tamaño y su completa portabilidad. Se utilizó el framework Django por las facilidades para la creación de sitios web complejos y su compatibilidad con Python. Las fases que se siguieron teniendo en cuenta lo que la metodología XP establece fueron las siguientes:

1. Exploración. En ella se definió el alcance del proyecto, se especificaron las funcionalidades que se deseaban informatizar para satisfacer las necesidades del cliente mediante 32 historias de usuario, estimándose el tiempo de desarrollo de cada una, el cual no era superior a los tres días. Entre las definidas se encuentran: actualizar y visualizar datos de las computadoras, componentes, periféricos, incidencias de la seguridad informática, comportamiento de la conectividad (enlace conmutado y arrendado), mantenimientos, cambios de piezas, los programas actualizados por computadoras, los datos de los usuarios con correo y conexión nacional e internacional, reporte general de computadoras por empresa, entre otras.

2. Plan de entrega. Se realizó una estimación detallada del tiempo a emplearse en el desarrollo de las historias de usuario y para eso se dividieron en tres iteraciones. En el cronograma de entregas se estimó que la duración de la primera iteración fuera de cuatro semanas, la segunda y la tercera tres semanas cada una.

3. Iteraciones. Se planificó la etapa de implementación, definiéndose las tareas para desarrollar cada historia de usuario en términos de diseño y programación, se describió cada una y se estimó el tiempo de duración.

4. Producción. Se diseñó, codificó y probó la aplicación web. Tras ser creada la primera iteración, se trabajó en las nuevas.

- Diseño: para lograr un sistema robusto, reutilizable y basados en las prácticas de la metodología seleccionada, se trabajó en un diseño sencillo y evolutivo. La base 
de datos se diseñó con 14 tablas normalizadas hasta la Forma Normal de BoyceCodd mediante la herramienta Embarcadero ER/Studio.

- Codificación: se tuvo en cuenta la reutilización de código para agilizar la implementación. Se empleó el método de indentación, popular en Python. Se estableció un estándar de codificación para lograr uniformidad y facilitar la comprensión del código.

- Pruebas: se realizaron pruebas unitarias y de aceptación para evaluar la calidad de la aplicación web de forma pragmática y descubrir errores. Las unitarias o de caja blanca fueron desarrolladas por los programadores para verificar el código, es decir, los detalles procedimentales (la lógica del sistema). Las de aceptación también llamadas pruebas funcionales o de caja negra fueron supervisadas por el cliente basándose en los requerimientos tomados de las historias de usuario, se verificó el resultado esperado de una transacción determinada, y se llevaron a cabo sobre la interfaz. Estas pruebas permitieron encontrar errores como: funciones incorrectas, errores de interfaz, errores en estructuras de datos, errores de inicialización, errores ortográficos, la no actualización correcta de los datos de una computadora y que no notificaba la actualización de un mantenimiento. Todos los errores detectados fueron corregidos a tiempo, lográndose una aplicación web de mayor calidad.

5. Mantenimiento. Durante el desarrollo se tuvieron en cuenta las opiniones del cliente. En esta etapa se identificaron necesidades que propiciaron cambios en la aplicación web, lo que dio lugar a mantenimiento de tipo adaptativo, correctivo y perfectivo.

6. Muerte del Proyecto. Se generó la documentación final y al no requerirse más cambios en la arquitectura, al cliente no tener más historias de usuario que incluir y al estar satisfecho con el sistema, pues éste generó los beneficios esperados, se dio por terminada la aplicación web.

Una vez que finalizó la implementación de la aplicación web, esta se desplegó en GREMCO y se capacitó al personal que interactúa con la misma. Además, se proporcionó un manual de usuario que contiene detalles de cómo se opera con ella para que pudiera evacuar cualquier duda sobre su manejo en el futuro.

\section{RESULTADOS}

La aplicación web cuenta con una serie de funcionalidades que la hacen una herramienta útil para gestionar la información relacionada con los servicios y medios de cómputo en GREMCO y las siete empresas subordinadas. En su desarrollo se intentó satisfacer las necesidades del cliente. Su interfaz es cómoda y facilita la navegación. Es configurable, permitiendo ser implantado con gran facilidad en cualquier grupo empresarial o empresa que controle la misma información.

En aras de garantizar la seguridad y confiabilidad de los datos que se gestionan, cuenta con una jerarquía de usuario para acceder a cualquier opción del sistema, dígase: introducir, 


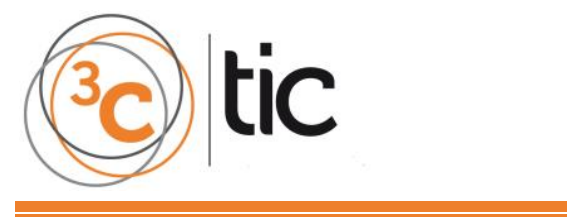

modificar o eliminar e incluso visualizar los reportes, garantizándose así que la información que se introduzca la hagan personas debidamente autorizadas. Se tuvo en cuenta que solo accedan a los registros de la empresa a la que pertenecen y que a nivel de grupo empresarial se tenga acceso a todo. La contraseña se encriptó en la base de datos mediante el método md5, que permite controlar las operaciones que se realizan mediante una especie de log que guarda los datos con la fecha y hora. La figura 1 muestra la página de inicio.

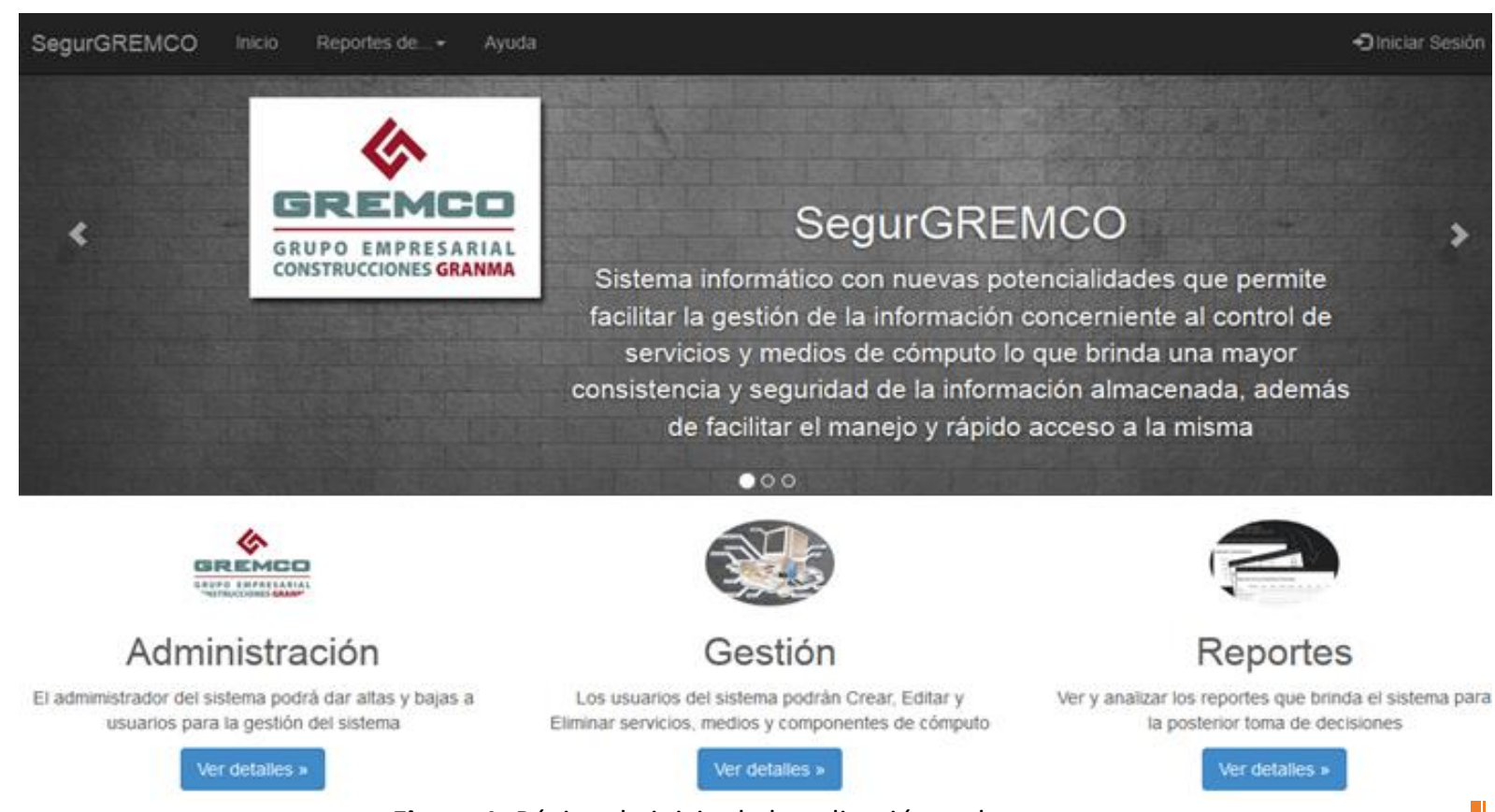

Figura 1. Página de inicio de la aplicación web.

Entre la información que se gestiona mediante la aplicación web se encuentra la referente a las computadoras, en la figura 2 se observa el formulario con esta opción. Se siguió el mismo diseño para que sea cómodo al usuario, por ejemplo, el botón aceptar siempre va a indicar almacenar la información en la base de datos. Se tuvieron en cuenta algunos elementos que ayudan a que los errores humanos se minimicen, como lo es en este caso, la selección en vez de entrarse del tipo de computadora y su estado, además que solo se pueda introducir en cada campo el tipo de dato correcto (letra, número o ambos). 

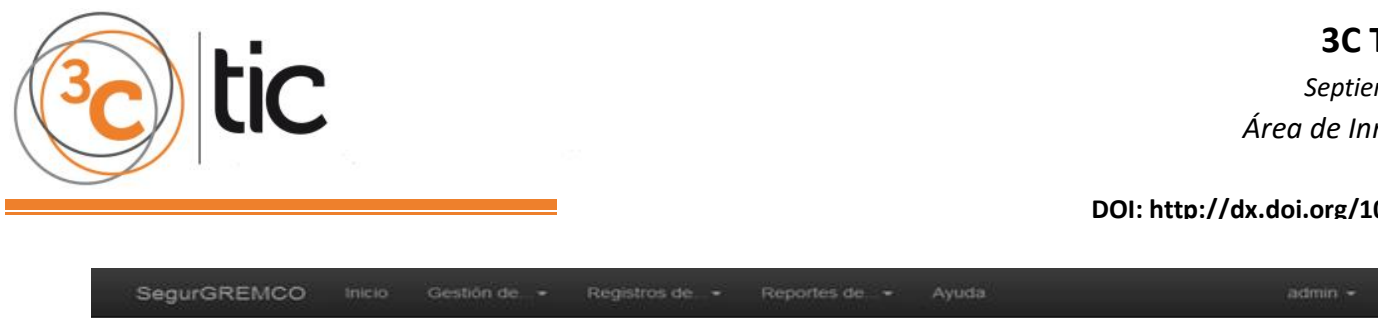

Gestionar computadoras

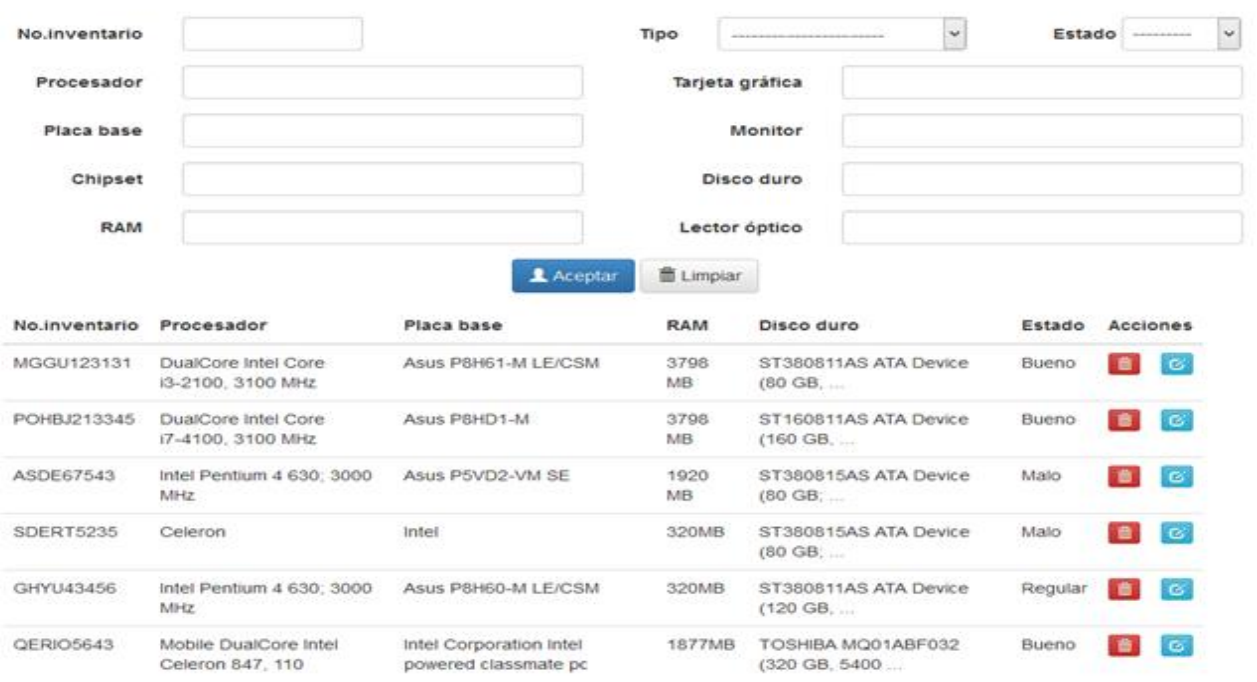

Figura 2. Gestión de los datos de las computadoras mediante la aplicación web.

También se pueden gestionar los periféricos, las incidencias de seguridad informática que se producen, el comportamiento de la conectividad en la empresa como la cantidad de enlace conmutado y arrendado, datos de los usuarios con correo y conexión nacional e internacional, el registro de mantenimiento y cambios de piezas que se realizan a las computadoras, entre otras informaciones.

Para obtenerse los reportes solo es necesario acceder a la opción y son emitidos de forma rápida según modelos oficiales, lo que sustituye los cálculos manuales que antes se hacían. También se pueden realizar comparaciones entre empresas e indicadores. Por ejemplo, como se muestra en la figura 3 , donde se indica la cantidad de periféricos de los que se dispone y su estado (malo (M), regular (R) y bien (B).

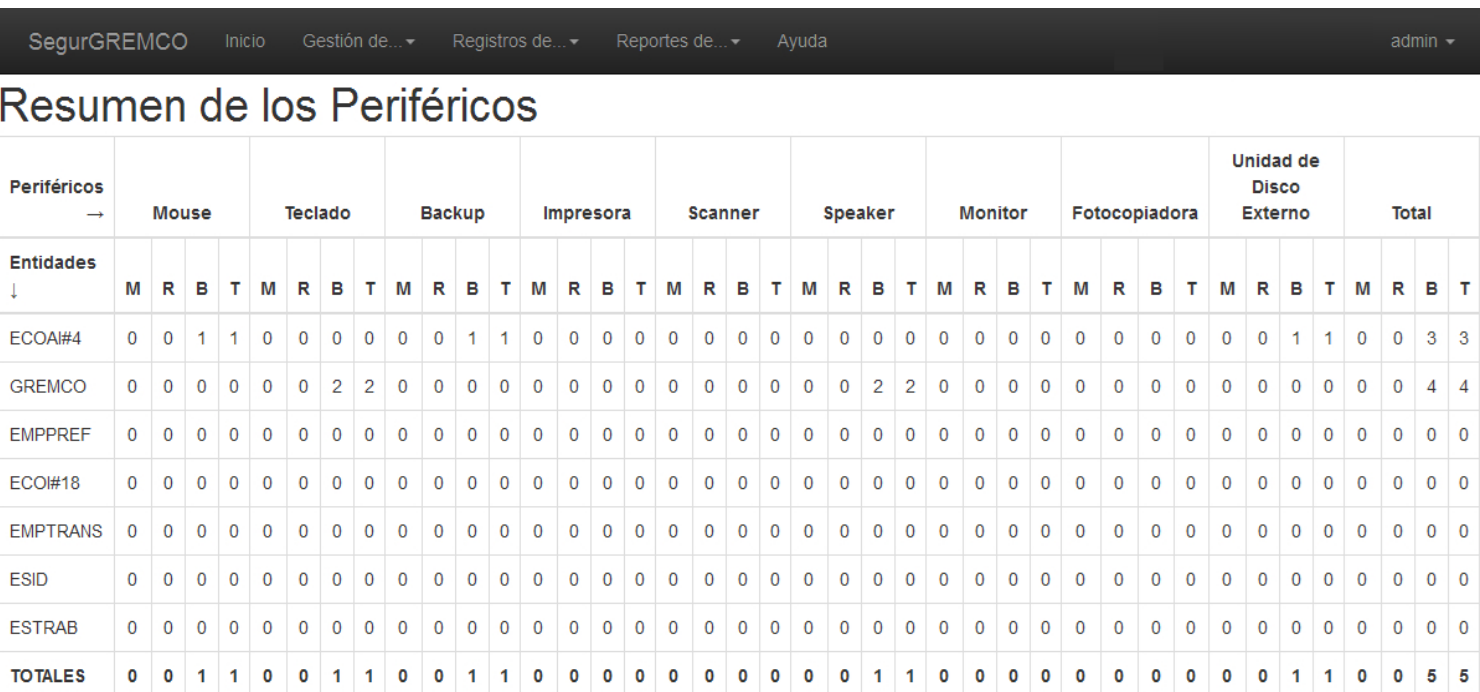

Figura 3. Reporte emitido por la aplicación web sobre los periféricos por empresa. 
La aplicación web brinda la facilidad de realizar salva(s) de seguridad de la base de datos cuando se estime necesario para garantizar la seguridad de la información ante la rotura del servidor. Se recomendó al cliente que las realizara periódicamente, las cuales podrían ser al finalizar cada jornada de trabajo y en diferentes fuentes de almacenamiento.

\section{DISCUSIÓN}

El éxito de un software se puede definir como calidad del sistema, de los datos y del servicio. La aplicación web impacta de manera positiva en los procesos y decisiones de GREMCO, al repercutir en todos estos aspectos. Con su implantación, no es necesario mejorar el equipamiento del que se dispone pues se desarrolló en función de sus requerimientos técnicos. Las tecnologías que requiere para su funcionamiento están basadas en software libre por lo que puede ser modificado en caso de cualquier error técnico. Se logra el ahorro de una serie de recursos como el papel al estar almacenada la información en formato digital. Representa beneficios en cuanto al factor tiempo, los errores humanos se minimizan y el control es más sistemático.

No genera empleo ni desempleo, se facilita en gran medida la realización de las actividades laborales. Se requiere de un mínimo de esfuerzo para utilizar la aplicación web, evita el estrés y mejora la calidad de vida al poder realizarse las operaciones con mayor rapidez. Se contribuye a elevar el nivel profesional y cultural de todos los trabajadores, ya que están interactuando con la tecnología que es utilizada en la mayor parte del mundo en cuanto a medios de comunicación e informatización.

El usuario, una vez que interactuó con la aplicación web fue capaz de percibir los beneficios que esta le proporciona para evaluar su calidad se empleó el criterio de expertos mediante el método Delphi. Éste consiste en la utilización sistemática del juicio intuitivo de un grupo de expertos para obtener un consenso de opiniones informadas. Es considerado como uno de los métodos subjetivos de pronosticación más confiables (Blanco, López y Mengual, 2010; García y Suárez, 2013).

Los expertos que evaluaron la calidad de la aplicación web fueron 31. Respondieron una encuesta que se confeccionó a partir de los siguientes indicadores generales de evaluación:

1. Resulta una interfaz amigable y fácil de operar.

2. Garantiza la disponibilidad de la información actual e histórica.

3. Facilita el análisis de la información actualizada.

4. Garantiza la seguridad de la información.

5. Constituye una herramienta útil para la toma de decisiones.

6. Disminuye el tiempo de respuesta.

7. Eleva la calidad de la información. 
8. Garantiza la obtención de todos los reportes que necesita.

9. Garantiza la obtención correcta de la información.

Después de realizado el procesamiento de la encuesta, se obvió que los aspectos $3,5,6,7,8$ y 9 son muy relevantes mientras que los aspectos 1,2 y 4 bastante relevante. Por tanto, estos resultados son un argumento a favor de la calidad y el impacto que tuvo la puesta en práctica en GREMCO de la aplicación web para la gestión de información de los servicios y medios de cómputo de los que disponen.

\section{CONCLUSIONES}

Con el desarrollo de la aplicación web propuesta en esta investigación GREMCO se cuenta con una solución informática que mejora la gestión y procesamiento de la información relacionada con los servicios y medios de cómputo de forma rápida y sencilla. Mediante su empleo se obtiene información en el momento que se necesite de manera detallada, precisa y con mayor consistencia, lo que mejora el análisis, la comprensión y eleva el nivel de eficiencia desde el punto de vista organizativo, de control y analítico. Avalan su calidad las pruebas de software y el método Delphi que se le aplicó. 


\section{REFERENCIAS BIBLIOGRÁFICAS}

Aladro, E. (2011). La teoría de la información ante las nuevas tecnologías de la comunicación. CIC : Cuadernos de Información y Comunicación, 16, 83-93.

Bagarotti, Y.C., Meneses, A. y Arias, Y. (2013). Experiencias durante la gestión de la calidad en proyectos que usan metodologías ágiles. Revista Ingeniería UC, 20(3), 45-53.

Blanco, J.E., López, A. y Mengual, S. (2010). Validación mediante método Delphi de un cuestionario para conocer las experiencias e interés hacia las actividades acuáticas con especial atención al Windsurf. ÁGORA, 12(1), 75-96.

Challenger, I., Díaz, Y. y Becerra, R.A. (2014). El lenguaje de programación Python. Ciencias Holguín, 20(2), 1-13.

Díaz, J. (2009). Las metodologías ágiles como garantía de calidad del software. Revista Española de Innovación, Calidad e Ingeniería del Software (REICIS), 5(3), 40-43.

Escobar, D.P. y Gualteros, A.C. (2013). Estudio de metodologías ágiles para proyectos de software en corto tiempo. Revista Tia, 1(2), 148-160.

Ferrada, X.V. y Serpell, A. (2009). La gestión del conocimiento y la industria de la construcción. Revista de la Construcción, 8(1), 46-58.

García, M. y Suárez, M. (2013). El método Delphi para la consulta a expertos en la investigación científica. Revista Cubana de Salud Pública, 39(2), 253-267.

Gauchat, J. (2012). El gran libro de HTML5, CSS3 y Javascript. Barcelona España.

Gutiérrez, C. (2008). Diseño web y arquitectura de información para sitios 2.0. Cuadernos de Información, 22, 58-65.

Hernández, R.L. y Greguas, D. (2010). Estándares de Diseño Web. Ciencias de la Información, 41(2), 69-71.

Lessin, J. (2013). Qué es Bootstrap y cómo funciona en el diseño web. Consultado: 25 de febrero de 2015, a partir de: <http://jorgelessin.com/que-es-bootstrap-y-comofunciona-en-el-diseno-web/>.

MICONS. (2014). Modelo del profesional de la especialidad Construcción Civil. Consultado: 7 de noviembre de 2014, a partir de: <http://micons.netcons.com.cu/>.

Miranda, M., Valdés, O., Pérez, I., Portelles, R., Sánchez, R. (2016). Metodología para la implementación de la gestión automatizada de controles de seguridad informática. Revista Cubana de Ciencias Informáticas, 10(2), 14-26.

Montesino, R., Baluja, W. y Porvén, J. (2013). Gestión automatizada e integrada de controles de seguridad informática. Ingeniería Electrónica, Automática y Comunicaciones, 34(1), 40-58. 
Tinoco, O., Rosales, P. P. y Salas, J. (2010). Criterios de selección de metodologías de desarrollo de software. Industrial Data, 13(2), 70-74.

Torres Lebrato, L. (2015). La gestión de información y la gestión del conocimiento. Revista Archivo Médico de Camagüey, 19(2), 96-98.

Vidal, M. J. y Araña, A. B. (2012). Gestión de la información y el conocimiento. Educación Médica Superior, 26(3), 474-484. 


\section{DECLARACIÓN ÉTICA SOBRE PUBLICACIÓN Y MALAS PRÁCTICAS}

La revista 3C TIC está comprometida con la comunidad académica y científica en garantizar la ética y calidad de los artículos publicados. Nuestra revista tiene como referencia el Código de Conducta y Buenas Prácticas que; para editores de revistas científicas define el COMITÉ DE ÉTICA DE PUBLICACIONES (COPE).

Así nuestra revista garantiza la adecuada respuesta a las necesidades de los lectores y autores; asegurando la calidad de lo publicado; protegiendo y respetando el contenido de los artículos y la integridad de los mismos. El Consejo Editorial se compromete a publicar las correcciones; aclaraciones; retracciones y disculpas cuando sea preciso.

En cumplimiento de estas buenas prácticas; la revista 3C TIC tiene publicado el sistema de arbitraje que sigue para la selección de artículos así como los criterios de evaluación que deben aplicar los evaluadores externos -anónimos y por pares; ajenos al Consejo Editorial-. La revista 3C TIC mantiene actualizado estos criterios; basados exclusivamente en la relevancia científica del artículo; originalidad; claridad y pertinencia del trabajo presentado.

Nuestra revista garantiza en todo momento la confidencialidad del proceso de evaluación: el anonimato de los evaluadores y de los autores; el contenido evaluado; el informe razonado emitidos por los evaluadores y cualquier otra comunicación emitida por los consejos editorial; asesor y científico si así procediese.

Igualmente queda afectado de la máxima confidencialidad las posibles aclaraciones; reclamaciones o quejas que un autor desee remitir a los comités de la revista o a los evaluadores del artículo.

La revista 3C TIC declara su compromiso por el respecto e integridad de los trabajos ya publicados. Por esta razón; el plagio está estrictamente prohibido y los textos que se identifiquen como plagio o su contenido sea fraudulento; serán eliminados o no publicados de la revista 3 C TIC. La revista actuará en estos casos con la mayor celeridad posible. Al aceptar los términos y acuerdos expresados por nuestra revista; los autores han de garantizar que el artículo y los materiales asociados a él son originales o no infringen derechos de autor. También los autores tienen que justificar que; en caso de una autoría compartida; hubo un consenso pleno de todos los autores afectados y que no ha sido presentado ni publicado con anterioridad en otro medio de difusión. 


\section{DECLARACIÓN SOBRE LA PROPIEDAD INTELECTUAL}

Los autores/as que publiquen en esta revista aceptan las siguientes condiciones:

1. Los autores/as conservan los derechos de autor y ceden a la revista el derecho de la primera publicación; que permite a terceros utilizar lo publicado siempre que mencionen la autoría del trabajo y a la primera publicación en esta revista.

2. Los autores/as pueden realizar otros acuerdos contractuales independientes y adicionales para la distribución no exclusiva de la versión del artículo publicado en esta revista (p. ej.; incluirlo en un repositorio institucional o publicarlo en un libro) siempre que indiquen claramente que el trabajo se publicó por primera vez en esta revista.

\section{POLÍTICA DE ACCESO LIBRE}

Esta revista provee acceso libre inmediato a su contenido bajo el principio de que hacer disponible gratuitamente investigación al público apoya a un mayor intercambio de conocimiento global. 


\section{${ }^{3}$ ciencias}

\section{CONSEJO EDITORIAL}

\begin{tabular}{|ll|}
\hline \multicolumn{2}{|c|}{ COMPONENTES } \\
\hline Director & Víctor Gisbert Soler \\
\hline \multirow{2}{*}{ Editores adjuntos } & $\begin{array}{l}\text { María J. Vilaplana Aparicio } \\
\text { Inés Poveda Pastor } \\
\text { Vicente Sanchís Rico }\end{array}$ \\
\hline Editor asociado & David Juárez Varón \\
\hline
\end{tabular}

\section{COMITÉ CIENTÍFICO TÉCNICO}

\begin{tabular}{|l|l|}
\hline ÁREA TEXTIL & $\begin{array}{l}\text { Prof. Dr. Josep Valldeperas Morell } \\
\text { Universidad Politécnica de Cataluña } \\
\text { España }\end{array}$ \\
\hline ÁREA FINANCIERA & $\begin{array}{l}\text { Prof. Dr. Juan Ángel Lafuente Luengo } \\
\text { Universidad Jaume I; Castellón de la Plana } \\
\text { España }\end{array}$ \\
\hline ORGANIZACIÓN DE EMPRESAS Y RRHH & $\begin{array}{l}\text { Prof. Dr. Francisco Llopis Vañó } \\
\text { Universidad de Alicante } \\
\text { España }\end{array}$ \\
\hline \multirow{2}{*}{ ESTADÍSTICA; INVESTIGACIÓN OPERATIVA } & $\begin{array}{l}\text { Prof. Dra. Elena Pérez Bernabéu } \\
\text { Universidad Politécnica de Valencia } \\
\text { España }\end{array}$ \\
\hline DERECHO & $\begin{array}{l}\text { Prof. Dra. María del Carmen Pastor Sempere } \\
\text { Universidad de Alicante } \\
\text { España }\end{array}$ \\
\hline INGENIERÍA Y TECNOLOGÍA & $\begin{array}{l}\text { Prof. Dr. David Juárez Varón } \\
\text { Universidad Politécnica de Valencia } \\
\text { España }\end{array}$ \\
\hline TECNOLOGÍA DE LA INFORMACIÓN Y LA & $\begin{array}{l}\text { Prof. Dr. Manuel Llorca Alcón } \\
\text { Universidad Politécnica de Valencia } \\
\text { España }\end{array}$ \\
\hline
\end{tabular}

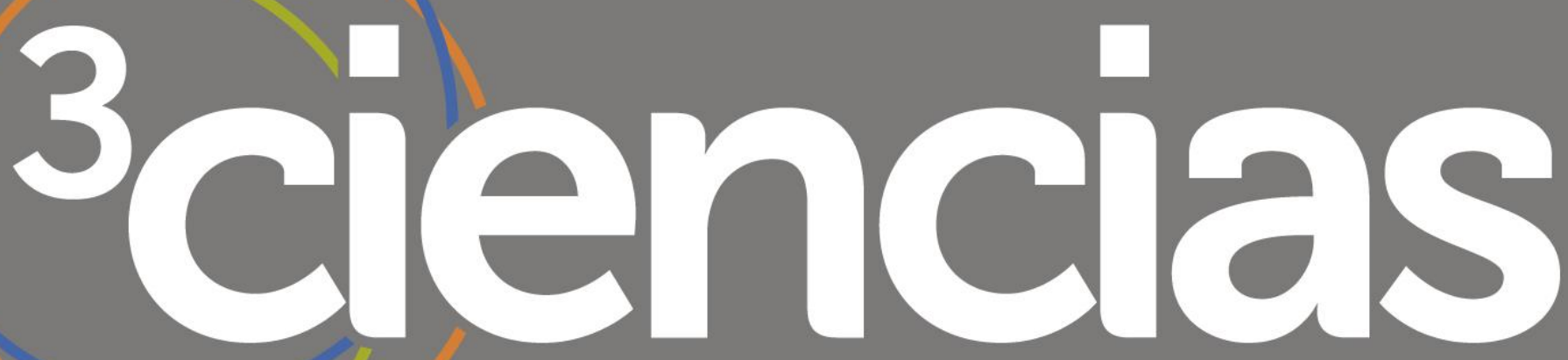


